

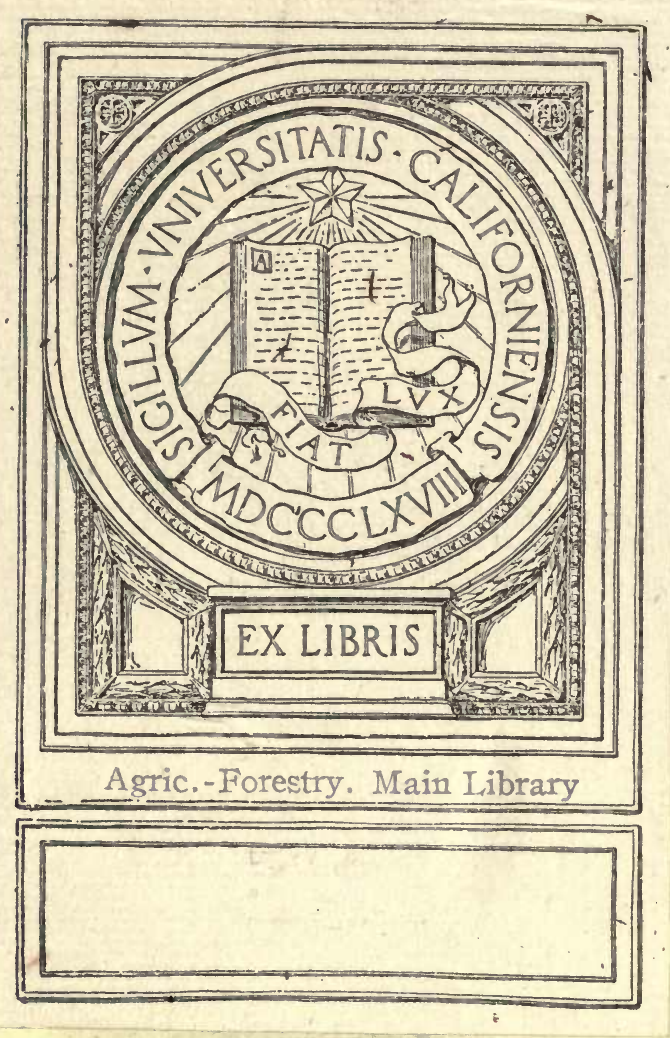








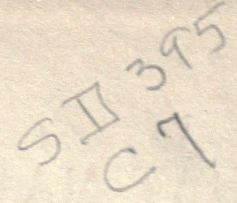

Entered, according to Act of Congress, in the yesr 1858 ,

BY HARLAND COULTAS,

In the Clerk's Office of the Distriet Court for the Esstern District of Pennsylvanla,

Agric.-Forestry. Main Library

$$
\because \because \because \because \because \vdots \vdots \vdots:
$$

$\therefore \because \vdots \because \because \because \vdots \vdots \vdots \therefore \cdots \cdots$ 
RESPECTFULLY DEDICATED

ALL LOVERS AND FRIENDS OF NATURE. 



\section{PREFACE TO THE SECOND EDITION.}

IT was originally my intention to have published my Tree in eight parts, and to have brought them out in succession, as rapidly as possible ; but I have decided, for the present, to stop at Part IV. A much larger subscription than I have yet obtained is necessary to anable me to carry out my original project. Trees will not grow without sap or sunlight, and if mine is, at present, only a mere shrub, and has not advanced to the condition of a California Sequoia, it is because I require more time and means.

Do not suppose, reader, that I am at all discouraged, or that I have the slightest intention to give up the work; but the present delay is absolutely requisite in order that I may be able to meet the expenses which I have incurred in its publication. An author who appears before the world in the character of a moralist, and a lover of Nature, must endeavor to live a pure and blameless life, and be upright and honorable in all business transactions.

No work which the press has received from my pen has been so much encouraged as the present one, and to my numerous kind friends and patrons I return my sincere thanks. The present edition is printed on much better paper, and is in every respect a decided improvement on the former one.

The question is simply this: "Will this book do me any good ?" "Is it worth its price ?" Gentlemen are respectfully requested to read and judge for themselves. As the author of the book, I wish it to stand entirely on its own merits. I wish no man to buy my book unless he thinks its perusal will do him good.

The biography of a tree, or of a flower, is to my mind an illustration of human life, every stage of which is 
interesting when life is properly conducted. There is the beauty and innocence of childhood; the enthusiasm and buoyancy of youth; the energy and strength of manhood, and the ripened wisdom and experience of age. Our vitality declines now almost imperceptibly, and, finally, man passes away like a leaf, a flower, a tree.

These influences affect not only the works of Nature, but those of man. We may retard the operation of the laws of decay, but we cannot suspend them. The most enduring monuments, once resplendent with the glory of the genius of man; his palaces and pyramids, or the lofty column which tells of the struggles of the past to future generations, may, for ages, defy the stroke of the lightning and the storms of the atmosphere, but they shall be conquered by its quiet and imperceptible influences; by its gently descending dews, and the disintegrating power of its oxygen, as time rolls onward. Their beauty and strength shall disappear, and other generations shall look thoughtfully on their ruins, and the lowly moss and lichen shall feed on their broken and dissevered fragments.

Life is short, and we must make the most of it; it is a warfare, and we must nerve ourselves for the conflict. How many spend it miserably in the vain pursuit of riches! Is this wise? It is our duty to obtain a competency, and prepare, if possible, a beautiful home for our family which they can call their own when we are gone; but the most valuable wealth that we can leave them, is a spirit of selfdependence and good principles. For uprightness of conduct is so noble and beautiful a feature, that it invariably makes a man friends and leads to inevitable success in the pursuits of life.

The few hints given in this volume as to the study of Nature, and how to spend life happily, will not, I hope, be lost on some of my readers, who will gratefully remember me for the good I have done them, when I shall have long passed away from this fleeting evanescent scene.

Storey Street, Mantuatille,

HARLAND COULTAS.

February 12th, 1860. 


\section{O NTENTS.}

Introduction,

\section{CHAPTER I.}

The building-up of the Tree-form out of its unit; or, the Life of the Tree traced throughout its vegetative period from infancy to puberty, 13

\section{CHAPTER II.}

The History of the development of Trees may be advantageously studied by a careful examination of the marks left by Nature on their young branches-The growths made by the Tree during the former years of its life, having been there accurately recorded, . 26

\section{CHAPTER III.}

The inner organization of Trees; or a description of the Anatomy and Physiology of the different species of Cells which enter into the

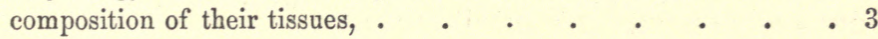

\section{CHAPTER IV.}

The Tree is constructed on the principle of a cone--Its leaves are the sources whence proceed the formative material used in the buildingup of its Stem and Branches, which is distributed amongst them after a common law, . $\quad . \quad . \quad . \quad . \quad . \quad . \quad . \quad 55$

\section{CHAPTER V.}

Those natural Causes which produce the inequality in the Development of the Branches and Buds of a Tree, illustrate clearly the laws of social inequality and subordination in civilized communities, .

\section{CHAPTER VI.}

The rhythms or oscillations of Growth in the Development of Trees are durably impressed on their Organism, and the Organization of Man is equally as susceptible of receiving and retaining impression. from without, 


\section{CHAPTER VII.}

The Leaf, with the entire edge, is alone to be regarded as a simple Leaf-The Leaf takes a higher form of Organization, and becomes compound in proportion to the Development of the fibrous portion of its Lamina-All the irregularities of its margin, such as Lobes, Teeth, Crenatures, Serratures, result from an effort at new leafletformation arrested in its first stages, . . . . . .

\section{CHAPTER VIII.}

A sketch of the History of Creation as recorded in the strata of the Earth, showing that the Trees which now cover its surface were not all created at the same time, but were introduced as the Earth became fitted for their reception-Trees were created in successionThose of a low type of Organization are the most ancient inhabitants of the Globe-The more highly organized Trees have been introduced at a, comparatively speaking, modern Geological epoch, .

\section{CHAPTER IX.}

Change which takes place in the constitution of Trees at the period of puberty-Organic Metamorphosis of their Leaves into Flowers and Fruit, and relative physiological rank of the Floral organs, . . 152

\section{CHAPTER X.}

Contains a Description of Trees remarkable for their gigantic growth and great age, found in different parts of the World, . . .

\section{CHAPTER XI.}

The Woods take the first rank in the communities of the Vegetable Kingdom-Reciprocity of action amongst Plants-A cool Atmosphere produced by. Woods-Their removal is followed by a warmer, drier Climate, and is beneficial in some cases-Woods on Mountains must not be cut down-Pernicious results of their removal in ItalyWoods useful along the Sea-shore, where the coast is low and sandy -Concluding remarks,

\section{CHAPTER XII.}

The Death of the Tree is founded on an inner law of its organism, and is not the result of accidental causes, . . . . 185 


\section{INTR ODUCTI $0 \mathrm{~N}$.}

Change is the soul of nature. Stars appear and disappear, and new ones come in their stead. The day gives its place to the night, and the night to the day. The moon is ever changing her aspect as she moves round the earth. Spring, summer, autumn, and winter follow each other in succession, and with this gradual change of the seasons, the earth is continually changing its plant-covering. Nature is ever moving onward, and mutability marks all these forward movements. The vegetable world is ever adapting itself to the ever-varying conditions of moisture, heat, and light, which mark the days and years of the earth's pilgrimage. One flower, for example, is seen to open as soon as the first rays of morning tremble on the horizon, another in the morning sun, a third at mid-day, a fourth in the evening, and a fifth at midnight. The animal world, too, strikes as it were the hours. Scarcely do the dew-drops glitter in the beams of the advancing sun, than the earth-worms come to the surface to enjoy themselves, the birds commence their song, the sun rises higher and the woods reverberate with their ever-varied melodies. But the sun sinks in the west and night hides from our view the glory and beauty of nature; and the nightingale warbles, the owl screams, the bat flies abroad, and an innumerable variety of beautiful moths sport themselves in the gloom. So appear and dis- 
appear successive generations of plants, animals, and men.

We have felt, for many years, interested in the plantworld, that beautiful and ever-variegated carpet with which Nature has overspread the earth, and which is ever changing its character as the seasons roll on. We have also printed several elementary works on Botany, and this time have chosen for our subject, a Tree; because it is a picture of the whole of Nature, and of the way in which Nature works.

It is quite evident that each part of a tree, whether it be leaf-scale, or leaf, sepal or petal, has its place assigned and task allotted in the construction of its organism; and that there is a system of mutual dependency and subordination which pervades all the parts of the tree from the cell upwards. Now this variety, and at the same time unity of organic action, so apparent in all the life-phenomena of a tree, and in all the mutations of its form is exceedingly instructive, for it throws light not only on the natural laws which govern society, but on the whole of organized Nature.

Nature is a mechanism whose parts are intimately associated with each other. The forest leaf, for example, has infinite connections not only with the tree which it helps to build, but with the atmosphere which it oxygenates, and with the raindrop which it absorbs and decomposes. And it is the same with every insect, moss, and mountain floweret. Each has its place assigned in the organism of the universe, and its allotted labors to perform. All take their part in effecting those grand changes now taking place in nature; and which are undoubtedly conducted on a plan devised by infinite intelligence and wisdom, and therefore perfect in all its parts, harmonious in all its arrangements.

In like manner that part of Nature called civilized society, notwithstanding all the evils with which it is necessarily accompanied, is equally a mechanism, and governed by natural law. It is my design in this work to try to 
exhibit this fact in its true light. Men have formed their Utopia. They have closed their eyes on the existence of natural evil ; they have denied that it is an inevitable necessity, and inseparable from the present condition of things; they have sought to make the world otherwise than God has made it. They have promulgated erroneous schemes of philanthropy, which, having no foundation whatever, either in truth or reason, can never do otherwise than mislead and betray. They would overturn the granite foundations of the present social fabric. Vain and futile attempt!

It is time that we looked these evils fairly in the face. It is time that we admitted their existence as an inevitable necessity, as part of the discipline of life; that we regarded those grand compensatory forces which are ever at work in the realms of Nature, and by means of which these conflicting elements are made to harmonize, and a just equilibrium brought about in the scale of human happiness. When will man learn wisdom and truth from the teachings of Nature? When will he open his eyes to those important practical lessons which may be learned from the commonest object? It is my intention, in this book, to show "What may be learned from a Tree."

We are about to write its life-history. We shall trace it from the first manifestations of vitality in the germinating seed until the period of puberty, when it puts forth flowers and fruit. We shall consider its phenomena after it has passed its prime, and show that it has its appointed limits in consequence of the same physiological law which governs the development of its organism, equally with that of the lowly plant which grows beneath its shade. We shall show that the tree may be regarded as a vast community of phytons, or plants, which co-operate in its construction and are mutually dependent on and subservient to each other We shall prove the individuality of these phytons which develope about the axophyte or stem of the tree and its ramifications or branches, by their difference of form and function, 
and also by those separate periods of time at which they arrive at a state of maturity and decay. We shall show that the amount of work done by these phytons, in their individual and collective capacity, constitutes the growth of each year, and has been recorded in the wood of its stem and on the outer surface of its bark. But all the parts of organic nature are so intimately connected with each other, that the careful study of any one part necessarily leads as a reward to correct ideas respecting the whole. This is particularly the ease with the tree, which is a microcosm, or little world, beautifully illustrative of those unchanging laws of individual and social development which lie at the foundation of the present social system.

My own experience has taught me that a work of this nature is likely to be very useful. It is emphatically written for the people-for those who feel life to be one continued struggle for existence. Many of the truths which will be illustrated are stern and incontrovertible realities, confirmed by the daily and hourly experience of life. Of all the author's botanical works, this is perhaps the only one that will survive him. One thing is certain, that it will be more generally understood. The reader of only ordinary education and intellectual power may readily comprehend the principles inculcated in this book, and see their applicability as guiding rules for the judicious and happy management of each day's duties. Reader, whoever you are, may this book prove to you a friend, may you be induced by its pages to look on the Tree with a new interest; and obtaining from its noble form a clear and truthful view of your own position and duty in life, become by the perusal of this volume, a wiser man and a better citizen. 


\section{CHA P T E R I.}

THE BUILDING UP OF THE TREE-FORM OUT OF ITS UNIT; OR, THE LIFE OF THE TREE TRACED THROUGHOUT ITS VEGETATIVE PERIOD -FROM INFANCY TO PUBERTY.

A TREE is indisputably the most highly-developed form which vegetable life assumes. In the appearance of one that has stood for centuries, there is something noble and majestic. When we look at its now massive stem and farextended branches, and then call to mind its smallness and feebleness at the commencement of its life; when we remember that this great tree was once so small as to be inclosed within a little seed, and that the tons of solid timber which it contains have been all drawn by that seed from the earth and atmosphere, we cannot but feel that we have before us a most impressive proof of the operations of the attractive forces. What an immense amount of vitally organized material has been here gathered together! It is God's own architecture ! This mass of vegetable matter is only earth and air which has undergone transmutation! The material alike of wandering zephyrs and rushing storms, of gently descending night-dews and angry thunder-showers, has been here, on this spot, metamorphosed!

Yet we pass these great and wonderful works of Providence every day of our lives without a thought. The gradual and silent building-up of a tree excites no curiosity, conveys no moral lesson. What may be learned from a tree? Clear and comprehensive views of the organization and laws which govern the civilized world! Rules of conduct which lie at the foundation of all success in business, all progress in the pathway to pre-eminence. It is the aim 
of this book to establish this fact by a direct appeal to nature and experience. And first of all we will give a brief sketch of the life-history of a tree from infancy to puberty, or from the commencement of germination till the period when the tree reaches its maximum height, and puts forth its flowers and fruit. By so doing, we shall be able to show the principles on which trees are constructed, and the reader will form for himself a correct idea or intellectual picture of a tree. As this is all-important to a thorough understanding of the principles inculcated in this book, we earnestly request that the purely botanical portion of it may have a most careful and attentive perusal.

The First Year's Growth.-If we plant a beech-nut in a suitable soil, when spring and warm weather come it will begin to germinate. It first attracts the moisture of the soil itself. This produces the softening and swelling of the tough covering of the nut, which is finally ruptured by the growth of the embryo or infant beech-tree in its interior, which sends downward, through the lacerated integument or seed-cover, a young rootlet, and upwards a young stem, to which are attached the first pair of leaves. These leaves, which are thick and fleshy, and constituted the great bulk of the seed, are in reality the nursing-leaves of the young embryo. Lifted above the ground and exposed to the light of the sun, they speedily expand, take a leaflike texture and hue, and become so much enlarged that they present quite a different appearance to that which they exhibited when they were folded together and enveloped by the seed-skin.

I call them nursing-leaves (folia nutrientia), because these words convey a more correct idea of the services which they render the plant, and are therefore better than the word cotyledons, or seed-leaves, terms employed by other writers. These nursing-leaves are only temporary appendages of the axis or stem, and perform a distinct and separate duty in connection with the building-up of the tree. 
They contain a store of starch, provisions elaborated by the plant which produced the seed. On this store of starch the young embryo or infant beech, with its little root and stem, bearing toward its summit the first phyton, or true aerial leaf, is wholly parasitic until it is sufficiently grown to draw a sufficient amount of sustenance from the earth and atmosphere, and can do without the nursing-leaves.

The polar opposition between root and stem, which is among the first indications of the commencement of active vitality in the young embryo, is wholly inexplicable, and continues throughout the entire life of the tree. During the first stages of its life, oxygen is absorbed from the air by the nursing-leaves of the growing embryo, and through its influence the starch contained in them is transmuted into a soluble sugary gum called dextrine, which is conveyed, by the water absorbed during the germination, to the young rootlet and to the gemmule, and also to the first true aerial leaf, or phyton. Thus nourished, this leaf speedily expands, takes the form peculiar to the plant, and remains permanently attached to them till the close of the growing season. It is otherwise with the nursing-leaves: for having yielded up their store of nutrient material to the first true aerial leaf, and given it the necessary degree of strength to enable it to support itself, they become gradually atrophied, or waste away and shrivel up, and we see them finally fall from the stem. With the full development of the first true aerial leaf, and the atrophy and ultimate fall of the nursing-leaves, the first stage of vegetative life is closed.

We have now a simple individual plant, or vegetable unit, consisting of root, stem, and leaf, having subterranean and aerial organs beautifully adapted to its nutrition; it is, therefore, perfect in all its parts. And now, the fully-developed tree, with its massive stem, branches, and roots, its noble canopy of foliage and flowers, stands before us in its simplest form. For the first true aerial leaf is the foundation of the vegetable fabric, the parent of those 
countless numbers of leaves which are developed through succeeding years, and by whose united labors a goodly tree is at last constructed, capable of withstanding the storms of the atmosphere, as the submarine structures reared by the coral insect resist the surges of the ocean.

It is therefore important to study carefully the organization and life-processes of the first true aerial leaf, or vegetable unit; for as its simple repetition constitutes the growth of the first year-which again must be regarded as a vegetable unit of a somewhat higher, more complex character, by simple repetition of which the entire tree itself is ultimately produced; so it is plain that a thorough knowledge of the physiology and organization of this first true aerial leaf must furnish a key not only to the growth of the first year, but of succeeding years, of which the tree is the solid and enduring monument.

Nothing is apparently more insignificant and feeble than our beech-tree at this period of its life. Look at the young, delicate leaf and stem of the phyton, or first plant, which does not even raise above the green blades of grass by which it is surrounded, thrown as it were on the charity of Nature ! It has lost its nursing-leaves and is left to provide for itself, surrounded by innumerable dangers. It is at first a struggle for life against fearful odds. It may be eaten by cattle, or be crushed by a careless footstep; want of rain or too much moisture in the soil, excessively hot or severely cold weather, may permanently injure its structure and bring its life to an early and premature close.

But if the seed was planted in a good soil, and the conditions continue favorable, an impulsive energy will very soon be called forth which shall carry it over every obstacle. Yea, verily, it shall extract nutriment from the very tempest which would hurl it to destruction, and render its enemy subservient to the advancement of its upward and onward progress.

See how beautifully Providence has adapted the organization of the two extremities of the phyton, or first plant, 
to the earth and atmosphere, the two sources from whence it must for the future draw its supplies of food. Its little root descends into the soil, and puts forth from its surface a number of fine, white, hairlike fibres, which are the instruments by means of which the plants absorb inwardly the subterranean nutrient material which surrounds them; its young stem ascends into the air, and the bark and fibre, which are arranged cylindrically in separate beds or layers in the stem, are spread out horizontally towards its summit, in the form of a flat green plate, or absorbent surface, called a leaf.

The bark, or cellular tissue of this leaf is penetrated by the fibrous portion of the stem, in the shape of veins and veinlets, which communicate freely with the roots in the soil, and thus act as conduits of the sap or nutritive material from one extremity of the plant to the other. In this manner the sap, brought from all parts of the plant, becomes, as it were, thoroughly spread out and aerated in the leaf. To facilitate the processes of evaporation and absorption, the leaf is provided with an epidermis, through the pores or openings of which the superfluous water of the sap is evaporated, and such gases absorbed from the atmosphere as are nutritious to the plant.

Hence, when fully developed, this leaf aerates the sap much more perfectly than the nursing-leaves; and as it is a true aerial leaf, it remains permanently attached to the stem or vegetable axis till the close of the vegetative season. This leaf appears, in fact, to be formed in reference to the atmosphere.

If we examine the gemmule, or young bud, situated just above the phyton, or first leaf, we shall find that the first leaf itself is now, in its turn, a nursing-leaf, and the parent of a numerous progeny of already partially-formed follicles. These, nourished by the sap elaborated in the first leaf, soon individually expand and separate from each other, little intervals of stem being formed between them. They now contribute individually to each other's support: the lower leaves aiding in the development of those that are above 
them, and contributing also to the growth of that portion of the axis or stem which is beneath them, and to the increase of the number of the rootlets in the soil.

Each of these phytons or leaves developes also, more or less perfectly, its own gemmule or young bud, which, undoubtedly, corresponds to the gemmule or bud formed by the first leaf, the unfolding of which constitutes the growth of the first season. But these new buds never come to anything the first year, but retain their rudimentary condition through the winter months, and appear as projecting points on the outside of the shoot, after the leaves which formed. them have dropped from the stem. The gemmule or bud formed by the first leaf, is the only one of the series which developes the first season.

As the heat and light of the sun decrease, the vital activity of the phytons or leaves diminishes, and the intervals between them gradually cease to form, until at length the elongation of the axis is wholly stopped. About this time the current of sap is diverted away from the leaves to the buds forming at the bottom of each leaf-stalk, and especially to the terminal bud which grows at the top of the shoot. This attraction of the sap or formative material away from the leaves by the newly-forming tissues of the buds, is undoubtedly one of the principal causes which produce their decay and separation from the shoot. When the leaves begin to change their color (the sure presage of their approaching fall), it is therefore an infallible indication that the sap is being diverted away from them to the buds, which have begun to grow, and that the shoot constructed by their united labors is about to be prepared for winter.

This preparation of the shoot for winter is effected by the development of another set of leaves, which other writers call bud-scales, but which I call (folia tegmentia) covering or protecting leaves. It is not nutrition, but protection which is required by the shoot during winter, and these leaves are organized expressly for this very purpose. They contribute nothing whatever to the support of the plant, but they shield it from the inclemency of the weather. It is 
their duty to preserve from injury theamount of work already done. A beautiful vegetable cone has been constructed by the leaf-labor of the first year, and it is left in their charge.

In the beech-tree, the bud-scales or covering leaves acquire a somewhat horny texture. They are without pores, and are, in botanical language, imbricated; that is to say, they cover one another like the shingles on the roof of a house. Beneath these vegetable roofs, thus admirably constructed, the young branch charged with all the nutritive leaves of the next vegetative season lies imbedded in a warm downy investment.

Thus, even the defoliated shoot or vegetable cone is not without its attractions. There it stands, exposed to the fierce north wind, coated with ice from top to bottom. It matters not that the snow-covered ground, in which its roots lie imbedded, is frozen as hard as granite, for there are the protective leaves, or bud-scales. These are the appointed guardians of its life, and well do they perform their office. As soon as spring and warm weather come, do we not see the young shoots and the bright green leaves, which they have covered and protected, come forth uninjured? Exposure to the air, which is now mild and pleasant, will do the newly-developed shoots and leaves no harm, but is a positive benefit. The services of the covering or protective leaves of winter are therefore no longer required, and we see them fall, one by one from the stem. Why? Because they have fulfilled the purposes of Providence in their creation. They are, therefore, removed from the post of duty.

The Second Year's Growth.-With the gradual increase of light and heat the snow and ice disappears, the ground becomes soft and friable, the air mild and pleasant, and in the grand laboratory of organic nature all is again ceaseless activity. The same beautiful yet evanescent floral forms adorn the earth; the bright green grass, the leafy verdure of the woods charm the senses. Our vegetable cone with its lateral and terminal buds feels the effect of the genial influences that are abroad, and soon give signs of a renewed 
vitality. The (folia tegmentia) covering-leaves separate from each other, and the new generation of nutritive leaves, sheltered by them through the winter months, are put forth uninjured into the atmosphere. The leaves proceeding from the bud at the summit of the vegetable cone, continue the growth of the main axis or stem, whilst those developed from the lateral buds give birth to branches. If now these new growths be carefully examined, it will be found that the new generation of leaves has constructed them on precisely the same plan as the first year's shoot. For these branches, and the addition which has been made to the stem in height, consist of precisely the same parts, viz. : a conical axis and leaves with buds in their axilla, and a terminal bud at the apex. Each new axis or shoot which has been superadded to the first year's shoot, must therefore be regarded as a simple repetition of the first year's shoot.

It is also plain that the branches are to the main axis or stem, the second year, what the leaves were to it the first year, performing precisely the same functions, only in a far more energetic manner; because in this case it is not one but several leaves which are engaged in elaborating the sap, which, when duly prepared in the leaves, passes from them into the main axis or stem of the tree through the common axis of the shoot, and thus contributes to its nutrition.

The tree has therefore a much greater amount of leaf-surface at work in the air the second year than it had the first, and its chances of life are consequently multiplied a thousand fold. For with every addition to the number of its leaves, the tree obtains a new instrument for extracting nutriment from the atmosphere, and elaborating such food as it attracts to itself from the soil. The amount of wood and bark formed is therefore much greater the second year than the first; it is, in fact, exactly proportionate to the increase in the extent of leaf-surface and the vital activity of the leaves themselves.

The sap having been exposed to the air and light in these additional leaf-surfaces, is again rendered nutritious, and 
not only contributes to the elongation of the stem and branches, but at the same time to the formation of a new conical layer, or enveloping mantle of wood and bark between the wood and bark of the previous year. Each shoot, with its system of leaves, contributes its part to the newlyformed layer, and the growth of the stem, in length and thickness, thus takes place at the same time.

Toward the close of the growing season, the sap is again diverted from the leaves to the buds forming in their axilla; and the protective leaves of winter having been fully matured, the second generation of nutritive leaves wither and fall from the stem and branches as before. Our tree, when defoliated, now shows a number of shoots associated together, and developing from a common axis or stem, all of which have been built up by leaves constructed on precisely the same pattern as the first year's shoot, and prepared for winter in exactly the same manner.

The Third Year the tree presents the same general vegetative appearances. The terminal bud continues the growth of the stem or main axis as before, the buds on the branches develope into branchlets, and contribute to the further extension of the branches and to the growth of the shoots forming at their summit; and the whole system of shoots thus put forth, with their leaves, co-operate in the formation of the sap into another enveloping mantle of bark and wood, which covers the stem and branches of the previous year.

In precisely the same manner does the tree continue to vegetate, every year increasing in size and strength, adding to the number of its leafy operatives, and the amount of labor done, until it attains its greatest elevation.

A peculiar alteration in its habit now becomes noticeable. For the sap is no longer expended in the extension of its stem and branches, but in the formation of its flowers and fruit. The period of puberty has arrived, the tree is in the full prime and vigor of life, and the growth of its stem and branches is gradually retarded, the vegetative efforts of each season being absorbed by the reproductive. The tree, 
therefore, now preserves pretty much the same landscape character and appearance year after year.

Our readers will now understand that the laborers engaged in building up the tree are its leaves; that these leaves become the parent of buds which develope into families of leafy operatives called shoots; that these shoots form other shoots, which are constructed on the same plan and pattern as themselves; that the families of shoots thus associated, form working communities called branches; and, finally, that the whole tree is built up by the united labors of its branches, which form every year out of the sap new layers of wood and bark, thus adding to the strength and stability of the entire structure.

Such is a brief outline of the building up of the tree-form out of its unit, the first phyton or leaf.

The following reflections naturally suggest themselves, and will we hope be adjudged a suitable close to the present chapter.

A tree commences life under very unfavorable circumstances, surrounded by ten thousand dangers, grows slowly, and has difficulties to contend against at every stage of its progress. Here we have a beautiful illustration of life as it is-a continual struggle against difficulty. All inspire after a better lot: but only a few succeed. These are invariably those who have the most life-energy and perseverance. The first steps in any undertaking are the most difficult; and all solid and enduring advancement is made slowly and imperceptibly. Let this never be forgotten. Pre-eminent talent in any business or profession is of slow growth, and is the result of industry and hard work. One difficulty surmounted leads to the conquest of others. If your aims be high and honorable, do not be discouraged, although your progress may be slow and difficult. Let your motto be onward. There must be no retrograde movement. You have nothing to do with fear; it will retard your progress and defeat you in the attainment of your object. If you are industrious and persevering, if, when you cannot make headway, you carefully guard the advantages which you have already 
gained, your success is only a question of time. You may not succeed, but if you are a father, your children may, if brought up properly. Recollect, a tree grows slowly, and becomes a tree despite of storms. Besides, after all, my friend, it is not one continuous storm, for there are occasional glimpses of sunshine to help you along! And you would do well to look at the bright as well as the dark side of things. But storms will assail you: many and many another. It is part of the discipline of life.

A tree extracts nutriment not only from wandering winds, but from "rutshing storms;" the most violent "thunder-showers" as well as the silently descending dews have contributed materially to the building up of its fabric. Except in winter, when there is no growth, no vital movement, the course of the tree is upward and onward in all kinds of weather. The wind may roar among its branches, and the rain fall in torrents, but it continues to grow despite these hostile influences, and becomes a great tree at last. The very strength which we admire in a tree has been extracted from a thousand tempests. Storms have already tended to give it stability.

It is ever thus with Nature's really great and noble. They show to the greatest advantage when assailed by storms. These only develope them. How frequently is innate talent brought out through the fear of wanting bread, the struggle to maintain a family! Individuals so circumstanced usually make the most valuable contributions to literature and the industrial arts. Man would never exert himself, he would live a life of inglorious ease and self-indulgence, he would do nothing to advance either himself or his species, if there were no difficulties in his pathway. He would retrogade, go back to primeval savageism. It is adversity which calls forth the nobility of his nature, and makes him transform every obstacle into a monument of his skill and strength. The wise and noble-minded are ever brave and calm when enemies assail. Conscious of the rectitude of their intentions, they meet the foe with boldness and decision of character, and 
the very storm is only a means of developing the intellectual and moral greatness of their nature. To the obscure and crooked ways of their enemies they oppose plain, straightforward conduct; to their calumnies, a pure and blameless life; to their meanness and unfairness, uprightness and honor in all their transactions. It is thus that they grow strong through conflict. Instead of being degraded, they are ennobled by the struggle, elevated in the good opinion of their friends; and like the tree, they derive a permanent advantage from the storm, and look all the better when it has passed.

We have in every tree an illustration of the maxim, "In union there is strength." A few leaves by their united labors form a shoot; and this, by repetition of itself, has produced a great tree. Just as the first shoot was built up by the leaves put forth by the growth of the first season, so the entire tree has been constructed by the labors of those successive generations of leaves with which it was annually adorned. It is true that the roots, by the food which they have taken up from the soil, have contributed their part to the general structure; but the stem and branches have been formed from sap which was first rendered nutritious in leaves. These humble yet perishable forms have been the architects of this noble and enduring structure.

So it is with man. Individually feeble, he becomes powerful by entering into combination with his fellows. Who has measured the magnitude of the earth, the planets, and the sun, and calculated the distance of the stars, by taking the diameter of the earth's orbit as a base line? Who has made to disappear alike the gloomy forest and the poisonous swamp, and produced on their site a landscape smiling with health and fertility? Who has girdled the earth with railroads, drawn down the lightnings from heaven, examined their nature, and given them their appointed channels, uniting the two continents with each other in telegraphic communication? Whose thoughts now traverse the ocean with the rapidity of the 
lightning's flash. It is MAN in combination who has done these things. The present state of perfection to which art and science have been carried is the necessary result of the labors of our fathers who have preceded us. The steam engine and electric telegraph are not the product of the present, but of all ages. They are the work of countless human generations; of beings frail and perishable as summer leaves swept by autumnal winds from the trees of the forest. It is thus that the noble tree of science grows-not the deadly Upas, disseminating everywhere poison and death, but the "Tree of Life," whose "leaves are for the healing of the nations."

We may also learn from the tree an impressive lesson of our own frailty. Where are the leaves which built up this massive and majestic tree, which carries in the interior of its stem the monumental history of its life, the impression left by centuries of seasons? And where are the workmen who felled the forest and drained the swamps of Pennsylvania, built her cities and railroads, and spread over her hills and valleys so many scenes of rural industry, peace, and progress? This is the work of former generations, who have passed away like summer leaves from the tree which they were engaged in constructing. We now supply their places, and carry on their labors. We profit by the industry and experience of those human generations which have preceded us. Each industrious man works not only for himself, but for posterity. We contribute a little during the active periods of our life, to the advancement of the science and the civilization of society, and then we pass away and are seen no more here, forever. "We all do fade as a leaf." 


\section{H A P T E R II.}

THE HISTORY OF THE DEVELOPMENT OF TREES MAY BE ADVANTAGEOUSLY STUDIED BY A CAREFUL EXAMINATION OF THE MARKS LEFT BY NATURE ON THEIR YOUNG BRANCHES-THE GROWTHS MADE BY THE TREE DURING THE FORMER YEARS OF ITS LIFE HAVING BEEN THERE ACCURATELY RECORDED.

Every part of a tree, whether it be a branch, shoot, or leaf, represents exactly the organic condition of the tree during the earlier periods of its life, and a certain stage of development through which the entire tree itself has already passed. For it is plain from the facts mentioned in Chapter I, that the tree was, at the commencement of the first year of its life a single leaf, and at its close a green herbaceous shoot, exactly like those annual growths which it now makes at the sides and extremities of its branches. In the spring of the second year, the buds formed by the leaves of the first year at the sides and summit of the first year's growth or shoot, developed into new growths or shoots, which were constructed after precisely the same pattern. They presented, in autumn, when defoliated, precisely the same external appearances, having side and terminal buds, and the same peculiar form of leaf-scar. We are, therefore, necessarily led to regard them as only a repetition of the first year's shoot. For as the leaf is a unit, through repetition of which the first year's shoot is formed, so also is the first year's shoot itself a unit, but of a higher and more complex character, through repetition of which the branches, and ultimately the entire tree itself is constructed. The whole is therefore represented in each of its parts; and if we take the terminal branches of the tree and study them carefully, we shall obtain clear and truthful views, not only of the condition of the tree during the first years of its life, 
but of those general and peculiar laws of growth which govern the entire tree itself. All the apparent confusion and irregularity among the branches and branchlets of a tree is the result of the operation of fixed and immutable laws of growth, to which the whole tree is subjected in common with each of its parts. The entire tree is not different from one of its branches in the principles of its construction. In fact, if one of the branches were severed from the stem and planted, it would not only represent one of the phases of growth of the tree, at an earlier stage of its life, but under favorable circumstances would actually grow into a separate and independent tree.

In this, as in the figures of leaves, we have avoided an extravagance of illustration, in order that our book may not be rendered too expensive. Besides, it is unnecessary. Trees are all constructed on the same general plan. Hence, we have taken our material, not from deep resources, but from common objects. It is proper here to remark, that the reader will understand more clearly the positions assumed, if he procure a number of branches of different trees, such as the beech, the hickory, the horse-chestnut, when defoliated or in winter, and attentively study the marks on the exterior of the bark and the mode of ramification. If the branches are gathered when the trees are in leaf, the foliage must be removed.

The reader is already prepared to admit, without further proof, that the growth of the tree is very fluctuating, and is greatly influenced by changes in the weather. In this respect, the organism of a tree is quite as sensitive as the mercurial column in the tube of a barometer. It is wellknown that the age of a tree may be ascertained by counting the rings visible on the cross section of its stem, and that the impress of centuries of seasons has been faithfully recorded in its woody layers. The seasons also leave their mark on the outside as well as the inside of the tree. When the young shoot, in early spring, unfolds itself from the bud, and the brown scales which enveloped the young leaves fall off, they leave ring-formed or annular scars at the bot- 
tom of the shoot, and we recognize in these numerous girdles, the place where, during the previous winter, the growing shoot remained in a state of rest. These budtraces often continue visible for many years on the bark of trees, and through this means we can ascertain the age of a branch and the amount of its annual growth, as exactly as if we had ourselves observed and marked its progressive growths from year to year. The clearest marks of these bud-traces may be seen on the branches of the beech, the horse-chestnut, and the maple, and are less visible on the bark of the birch, the linden, and the fir, where they are not recognized through the growth and changes of the bark.

The distance between two sets of bud-rings, estimated from the under and upper limit of the rings, shows the amount of shoot developed during the season; and the age of the shoot can therefore be estimated by counting the number of sets of bud-rings visible on its bark.

So also the rate of growth of the shoot may be deduced. It will be seen from the variation in the amount of shoot developed between the bud-rings, that the growth of the primary axis and its branches varies from year to year, and that powerful growths are sometimes followed by growths which are greatly retarded. Each branch has, in fact, its own peculiar history of growth; and trees of different species differ not more widely in this respect than two branches on the same tree.

But not only the fallen-off scales of the winter's bud, but also the green leaves of the stem leave behind them a peculiar scar on the bark, which marks the point of the stem to which they were attached, and the number of leaf-scars between two bud-traces, therefore enables us to estimate correctly the number of leaves which were put forth during the year, and thus we are able to picture to ourselves, not only the amount of growth of the branches, but also the extent to which the foliage was developed on them, and so, as it were, to make the tree live again.

We may also add to all this, that in many trees the 
flowers too leave their traces, either in the form of withered flower-stems, or a peculiar mark, which continues to be recognized up to a certain time. Where the inflorescence is axillary, as in the Ash, the flower-scar is situated just above the leaf-scar, and cannot fail to be readily recognized; and thus the past history of the development of the flowers is recorded on the bark as well as the rate of growth and the number of leaves.

The specific peculiarities of trees manifest themselves in the smallest details of their architecture, so that the least bud-trace, leaf, or flower-scar, suffices by the peculiarity of its form to enable us to recognize the species of tree to which it belongs, and of which it is characteristic.

To render the principal of these researches clearly understood, we have selected the upper part of one of the branches of the purple beech (Fagus pupurea), which we have had carefully drawn from an ambrotype, so that our engraving is perfectly reliable, and presents a true and faithful copy of the original branch. We have also constructed a biological table, in which we have exhibited numerically the different growths made by the primary axis and its branches, and the number of leaves and buds annually developed.

By looking at the engraving, the reader will see that the main stem or primary axis of the branch has developed ten secondary axes or branches. The growth, number of leaves and shoots, or in other words, the history of the development of each of these ten secondary axes or branches has been also registered in the table, in the same way as the annual progress in vegetation made by the primary axis. The figures in the engraving opposite the annular scars left by the covering-leaves or bud-scales, will also assist the reader in estimating the amount of growth made by the branch, year after year; for he has only to bear in mind that these annular scars mark the place of the bud or terminal growth of the branch during the year indicated by the figures, to place the exact vegetative condition of the branch at any one of the previous years of its existence, as it were, in a moment before his eyes. 


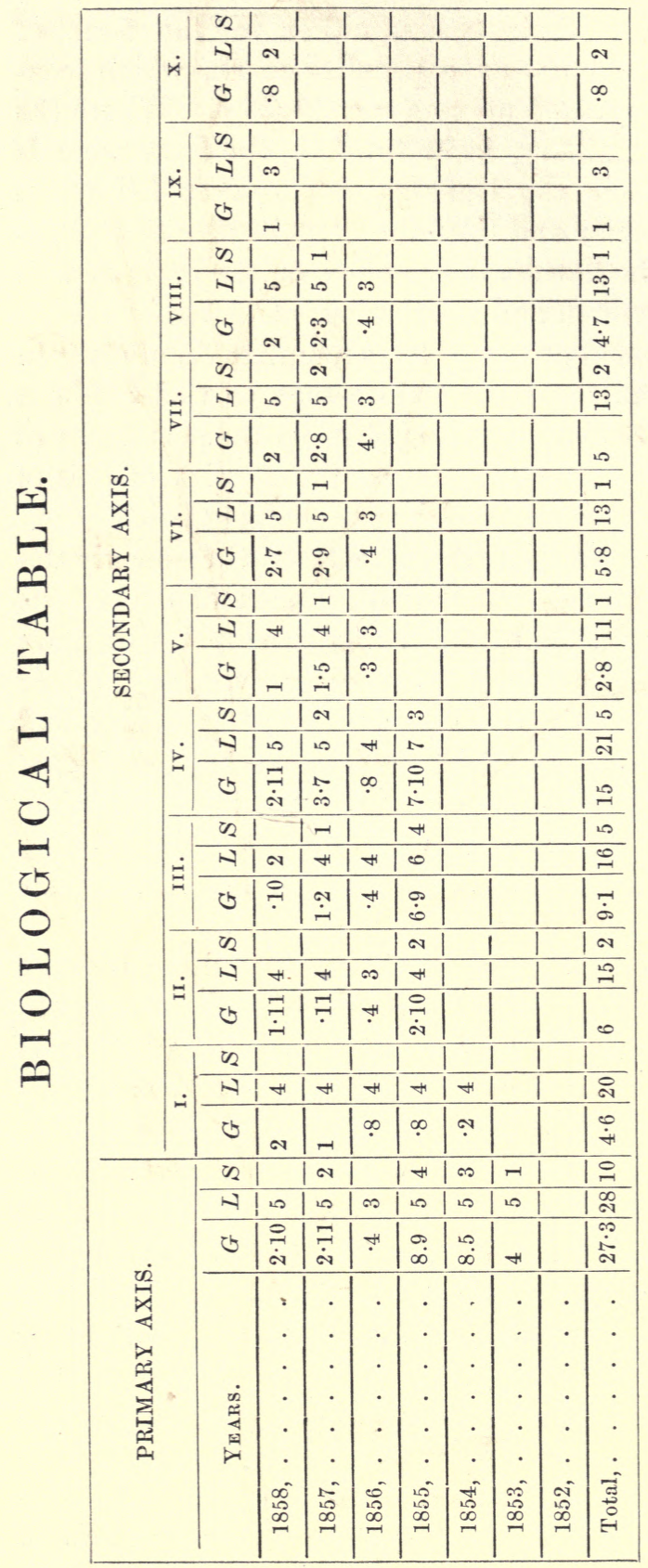

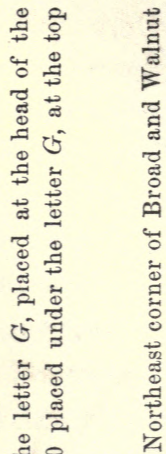

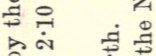

है के है

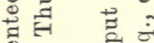

品

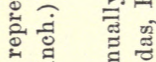

เั สี สี

की पू क्षे की

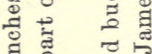

ฝี

है

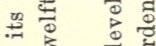

๑

का की

:

$\infty . \Xi \frac{7}{\omega}$

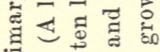

เี

‡.

正

를.

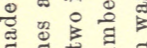

घ 늉 छ

कू. 웅

落活告击

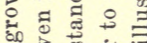

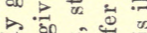

苛 की

突

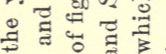

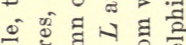

을

औ०

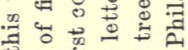

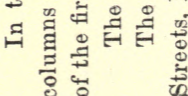




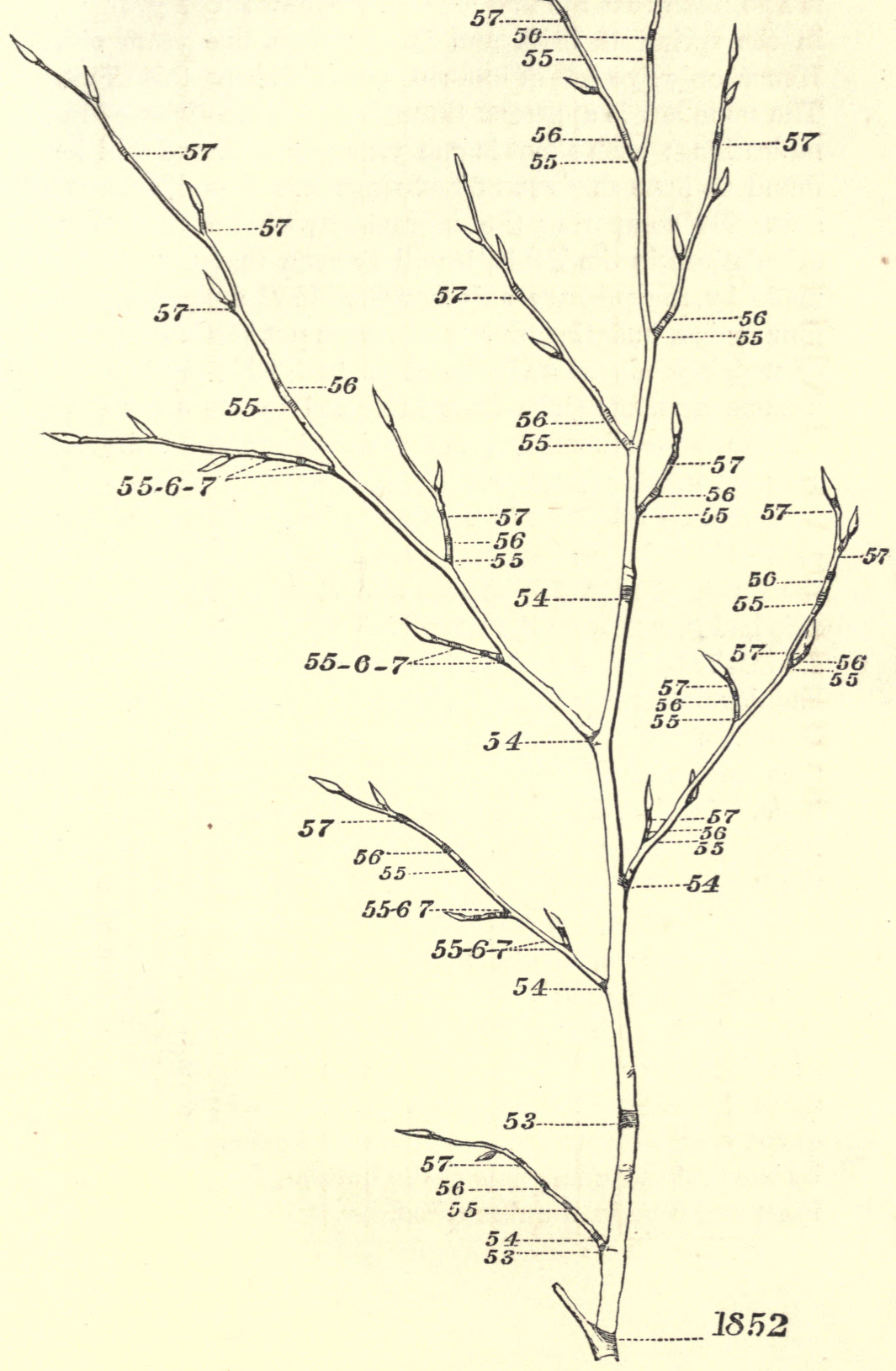


This branch was cut in the latter part of March, 1858; and as there are six sets of bud-rings on its main axis, it is evident that it is six years old, and that its growth from the bud must have commenced in the spring of 1852 . It is also plain that the first side-shoot commenced growing in the spring of 1853, and is, therefore, five years old. Hence, only five sets of bud-rings are visible on this shoot. The same law is apparent through the entire series of ramifications; each shoot is one year younger, and will be found to have one set of bud-rings less than its parent axis. By comparing the engraving with the numerical calculations in the Table, it will be seen that the growth made by the primary axis between 1852 and 1853, was four inches, and that five leaves were put forth, only one of which produced a vitally active bud, which ultimately became a shoot. The buds produced by the other four leaves were rudimentary, and, as is evident from the engraving, never came to anything.

Again, by reference to the figures in the Plate and the calculations in the Table, the condition of the branch in the spring of 1854 will be seen at a glance. The primary axis had grown from the set of bud-rings marked 53 to the set marked 54, a distance of eight inches and five lines: it had developed five leaves, and as there are three branches connected with this portion of the main axis, it is evident that three out of the five leaves produced vitally active buds. So, also, the first side-shoot or secondary axis grew two lines and put forth four leaves. It grew, in fact, about the length of a bud-trace, or took a minimum of development. The distance between the two broken lines at the bottom of the engraving, figured 53 and 54, shows the extent of growth of the first side-shoot between 1853 and 1854. This, then, was the exact condition of our beech branch in the spring of 1854. There were terminal buds at all the points of the main axis marked 54 ; and consequently, with the exception of the slight side-growth made by the first secondary axis at the bottom, the primary axis itself still remained unbranched. 
In precisely the same manner, the extent to which this branch had grown in the spring of 1855 may be ascertained. It is only necessary to bear in mind, that at all the points on the main axis and its branches marked 55, there were buds or terminal growths, and that at these points the growing shoot was in a state of rest, in order to see that the three buds formed the previous year, or on that portion of the main axis contained between 53 and 54, had grown into three considerable branches, of the respective lengths of two inches and ten lines, six inches and nine lines, and seven inches and ten lines. There were, therefore, four well-marked secondary axes connected with the primary axis below the bud-trace marked 54 on the primary axis, whilst the four branches situated above it, and included between 54 and 55, were still in the bud condition.

Between the years 1855 and 1856, the growth of the primary axis appears to have been very greatly retarded. It grew only four lines, put forth three leaves, and there was no side production. The same check to vegetation is also beautifully apparent on the branches during the same season. This is well represented in the engraving, and the figures in the table show a similar growth of four fines, three leaves, and no side production, of all the branches with the exception of the first and fourth, which grew eight lines and produced four leaves. This shows the intimate physiological connection subsisting amongst a system of branches, and that if the growth of the primary axis is retarded, the growth of the secondary axes experience a similar vegetative check.

In like manner, the reader can easily ascertain the condition of growth of the branch during the years 1856 and 1857, and thus accurately trace the several mutations of form through which it passed anterior to assuming its present one, in the Spring of 1858, as represented in our engraving.

The following curious and highly-interesting facts may also be deduced from the calculations of the above Table.

The figures 28 , at the bottom of the first column 
marked L, show the number of leaves put forth by the primary axis; and the sum of the figures of the ten columns marked $\mathrm{L}$, of the secondary axes, or, $20+15+16+21+11+13+13+13+3+2=127$, shows that one hundred and twenty-seven leaves were put forth by the ten secondary axes or branches; therefore, the total number of leaves which constructed the entire branch, was $127+28=155$.

If the reader will refer to the Table and then to the Plate, he can form a true estimate as to the size of the branch. The length of the primary axis is twenty-seven inches and three lines, and of the largest secondary axis fifteen inches : yet it is the leaf-labor of one hundred and fifty-five leaves! The branch itself we have shown to be only six years old. What then must be the immense number of leaves engaged in the construction of trees which put forth thousands of such twigs, comparatively speaking, from their immense spreading branches, which grow from one to two hundred feet in height, and whose giant forms have stood for hundreds and even thousands of years? Who can estimate the quantity of leaf-surface spread abroad in. the atmosphere from the first commencement of germination, and the amount of leaf-labor necessary to rear such vast, noble, and enduring vegetable monuments? "The Washington Elm, at Cambridge,-a tree of no extraordinary size-was some years ago estimated to produce a crop of seven millions of leaves, exposing a surface of two hundred thousand square feet, or about five acres of foliage."*

Again referring to the Table and the engraving, we find that the increase of leaf-surface each year, was as follows:1853,$5 ; 1854,9 ; 1855,25 ; 1856,30 ; 1857,41 ; 1858,44$. That is to say, in 1853 the branch put forth five leaves; in 1854, nine leaves, \&c. \&c. These numerical results are obtained by adding together the figures under L, opposite the years, across the columns.

* "First Lessons in Botany and Vegetable Physiology," by Asa Gray, 1857. 
It is proper also to remark here, that with every increase in the number of leaves spread abroad in the atmosphere, by a young tree or branch, there must be necessarily an increase in the rapidity of its growth, because it has a greater amount of leaf-surface at work in the air. Its chances of life, and of arriving at a state of maturity, become greater as its leaves increase in number. But this law must be understood with considerable modifications.

It will be seen by reference to the Table and the Plate, that the growth of the branch was greatly retarded from 1855 to 1856 . The primary axis that season grew only four lines, and the ten secondary axes were also equally kept back, so that very little wood was formed that year; altogether it amounted to only three inches and seven lines. Yet there were thirty leaves at work that season, being four more than was put forth the previous year, when a much greater amount of work was done, twentysix leaves forming not less than twenty-seven inches and six lines of new shoot. It is clear from this, that growth is proportionate, not so much to the amount of leaf-surface spread forth in the atmosphere, as to the vital activity of the leaves themselves.

Again, by consulting the Table, it will be seen that although twenty-eight leaves were employed in constructing the primary axis, yet only ten produced buds which ultimately became branches; also, that these ten branches, although constructed by one hundred and twenty-seven leaves, developed only seventeen shoots, as is evident by adding together the sum of the figures at the bottom of the columns marked S, under "Secondary Axis;" it follows, that of these one hundred and twenty-seven leaves only seventeen produced vitally active buds. Therefore, the total number of abortive or rudimentary buds in the entire branch must be $155-(17+10)=128$.

The number of shoots annually put forth, were, in 1853,$1 ; 1854,3 ; 1855,13 ; 1856,0 ; 1857,10 ; 1858,0$.

The increase in the growth of the entire branch was, in 1853,$4 ; 1854,8 \cdot 7 ; 1855,27 \cdot 6 ; 1856,3 \cdot 7 ; 1857,18 \cdot 8 ; 1858$, 
19.9: that is to say, in 1853 , the branch grew four inches; in 1854, eight inches and seven lines, \&c. \&c. These results are obtained by adding together the sum of the growths of the primary and secondary axis, placed opposite the years, across the columns, as before.

We have therefore, in this Table, the whole history of the annual growths of our beech-branch placed at once before the eye. Now the importance of such tables, as presenting a truthful picture of the growth of trees, is at once apparent. Similar tables might be constructed, representing the annual growths made by one of the terminal branches of the horse-chestnut or any other tree; and provided the measurements and observations were accurately made and registered, the comparison of the tables would show not only the general laws of growth, which were common to all of them, but those peculiar specific laws to which each was subjected, and by the operation of which they were made to differ from each other.

The history of development is now the watchword of the day in botany; and it is evident that by a careful construction of tables like the above, from references made to marks which Nature herself has made, we can, by a simple yet most accurate method, study the history of development, and this too in the strongest sense of the word. Such tables give to botanists a view of the past life-changes of the branch or portion of the tree whose biology is thus registered, just as the marks left by Nature in the strata or upturned leaves of the "Stony Volume of Creation," enable the geologist to picture to himself the condition of the earth during the earlier epochs of its formation.

Of the tree, it may be truly said that THE WHOLE IS REPRESENTED IN EACH OF ITS PARTS. The careful study of its development is, therefore, physiologically speaking, most important, because beautifully illustrative of this grand principle of organic life and form. 


\section{CH A P T E R III.}

THE INNER ORGANIZATION OF TREES, OR A DESCRIPTION OF THE ANATOMY AND PHYSIOLOGY OF THE DIFFERENT SPECIES OF CELLS WHICH ENTER INTO THE COMPOSITION OF THEIR TISSUES.

IF we wish to recognize the law according to which the tree is built up out of its parts as a compound harmonious whole, we must first resolve the representation of the whole into that unit which lies at the foundation of its superstructure. This we have already done, to some extent, in the two previous chapters. Taking the tree, in the most extended signification of the term, as a separate individual or unit with reference to a forest, we have shown that this individual tree consists of a number of individual plants of a highly composite character called branches, which differ from the entire tree itself only in the smaller scale on which they are constructed, and which actually prefigure the amount of growth of that tree at an earlier stage of its life. These branches are formed by a union of yet simpler individuals called shoots, and the shoots themselves are built up by phytons or leaves, individuals or units which rank still lower in the series. In this manner we have been lead to the leaf at the fundamental organ in the building up of the tree-form.

But this analysis may be carried much further. It may be applied to the inner organization of the tree. Thus the axis or stem separates into two distinct systems the bark and the wood, as the two highest units of its anatomical composition. Each of these systems again resolves itself into a repetition of single annual layers. If we examine one of these layers with a microscope, we shall find it also to be a compound, and that it can be resolved into indi- 
viduals having distinct peculiarities of form and function, called cells. We have now arrived at the lowest and simplest individual or elementary organ, the CELL.

By the aid of Chemistry we can descend however, another step, and can resolve the cell into its original elements of sugar, water, salts, and protein compounds, and these again into their ultimate elements, Oxygen, Hydrogen, Carbon, and Nitrogen-elements into which this grand, living, and wondrous architecture of Nature is at last resolved, when it has passed through all the phases of its life, as its defoliated form slowly disappears from the landscape.

Now as all clear and correct views of the anatomy and physiology of trees must be based on a knowledge of their minute structure, before proceeding further we shall give some account of these simple elementary cells; for by this means we shall be able to explain more satisfactorily certain superficial and very obvious appearances of their bark and wood, and thus advance another step in the elucidation of the philosophy of their growth. It is indeed necessary to the perfection of this picture of the building-up of the tree, that we should begin with the simplest building stone, the CELL, which is the basis of the whole living superstructure, and to which we have been led by the above analysis.

If we examine the transverse section of the stem of a young beech-tree, we shall find it to be composed of a number of concentrical and almost circular beds or layers of wood, ensheathing one another about a common centre, which is occupied by a canal of medulla or pith, and the whole of which is covered by the bark formed on the exterior of the stem. Even without a microscope, there is no difficulty in distinguishing the bark, the wood, and the pith, and thus in ascertaining the fact that the stem is composed of three separate and distinct systems; but when we examine a thin cross-section of one of the newly-developed shoots with the microscope, we obtain a far more correct view of its anatomical structure. We see that the bark and pith are composed of a number of bladder-like vesicles or cells of a 
variable form, which are united among themselves and form a continuous mass; and that the woody portion of the stem consists of thick-walled cells, among which are numerous openings exhibiting quite a distinctive character. The examination of a longitudinal section of the same shoot proves that these openings are the mouths of vessels of a cylindrical form, and that the thick-walled cells are sections across tubes which taper to either extremity, terminating in a point.

Attempts have been made by botanists to classify these different species of cells according to their outward form, which have failed to give satisfaction: their form being too variable to admit of a classification of them on such a basis. A much better character, because a more permanent one, is afforded by their physiological peculiarities. Guided by this principle, we may readily distinguish, in the stem of the beech-tree, six different species of cells. In the bark, three species, viz., the cells of the epidermis, those of the corky or tuberous envelope, and the bast-cells; in the wood, two species, the fibre-cells, and the vasiform or ductcells; and in the pith and medullary rays, one species, common parenchyma.

Each of these species of cells carries its own life, has its own peculiar period of growth and vital activity; and its cells differ morphologically as well as chemically from the cells of the neighboring tissues.

\section{THE BARK.}

The Cells of the Epidermis clothe the outer part of the bark of trees during the first year of their life, and subsequently the surface of those green herbaceous shoots which are annually put forth from the branches. These cells are in form, flat and tabular, and as they are without chlorophyl, and are united among themselves with an extraordinary degree of force, they may be separated from the subjacent tissues, without being detached from each other, as a continuous transparent plate or membrane. In the young and tender condition of the stem of trees the epidermal cells are of considerable importance; but they survive the 
first year only in a few cases. In general, these cells die toward the middle of summer, and the epidermis becomes fissured and rent. The epidermis is therefore absent from the old stems of forest trees. The pores must be regarded as a variety of the epidermal cells.

The Cork Cells or Tuberous layer.-These cells lie immediately beneath the epidermis. They are more or less flat, tabular, and thin-walled cells of a brown color. They form themselves under the epidermis, and usually appear first as lenticels through the chinks of the epidermal layers. The commencement of the cork formation can be observed under the epidermis of the young branches of the oak, birch, and beech, in the middle of summer, or at the commencement of autumn. It is the cork which gives to the trunk of trees their peculiar color and rugged appearance. When the cork-cells form, the epidermis speedily dies off, and the cork supplies its place and in some measure its function. It restrains, equally with the epidermis, the evaporation from the underlying cells, and affords them an excellent protective shelter from hurtful outward influences. Cork invariably forms itself over the wounds of plants as a protective envelope. Therefore, although the life of the cork-cells is of short duration, they form when dead, a very important tissue, and continue to be of considerable service to the tree. The rough fissured bark on the outside of old trees chiefly, consists of layers of dead cork-cells.

The BastCells.-These form the fibrous portion of the inner bark, and develope vertically as elastic tubes, more or less elongated and thick-walled, which usually lie together in fascicles or bundles, and are united with considerable force. It is these bundles which constitute the textile fibres in flax and hemp, and in general in all plants cultivated for the fabrication of clothing. The bast-cells are also a very important tissue for the manufacture of paper and cordage. They elongate themselves with the parts of the plant in which they originate without forming new cells, and often attain to a considerable length. It is in the bastfibres that the sap descends after its elaboration in the 
leaves. The fluid contents of these cells are, therefore, as manifold as that of the parenchyma cells. The bast-cells of one plant contain quite a different fluid matter to that of another plant. In one, the fluid is poisonous; in another, nutritive: here it is a white, yellow, or orange-colored milk sap: there, caoutchouc, chlorophyl, or resinous matters are present.

Although the bast-cells form the innermost layer of bark, in no case do they rest immediately on the wood. They are always separated by a bed of cells more or less thick, called the cambium layer.

THE WOOD.

The wood includes nearly the whole of that part of the stem situated beneath the bark. It consists of a number of ligneous circles, visible on the cross-section, which are traversed by lines radiating from the centre to the circumference of the stem, that is to say, from the medullary canal to the bark, called the medullary rays.

This disposition of the wood in circular beds or layers, takes place in all the trees of countries where the season of growth has only a limited duration, and is followed by a period of cold and vegetable inactivity. Each year there is formed in spring a new bed of wood, and at the same time a fresh layer of bark. The age of a tree is, therefore, in most cases, the same as the number of ligneous circles which can be counted on the cross-section of its stem. In the same manner the age of the branches may be computed.

This fact must be mentioned with some restrictions; for, in certain circumstances, as for instance, when a warm spring is succeeded by a wet, cold summer, vegetation receives a check, and a ring is formed prematurely; with the return of more favorable weather, the tree again makes a rapid growth, so that at the close of the vegetative season two rings have been formed during the same year. The rings become less distinct in Exogenous trees as we travel South. On approaching warmer climates, where vegetation continues almost withoutinterruption throughout the whole 
year, the rings become confounded one with the other; they are much thinner, and so multiplied that they cease to be reliable, and do not indicate in any manner the age of the tree.

The trees of temperate climates usually thicken themselves in their whole circumference, and the unequal development of only one side must always be regarded as an exceptional case. In tropical countries there are, however, trees whose stems take the most wonderful forms, in consequence of the unequal development of their sides. Some of them belong to the genus Bauhinia, Natural Order, Leguminosæ. The most striking example among the species of this genus is furnished by the stem of Heretiera Fomes. The first year the stem of this tree is normally formed, a small wood-ring surrounding the pith; but afterward it annually thickens by crescent-like deposits of wood on two opposite sides; the stem thus presents a flattened, compressed appearance. "I examined such a stem," says Dr. Herman Schacht,* "which was eighteen inches in one direction, in the other, on the contrary, it was only two inches broad," presenting "in some measure, the appearance of a natural plank, surrounded by a weak bark."

Anomalous forms of Exogenous stems also exist amongst tropical trees belonging to the Natural Orders Bignoniaceæ, Malpighiaceæ, Menispermaceæ, and Aristolochiaceæ. $f$

In the wood of beech-trees, two distinct species of cells can be recognized, the fibre-cells and the vasiform or ductcells.

The fibre-cells form the principal part of the wood of each ligneous deposit. They are elongated and extremely attenuated cells, tapering to either extremity, and lying together in bundles more or less compact, which are developed vertically. It is through the fibre-cells of the wood that the main current of the sap flows in the spring. Their vital

* "Lehrbuch der Anatomie und Physiologie der Gewachse," page 345, Berlin, 1856.

† See, "Precis de Botanique et de Physiologie Vegetale," par A. Richard ; page 75-80, Paris, 1852. 
activity, however, only continues for a short time. Their walls are soon thickened by earthy matter, which goes on accumulating, until their cavities are finally closed, and the sap ceases to circulate through them. The color then changes, and they no longer take any further part in the vital operations of the tree. Their function is now purely a mechanical one; for the very same matter which terminates life endows them with force and persistence. The fibre-cells thus lignified, form, as it were, the skeleton or framework of the tree, and withstand outer influences as well as inner decomposition much longer than the other tissues. They are the very last to yield to dissolution.

The vasiform or duct-cells are spread through the mass of fibrous tissue. They originate out of a row of cells, the cross walls of which are absorbed, so that, when fully developed, they form one continuous tube. These ducts may be readily distinguished from the wood-cells among which they are interspersed, as their interior diameter or bore is much more considerable, and they remain permanently open. The open mouths of the ducts are very conspicuous on the transverse section of common pine-wood, where they resemble pores. There are several varieties of this species of cell termed by botanists, dotted, annular, spiral, and scalariform ducts. The whole of these vessels at first contain sap, which is afterward displaced by air. They may be regarded, in fact, as the air-vessels of plants, by means of which the sap in their interior is brought into communication with the atmosphere. This is the reason why these ducts or air-tubes are placed amongst the fibrecells or sap-tubes, as inspection plainly shows.

The ducts and fibre-cells are, however, arranged in the stem according to a definite law, as inspection plainly shows; for the former preponderate in number toward the interior portion of the ring, whilst the fibre-cells are most abundant towards its exterior. The bounding line of each year's growth is easily distinguished by this internal arrangement of the ducts, and its cause is to be sought for in the vital economy of the tree itself. The inner portion 
of the wood-ring, with its loose and porous structure, is constructed in spring, when the greatest amount of sap is needed for the nutrition of the growing leaves, shoots, and flowers. Hence the wood-cells formed at this time have wide cavities, and their walls are but slightly thickened. They have been called by botanists ducts, and through them the current of sap flows in early spring, when it is most in demand. But in summer and autumn, when the new leaves and shoots are fully developed, less sap is needed. The outer and more compact portion of the wood is formed at this time, and the wood-cells then developed are adapted in their tubular capacity, to the diminished necessities of the tree; their cavities are much smaller and their walls thicker. It is the long, attenuated forms of these cells which has led to their being called fibre-cells.

The fibre and duct-cells die early. There is a gradual cessation of their vitality, inseparably connected with their formation. So soon as a cell ceases to form new cells, or to develope or carry nourishing matter in it, so soon as its fluid contents disappear and it becomes filled with air, it may be considered as dead. This is the condition of the fibre and duct-cells when fully developed; then the sap disappears from their cavities, and we find in them neither protoplasm nor cell-nuclei. Their nitrogenous contents have been expended either in the lignification of their walls, or they have been absorbed by the neighboring cells. With the disappearance of this formative material, the life of these cells necessarily terminates.

THE PITH AND THE MEDULLARY RAYS.

These are parenchyma cells; the most widely diffused, important, and variable tissue of plants. The parenchyma cells of the pith are spherical or ovoid when they are but slightly united together, but more often they become more or less polyhedral by reciprocal pressure.

In the young stem, the pith is of considerable importance; it abounds in nutritive matter, which serves to nourish the young buds on its surface, and is often of a green color, 
more or less intense. But when the buds develope into branches, supporting leaves, flowers, and other appendages, the nutritive liquids accumulated in the pith are absorbed, the particles of green matter disappear; and when the vegetation commenced in spring is arrested in autumn, the cells of the pith are dry, colorless, and empty: they are then, in fact, dead cells.

The parenchyma cells of the medullary rays are of a quadrilateral form, and develope in horizontal radiating lines from the pith to the bark. These lines are easily distinguished on the cross-section of the stem, when the wood is compact and not too deeply colored: the oak, for example. Their looser structure and lighter color renders them in such circumstances more visible. The medullary rays develope vertically as well as horizontally, and partition off the wood into a number of wedges, in the form of elongated triangles, of which the point that is a little obtuse corresponds to the medullary canal.

The medullary rays are of great service to the old wood. They maintain an exchange of sap between the cells of the pith, wood, and bark; and when the pith-cells are quite dead, they unite the older annual layers of wood with the younger and with the bark, and thus continue the communication. They therefore survive the death of the pith-cells, and even of the wood-cells, in the midst of which they radiate. The medullary rays of a five or six years' old woodring, are still vitally active cells, filled with sap.

We have now given the anatomical and physiological peculiarities of the different species of cells which, united, form the tissue or substance of the stem of a beech tree. We proceed to investigate the physiological phenomena of these cells, as combined together into a continuous tissue, and thus give the reader as clear and philosophical an idea as possible of the growth of the tree.

The remarkable disposition of the substance of the bark and wood in circular strata or layers, results from the annual formation of a new stratum or bed of wood on the exterior of that already existing there, and of one or more 
layers of bark on the inner surface of the bed of bark formed during the previous year.

If during winter, when vegetation is in a state of repose, we examine the cross-section of a young stem or branch, we shall find it in the following state. The bark and wood are firmly united with each other, and lying directly between them a bed of parenchyma will be seen, deprived of green granules, which is called the cambium layer. This bed has been formed during the preceding summer, from the descending sap or cambium, which spreads itself between the bark and wood; and it is through the transformations effected in its cells that new rings of wood and layers of bark are annually produced. Parenchyma is the original form of every species of cells. If we examine with the microscope a section of a young leaf, or root, or any other organ of a plant, we shall find that it is composed entirely of parenchymatous tissue in the first stages of its development; as growth progresses, these cellules are gradually transformed into fibre-cells, and vasiform tissue or ducts. In the same manner, the different species of cells, forming the annual growths of wood and bark, are generated from the parenchyma cells of the cambium layer.

During winter we perceive no change in the cells of the cambium layer, which are filled with nutritive matter, whilst the cells of the medullary rays contain starch. As soon, however, as spring commences, the starch granules are converted into a soluble sugary gum called dextrine, with which the cells of the cambium layer are speedily gorged, so that the bark and wood are now easily separated. It is out of this viscid mucilaginous matter, or cambium, that the new layer of bark and wood is annually produced. For as the weather gets warmer, the vital activity of the cells of the cambium layer becomes fully aroused, and they generate cells of the same nature as those with which they are organically united, out of the cambium or sap with which their cavities are charged, and elongate into fibre and bast-cells; wood producing wood, bark forming bark, the cells preserving their original form of parenchyma only in those portions 
which correspond to the medullary rays. In this manner a new layer of wood and bark is annually formed.

The parenchyma cells of the cambium layer retain their vital activity longer than any other cells in the tree; for, as new cells are developed from this tissue every season, the death and birth of its cells keep with one another equal steps. These cells may continue to be vitally active to some extent: even when the life-processes have ceased through nearly the entire structure of the tree, here life may still linger, these cells being the very last to yield up their vitality.

The vasiform or duct-cells in early spring, when the ascent of the sap is most powerful, at first convey it to the leaves in conjunction with the fibre-cells of the wood. But, as the flow of the sap becomes less vigorous, it gradually disappears from the ducts, owing to their deficiency in the requisite amount of capillarity, which thus become filled with air; the finer capillary tubes of the fibre-cells, however, still induce a continuance of its flow through their cavities.

As the sap speedily subsides in the ducts, earthy deposits necessarily accumulate sparingly on their parieties or walls, and their tubes remain permanently open. The interior diameter of the duct-tubes is from the first much larger than the bore of the fibre-tubes, hence the sap continues to flow in the latter much longer than in the former: in fact, throughout the season. As every additional deposit of earthy matter on the walls of the fibre-cells necessarily gives them a finer degree of capillarity, the sap continues to flow in them through subsequent seasons, until their tubular character is obliterated altogether. When this is the case, the life of the fibre-cells is terminated, and they exercise a purely mechanical function.

This solidification of the fibre-cells is usually connected with a change in the color of the wood, more or less marked. If the transverse section of the stem of an oak or cherrytree be examined, a very perceptible difference will be seen between the circular beds of wood toward the interior of the stem, which are of a deeper color and more compact than 
those situated nearest the bark, which are, on the contrary, pale, and of a looser texture. The pale wood nearest the bark is called the alburnum, or sap-wood, as the sap still continues to circulate there to a greater or less extent; the older, more compact, deeply-colored, and more solidified wood, which occupies the more interior part of the stem, is called duramen or heart-wood. This wood consists of dead, indurated cells, the cavities of which have been filled up with earthy matter or lignine, and is the part chiefly valued by workmen as most suitable for manufacturing purposes. The various fancy-colored woods employed by the turner and cabinet-maker, consist of the heart-wood only, which assumes different colors in different species, being black in the ebony, bright yellow in the barberry, purplish red in the cedar, and dark brown in the black walnut. The alburnum in all these trees, even in the ebony itself, is always white, and is chipped off with the axe before the wood is shipped, as a part of little or no value.

The years' rings are manifest not only in the wood, but also in the bark; and in the pine and other trees those last formed continue to be unbroken for a number of years. But whilst every new layer of wood is deposited on the exterior surface of the last year's wood, the diameter of the wood is a constantly increasing quantity, each ring of wood remaining unaltered in its dimensions and position until its cells finally decay; each new layer of bark is deposited on the interior surface of the ring of bark of the previous year; hence, the bark-rings or layers, previously deposited, are subjected to gradual but incessant distention, and are finally fissured and rent. The interior growth of the bark, combined with the annual development of the subjacent woodrings, thus prevents an accumulation of bark to any very great extent, on the exterior of the stem. Hence it is that, on the cross-section, the bark bears but a small proportion in thickness to the wood. In the common plane tree, after the eighth or tenth year, all the old layers of bark fall away entirely in the form of brittle plates. The innermost layers of wood, and the outermost layers of bark, are therefore, 
after a certain period, both deprived of life. The cork tree (Quercus suber) however, is an exception. On the stem of this tree, which is cultivated in Spain, Portugal, and the South of France, the bark grows to a considerable thickness, and is removed from the tree every eight or ten years. It is taken off in sheets or tables, much in the same way as oak or larch bark is removed. After being detached it is flatteried, by presenting the convex side to heat or pressure. In either case it is charred on both surfaces, to close the transverse pores previously to its being sold. The carbonized surface produced by this charring may be seen in bungs and taps, but not in corks, which being cut in the direction of the wood, the charring is taken off in the rounding. The dead bark is taken off for the first time when the tree is about fifteen years old; it soon grows again, and the tree may be rebarked three times, the bark improving every time until the tree attains the age of thirty years.

The old, dead, and fissured bark on the exterior surface of yon aged tree, was once a young, living, and continuous tissue in immediate contact with the wood, and has been gradually separated from it, by the subjacent growth of successive strata, or rather annual generations of bark-cells. Life has in succession passed from these away. The older and more exterior, shelter the younger and more internal bark-cells. Vegetative life is at present,* torpid and inac彎tive, and the snow covers the ground; but the sun shall again shine bright and warm on that now leafless tree, and under its influence another generation of young and vitally active bark-cells shall develope, and be pushed forward to die on the exterior of the stem and be ultimately thrown off like the generations which have preceded them.

From the whole of these facts it may be inferred, that the life of a tree depends on a harmonious working together of both its living and dead cells, the latter remaining not only as a mechanical prop or foundation for new generations, like the dead individuals of a coral reef, but giving to the entire organism additional strength, after they have ceased to

* This passage was written in the winter of 1857 . 
take part in its vital operations, and therefore still remaining a necessary part of it, as a living physiological whole.

It is also evident that the different species of cells which united together form the tissues of trees, like their leaves and other organs, are individuals having distinct physiological functions to perform. These plant-cells differ from the phytons or leaves only in the greater simplicity of their organization; both are governed by the same general laws, having a life peculiar to themselves, and their own period of arriving at a state of maturity and decay. There is also, evidently a similar division of organic labor amongst the cells, as amongst the leaves; each cell contributes its part to the building up of the tree, and the separate and combined labor of the whole of them is necessary in order to effect those various transmutations and changes of the raw nutritive material, or sap, into its final products. We know that some of the cells, such as the fibre and duct-cells, are principally employed in carrying the raw material from one part of the cell community to the other, and that these changes are wrought in the parenchyma cells, not of the leaves alone, but in parenchyma everywhere; for the parenchyma cells of the root and pith are frequently as rich in starch as those of the bark or leaves. But we are at present profoundly ignorant not only of the nature of these transmutations, but also of the order in which they take place: for that the entire series are governed by fixed laws of sequence is plainly indicated by the whole of the vital phenomena of the plant.

We see it put forth a regular series of organs, which follow each other in a determinate order of time, and not only contribute to the nourishment of each other, but yield up life in succession in effecting a progressive metamorphosis of the constituents of the sap, and the advance of the plant towards the perfection of its structure. And first the seed-covers are ruptured and the nursing-leaves atrophied in the development of the first series of phytons ; these latter die in developing the stem and the buds on its outside. These buds consist of a series of covering leaves, which shelter the 
punctum vegetationis or growing point of the young shoots through winter; they die and fall off in spring. When the new generation of phytons are put forth into the atmosphere, another series of covering-leaves are formed by them, which are left in charge of the growing points of the shoot through winter, as before. In this manner there is an oscillation. between these two kinds of leaves in trees for a series of years, until the tree arrives at an adult state. The different phytons of the flower designated by botanists as sepals, petals, stamens, and pistils, whose individuality is so strikingly marked, then make their appearance, and these die in succession in developing the walls of the pericarp, or seedvessel. Lastly, the vitality of the walls of the pericarp itself is exhausted ; for the whole of the nutritious contents of its cells must pass through the funiculus, or vegetable umbilicus, the little stalk by which the seed is fastened to the seed-vessel, into the nursing-leaves and seed-covers, before the germ of the future plant can be fully formed.

There can, therefore, no longer remain a particle of doubt about the fact that the cells which form the organ of a tree, work together in communities according to fixed laws of succession, and that the design of the whole of these arrangements is to effect such changes in the sap as to secure its final transmutation into those peculiar products by which the tree is distinguished. Just as in civilized communities the raw material of our manufactures goes through a regular series of changes in the hands of a great number of workmen, before the goods are manufactured and fit for sale, so with the ultimate products of plants, which are as various as the plants which produce them. These have all been manufactured from the raw material, or sap, which has gone through a regular series of preparatory metamorphoses, or changes in the interior of the plant. The lowest order of individuals employed in effecting these changes are the cells, which combined together into communities form those different varieties of phytons which develope about the axis or stem of the plant. These phytons or cell-communities constitute a still higher type of individuals, which appear 
in regular order and change their form and color as the metamorphosis of the sap progresses. In herbaceous annuals and perennials, a few weeks or months is all that is required to transmute the sap into its final products; but in perennial ligneous plants, such as shrubs and forest trees, the period of metamorphosis is greatly protracted, and it is sometimes years before the whole thing culminates, and the luscious fruit hangs at last from the branches.

The recent advances which have been made in Vegetable Anatomy and Physiology, result from the right application of chemical reagents to sections of vegetable tissue, when placed beneath the microscope. The principal reagents employed in these researches are Sulphuric Acid, Iodine, Caustic Potash, Sulphuric Ether, Alcohol, and Ammonia. Through the use of these reagents, a few facts have been brought to light. Starch, for example, is detected by Iodine, if present in the cells, by the blue color which the granules assume. In this manner starch may be readily ascertained to exist in the tubers of the potato and in the milky juice of Euphorbia splendens. It is only necessary to place a thin transparent slice of the tuber of the potato or a single drop of the milk of the Euphorbia, under the mieroscope and apply Tineture of Iodine, when the granules will immediately become visible by the deep blue color which they will take.

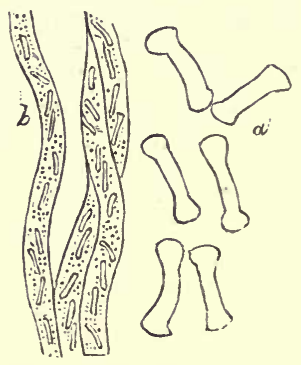

a. Club-shaped granules in milky juice of Euphorlic splendens. $\quad$ b. Three of the lactiferous vessels, with starch granules in situ.-QUEKETT.

In a similar manner, the chemical nature of chlorophyl, the substance which gives to the leaves of plants their green 
color, has been examined ; so also, gum, sugar, resin, and the other products of the cells. It has been ascertained that starch passes into dextrin and sugar, which substances are again transmuted into starch; but when we look at the rich diversity of vegetable productions and find that the most learned chemists and physiologists are compelled, through pure ignorance, to speak in the most general terms about the nature and order of these changes, we cannot but feel how little the works of Nature are understood. Look at the flowers in any garden! What an endless variety of color, form, and fragrance! Each variety of leaf connected with the stem, including the pistils, stamens, petals, sepals, and even the bracts, stipules, and bud-scales, are doubtless formed with an especial reference to the elaboration of the sap into those final products by which the plant is characterized; yet, notwithstanding all that has been written and said on the subject, it must be confessed that we cannot, as yet, appreciate the perfection of the machinery, or trace the progress of the raw material through all its changes, until it reaches its final metamorphosis. In this respect, not only the tree, but the commonest weed is an interesting study; it exemplifies the laws of growth quite as much as the costly exotic in the conservatory. The flowers and forest trees which cover and adorn the earth, may be regarded as so many beautiful living problems, which are everywhere presented to us by the Great Intelligence for our solution.

And now, reader, may I be permitted to lay before you some reflections which appear to me to be suggested by the facts advanced in the last two chapters.

Be usefully employed, never be idle. This grand moral lesson is taught us by every portion of the fabric of a tree. Not only each goodly branch and vigorous shoot, each frail and perishable leaf of the many thousands which have passed forever away, but even the minutest and most insignificant bract and bud-scale has contributed to the formation of the tree. Some of the phytons were neither green nor gorgeous in their apparel, their external appear- 
ance was insignificant, and the task allotted to them in the labor of construction was small; but it was nevertheless, physiologically speaking, an important one : for phytons, even when for want of a proper supply of sap and sunlight they can produce nothing but starveling shoots, or take the form of stipules or bud-scales, are nevertheless necessary in the places where they are situated, in order to develope other parts which are of more service to the tree. They form a link in the chain of mutual labor. And not only individually do they receive support from the tree, but each labors according to the extent of its capacity in yielding the tree an equivalent, in insuring it the means of protecting and sustaining its life.

Even the little cell, through the increase of which the whole mass of the tree itself is formed, plainly teaches us this great moral lesson. According to physiologists, man himself was, at the commencement of life, nothing but a single cell. The inner organization of trees, and the peculiarities of their cell-life, has therefore some claim on his consideration.

Variety of form and function is characteristic of all the parts of the tree, and not less varied are the gifts of the individuals constituting the population of a city or country. It is this variety of gift, this division and association of labor for a common object, which has created society. And there can be no growth or progress either 'of individuals or communities without labor.

Let me define what I understand by the term labor. To many persons this word conveys ideas of nothing but suffering, constraint, and fatigue. This is not what I mean. I call labor any useful employment of our physical and intellectual powers; some occupation of mind or body, no matter what, by means of which we insure our own progress and the advance of society. This lesson is taught, not only by all the individual parts of the noble forest tree, but by every flower and blade of grass : in fact by all the individuals of the vegetable world. All are at work, and what is more to the purpose, usefully employed. 
Many plants are well known to be valuable as sources of food and medicine; and doubtless others exist around us which are equally valuable, although at present the REASON OF THEIR CREATION is not so apparent. Orie thing is clear, that there is no such a thing in Nature as a plant which is perfectly useless. Even weeds develope habits of care and industry, which are called into exercise in effecting their extirpation; in addition to this, they undoubtedly perform their allotted task in the great laboratory of Nature, and are the instruments by means of which nutritive matter is extracted from the passing wind and the falling rain-drop, which they deliver to the soil on which they finally decay. A weed is, properly speaking, a plant out of place. Any plant may become a weed if it is allowed to multiply to an unreasonable extent, so as to prevent the growth of other plants which it is desirable to cultivate.

I have spoken of the lessons of industry taught by the vegetable world, but-the reader must pardon the digression-even the lifeless elements, the winds and waters, what are these but the great labor-forces of Nature? Those clouds must be brought from yonder ocean to water this thirsty landscape; these rocks must be pulverized and converted into fruitful soils; the winds that wander by you, reader, are engaged in the discharge of these duties. See the ocean at work, battering down the rocks along the sea-shore; and the rivers at work, transporting the materials of hills and mountains to the ocean. It is thus, after myriads of ages, that the land and sea are made to change places. "The sea," says Sir John Herschel, " is constantly beating on the land, grinding it down, and scattering its worn-off particles and fragments, in the state of mud and pebbles, over its bed. Geological facts afford abundant proof that the existing continents have all of them undergone this process, even more than once, and been entirely torn in fragments, or reduced to powder, and submerged and reconstructed." All this work is done by the winds and waters.

Surely in such a world, all labor directed to useful purposes is honorable employment, and renders the laborer 
respectable. Can any position be more false, unnatural, and ruinous in its tendencies, than one founded on the doctrine that labor is degrading? Yet the majority of men are making it the business of their lives to render them-: selves and their children independent! Independent of what? Not of labor, surely. Riches are very uncertain possessions. Better bring up children to a regular business, even if you have wealth to leave them. Let them be early taught to work. Then they will be more likely to live long and happily, and to maintain that position in society to which your industry has elevated them.

Every person in good health ought to employ his powers. Labor is ennobling. It is the sure road to a high and honorable eareer. All the great men of ancient and modern times have aequired distinetion through labor. Demosthenes and Newton acquired their imperishable renown in this manner. In a letter to one of his friends, Newton says, "If I have done the public any service, it is due to nothing but industry and patient thought." It is the idle man alone who degrades himself. He lives in the habitual violation of a great natural law, and becomes enervated both in body and mind. It may be that he is possessed of all the appliances of wealth and modern civilization, yet he lives wretchedly and is cursed with ennui. Where is the flashing eye, the light elastic footstep attendant on useful, agreeable, and profitable employment? You might be surrounded by the creations of your own genius, with the advantages which you have at your command, if you possessed any nobility or energy of soul. You are miserable, because you are idle-a jarring string amid the surrounding harmonies of industrious nature. Everything about you is a rebuke on your conduct. All nature cries shame on your idleness. You ought to blush to look at the flowers of the field, the blades of grass, or those monuments of leaf-industry, the trees, in all their endlessly diversified varieties of architecture. It is impossible for any family to continue pre-eminent in a community, unless, along with the wealth which they receive is transmitted the industry and life-energy of their ancestors. 


\section{H A P TER IV.}

THE TREE IS CONSTRUCTED ON THE PRINCIPLE OF A CONE. ITS LEAVES ARE THE SOURCES WHENCE PROCEED THE FORMATIVE MATERIAL USED IN THE BUILDING UP OF ITS STEM AND BRANCHES, WHICH IS DISTRIBUTED AMONGST THEM AFTER A COMMON LAW.

IF we look at the stem and branches of a tree in winter, when it is deprived of its leaves, we shall see at once that it is constructed on the principle of a cone; for the main axis or stem of the tree is broadest at its base, and gradually decreases in thickness toward the extremities of its branches. Any branch is, in the place where a side branch originates, stronger than the last at its base, so also this side branch is stronger than the branchlet which it produces, and in this manner the thickness of the stem or principal axis steps, as it were, away by degrees from branch to branch, until at length it loses itself in the fine branches of the youngest generation of shoots. It is well known that the cone is the stablest structure in nature, and the tree may be regarded as an arborescent cone.

It was shown on page 38, that the stem of a young beech tree exhibits, on the cross-section, a number of concentrical and almost circular beds or layers of wood ensheathing one another about a common centre, which is occupied by a canal of medulla or pith, the whole being covered by the bark formed on the exterior of the stem. The longitudinal section, on the contrary, shows that the stem is composed of a series of superposed, and hollow, elongated cones, the old conical layers or growths of the last and previous seasons constituting a firm foundation for the new conical layers of the next and succeeding years. Through the whole of these cones the pith penetrates as a continuous cylinder.

The conical growth of the tree is the result of the conical formation of the first year's shoot, which is the foundation 
of the subsequent annual additions of wood and bark; for as these are deposited in strata, which lie parallel with the wood and bark of the first year's shoot, the conical form of the superposed layers is necessarily retained.

Growth in length and growth in thickness must therefore be hereafter regarded, not as two different factors, but as the result of one and the same vegetative cause, viz., the formation each year of a new conical layer or enveloping mantle of wood and bark, which extends from the top to the bottom of the tree. In order to make clear the connection which subsists between these two contemporaneous acts of growth, we shall leave the bark out of consideration for the present, and confine ourselves to the wood as the peculiar variable part, and that which principally determines the thickening of the entire axis.

The annexed figure represents an ideal longitudinal view of the primary and secondary axes of the beech branch already prefigured and described in Chapter II, and is intended to illustrate the nature of conical growths, and the connection which subsists between the axis and its ramifications.

It is quite plain that, as each new cone developes from the terminal bud which is situated at the summit of the previous year's cone, the sets of bud-rings which are visible on the exterior bark of the young stems and branches of trees, and which mark the growth of each year, must correspond respectively with the summits of each individual of the superposed series of cones; and that, as these cones are formed by the leaves of each year, their summits rise above one another according to the greater or less amount of vital activity of the leaves during the season of growth. Hence, figures ' 53 point out the summit of the first and innermost cone, which corresponds exactly with the position on the exterior bark of the first set of budrings. It is the same with the tops of the other enveloping cones marked '54, '55, '56, and '57. The figures indicate not only the tops of the cones, but, at the same time, the place of the annular scars left by the bud-scales on the bark.

Hence, in order to estimate the age of an axis from a given 


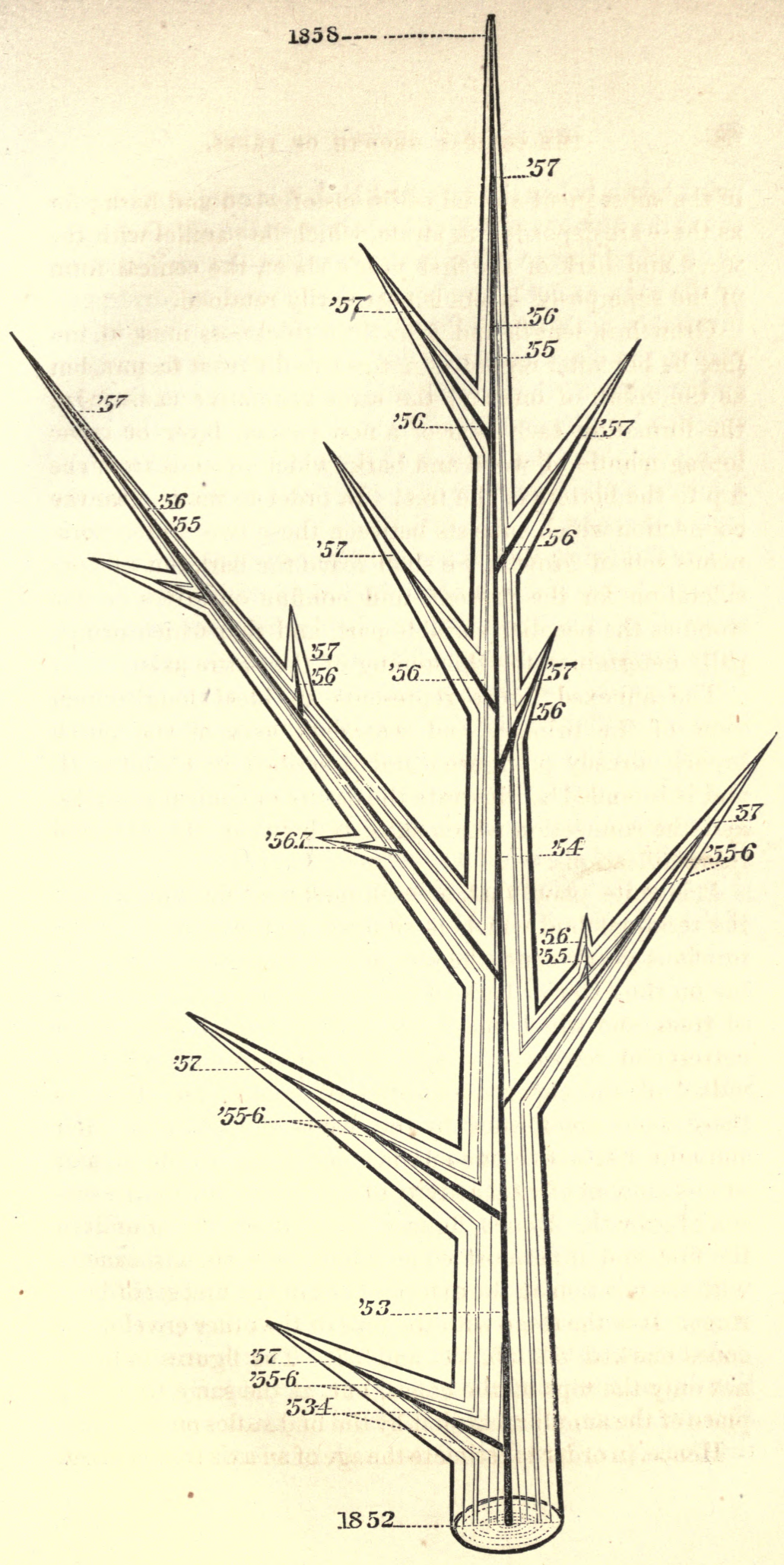


point taken below the terminal bud, it is only necessary to count the number of sets of bud-rings on the exterior bark, or of years' rings visible in the wood on the cross-section of the axis, as both numbers will be found to correspond invariably with each other. To make this plain to the reader, the diagram shows not only the relative position and number of the several conical growths, but their respective lengths and breadths at the same time, the latter being visible at the bottom of the diagram in the form of a corresponding number of circular and concentric woody layers or strata.

The following simple geometrical consideration will, we hope, aid the reader in obtaining an approach to a proper conception of the relation subsisting between growth in length and increase in breadth among the branches of trees. If he regards the diagram attentively for a few moments, he will see that the two sides of the innermost cone, estimated from the point immediately below the terminal bud marked ' 53 , form, with the diameter or breadth of the cone at its base, an isosceles triangle. Now, supposing the base of this triangle to remain constant and its two sides to vary, it is plain that the angle of acumination formed at the apex of the triangle will be a function of its sides, for this angle will become greater or smaller, in proportion as we suppose the apex of the triangle to approach to or recede from its base, and its two sides to shorten or elongate. For the shorter and more abbreviated the axis of the cone, the more relatively enlarged is its base, and the more clearly is it conical; but the more its axis is lengthened, so much the more do the two sides of the cone approach to a state of parallelism, and the axis tend to a cylindrical form.

These considerations prove that the following law will express the relation subsisting between the two dimensions of length and breadth; the branches are more cylindrical the longer they are, and more conical in proportion as they are shorter.

As examples of well-marked conical growth we may mention those extremely abbreviated, or more properly speaking, abortive shoots, called thorns, of which (Cratcogus crus-galli) the Cockspur thorn furnishes us with an admirable instance. 
In the case of (Salix Babylonica) the Weeping Willow, on the contrary, we have an instance of branches which tend more to a cylindrical than to a conical form. In consequence of this peculiarity, the branches of this tree are long and pendulous, their waterfall-like curvature is extremely graceful, and, as they wave backward and forward in the wind, the tree presents one of the most beautiful and picturesque of objects.

But the conical growth of trees is sometimes strikingly apparent in their landscape character, or general outline when viewed from a distance. This is the case in the great Natural Order, Coniferæ. The trees belonging to this order such as (Juniperus communis) the common Juniper, (Juniperus Virginiana) the Red Cedar, and the different species of Fir and Pine, when seen from a distance, are clearly conical in their outline. This, in fact, is more or less the original form of all trees in the first stages of their development. For, at first, growth takes place principally in the direction of the leading axis or stem, and the growth of the branches is consequently greatly restricted; but after a certain number of years, the stem obtains its maximum elevation, and growth is diverted to the branches. The tree then loses its conical form and begins to spread out on all sides, forming, as in the case of the Linden and Elm, a magnificent dome or crown. In the Coniferæ, however, development is not carried so far, and the tree still retains its cone-like appearance through all the stages of its life. For this reason, as well on account of the simplicity of their flowers, these trees may be considered of a low order of organization.

The leaves of the tree are the true sources whence proceeds the elaborated formative material used in the building up of its stem and branches. Now, this law is plainly apparent in the single axis, the structure of which depends on the manner in which the phytons are superposed and combined, and in the peculiar arrangement of the vascular bundles below them. The phytons which produce the single axis are arranged spirally around the axis in accordance with laws peculiar to each species.

This spiral disposition of the leaves is a provision for se- 
curing the symmetrical arrangement of the branches which proceed from the buds in their axillæ, and the uniform deposition of the nourishing matter which proceeds from them around the axis. For as the wood is formed by the leaves, when these are placed in regular order over every part of the circumference of the axis, as in the Elm, the Becch, and the Linden, the branches and shoots are cylindrical; for the woody matter formed by the leaves is then distributed equally on all sides. On the contrary, when the leaves on the stem and branches are opposite, the pairs being placed at right-angles to each other, as in the Spindle tree and Maple, the descent of nourishing matter from the leaves is necessarily limited to that portion of the stem immediately below them, and consequently the young shoots and branches of these trees are square.

Not only the form of the single axis, but also the extent to which it is developed, depends on the leaves; for when their vital activity is enfeebled, no internodes or naked intervals of stem are formed between them, the axis is reduced to a rudimentary condition, and they become crowded together into little clusters. If the growth of the axis is thus arrested, year after year, it may increase in length slowly; but there is no increase in its breadth or thickness. A Beech branch now lies on the table before me, and I find that one of its side branches, which is only twelve inches in length, is nevertheless thirty years old, and yet it is not any thicker than one of the young terminal shoots of the same branch, which has grown nearly as much in a single year.

Hence, it will be found that in proportion as the length of an axis increases or decreases from year to year, in the same proportion is there a corresponding amount of increase or decrease in the breadth of the wood-rings visible on the cross-section. In order to verify this truth, it is necessary to select branches, the leaves of whose side axes are annually put forth as leaf-clusters, and which therefore take a minimum of development, and exercise the smallest possible amount of physiological influence on the branch, and where powerful growths are suddenly succeeded by 
growths greatly retarded. One such branch now lies before me, whose principal axis is eighteen inches long, and whose side axes have taken a minimum of development.

It grew the first three years five inches annually, or altogether fifteen inches; but in the last four years the growth stagnated, or averaged only nine lines annually; and the cross-section of the branch actually shows the three inner rings or woody layers, formed by the leaves of the first three years, to be much broader than the four outer rings, the leaf deposits of the last four years.

The same relation between the breadth of the wood-rings annually formed, and the extent to which the main axis is developed, will still continue to subsist even after the side axes have grown to some considerable extent, provided their growth is accelerated or falls back together with that of the principal axis. If the reader will refer to Figure 2, he will see that the primary axis made a considerable growth the first three years, or between 1852 and 1855, and that from 1855 to 1856 , the growth of the axis received a remarkable check, the vegetation of the side axes being retarded at the same time. Now, let him look at the rings or breadths of the respective cones annually formed, which are represented in the cross-section of the axis at the bottom of the diagram, and he will see that the wood-ring or conical stratum of woody matter deposited the fourth year, is much narrower than the other rings.

It is not, however, always the case in a system of axes, that the growth of the primary and secondary axes advances or falls back together. It not unfrequently happens that the growth of the primary axis is retarded, whilst at the same time some of the secondary axes make considerable headway. Hence, when the primary axis puts forth one or more generations of side-shoots, the growth of each must be taken into consideration in estimating the amount of wood formed by the leaves. A Beech branch, for example, eighteen inches long and nineteen years old, shows on the transverse section of its wood, from within to without, sixteen narrow and then three broad rings. These breadths of the wood-rings do not correspond with the suc- 
cessive annual growths in length made by the principal axis ; for in this case quite another result is obtained, that axis having hardly grown at all after the sixteenth year. The three broad wood-rings last formed must therefore have derived their matter from the branches, and we find on examining the side axes, which are thirty-three in number, that eleven of them, formed the last three years, are the most developed; to these is therefore to be attributed the three broad wood-rings.

The above investigations would seem to lead irresistibly to the conclusion, that the breadth of the wood-rings is determined not only by the activity of the leaves of the terminal shoot of the axis, but that the leaves of the side axes, or of the whole system of axes, co-operate, and therefore that the leafage of each season forms a common source, whence is derived not only the nutriment forming the new layer or covering of each individual branch or system of axes, but of the main axis or support of the whole of them - the stem. For not only each leaf, but each twig, branchlet, and branch contributes its part, during the season of vegetative activity, to the formation of this new conical layer or woody mantle, with which the tree is annually reclothed from the tops of its branches to the extremities of its roots,-a new garment of unity, so to speak.

A clear conception of the entire process of this annual renovation, can only be obtained by giving due prominence to the fact, that the growth and life of the tree after the first year is entirely superficial, and totally confined to the forming stratum of new bark and wood. The bark and wood-cells constituting the growth of each year, die when their vital activity ceases in the Fall. There is no renewal of their life on the return of Spring; for, as we have already stated on page 44 , "So soon as a cell ceases to form new cells, or to develope and carry nourishing matter, so soon as its fluid contents disappear and it becomes filled with air, it may be considered as dead." Now, this is precisely the condition of the duct-cells, and to a certain extent of the fibre-cells, at the end of the first year. They are fully formed the first year, and when the life of the 
tree is reawakened in the Spring of the next year, they no longer grow, or assimilate formative material. They are dead, rigid, unyielding. For the sap is drawn away from these old and full-grown tissues, by the young and newlyforming stratum of bark and wood, and although its flow through the finer capillary vessels of the fibre-cells may be again renewed,- this flow arises from causes purely mechanical,- there is no assimilation of formative material. In fact, the only change that takes place in the fibre-cells after the first year, is the gradual filling up of their cavities by deposits of lignine or earthy matter, whilst the ductcells, being devoid of sap, after the first year are never filled up, as inspection plainly shows.

Let the reader again refer to the diagram, which shows, not only the conical growth of the primary axis of the branch, but also the conical growths of its secondary and tertiary axes, or branchlets and twigs, and how they are connected with the primary axis. Commencing with the first, second, or third ring from the outside, which form the foundation of three successive conical deposits, and tracing them upward over the summits of each branch and branchlet, he will find that each forms a continuous and unbroken bed of woody matter; and he will easily understand, when the tree grows again in spring (if we suppose the thick exterior and bounding line of the diagram to represent the newly-forming stratum of bark and wood-cells), how, from different points of the surface newly-forming on the last year's branches and branchlets, fresh shoots may be pushed forth. It is thus, as the tree continues to grow, that a series of new and more extensive communications are annually opened with that grand reservoir of vegetable food, the atmosphere; and the newly-deposited living stratum is just as continuous as that of former years, and its life passes away with the falling of the leaves. For it is the leaves which are the source of the formative material which proceeds from them to the shoots, from the shoots to the branchlets, and from the branchlets to the branches, whose union forms the main stem of the tree, just as a thousand little streamlets, descending from mountain and 
hill, pour together their tributary waters, which, united, form the broad river which rolls on to the ocean.

But, although the number of leaves of the whole tree, as of each branch, from year to year continues to increase, yet the thickness of the conical layers, after a certain point of time in the development of the main axis or stem, as regularly diminishes. The cause of this decrease in the breadth of the wood-rings arises from the fact, that the surface of the enveloping cones continually increases as the tree gets older, so that the formative material, from the leaves, is spread over a more and more extended area. Now, up to a certain period in the life of the tree, the increase of leaf-surface in the atmosphere keeps pace with the gradually increasing surface of the cones, and this produces that uniformity of breadth which characterizes the woodrings formed each season; but, when the main stem and branches of the tree approach the maximum of their development, owing to the diminished vital activity of the leaves, less woody matter is formed, which still continues to be spread over a constantly increasing extent of conical surface; hence the thickness of the woody strata gradually diminishes as the tree draws nearer to the limit of its life.

It is thus that, in the course of centuries, solid and enduring vegetable monuments are reared; trees which outlive the successive generations of man-broad at the base and tapering to the extremities. Nature builds on the conical principle to insure their stability; and the dark and sombre forests of oak, pine, and fir, which elothe the sides of mountain, whose summits rise above the snowline, are constructed on the same architectural principles as the mountains themselves; for the avalanche loosening from its mountain heights, and coming down with an accelerated rush into the subjacent valleys, and the leaf falling from the tree, are both detached from cones. Such is the beauty, simplicity, and grandeur of the works of Nature!

Reader, startle not at the boldness of this language. It is strictly true. Great and little are but relative terms, distinctions made by finite and imperfect minds. Sir 
John Herschel, in his admirable "Preliminary Discourse on the Study of Natural Philosophy," says, page 173 :"The student who makes any progress in the study of natural philosophy will encounter numberless cases in which this transfer of ideas from one extreme of magnitude to the other is called for. He will find, for instance, the phenomena of the propagation of winds referred to the same laws which regulate the propagation of motion through the smallest masses of air; those of lightning assimilated to the mere communication of an electric spark, and those of earthquakes to the vibrations of a stretched wire. In short, he must lay his account to finding the distinctions of great and little altogether annihilated in nature."

\section{H A P T R V.}

THOSE NATURAL CAUSES WHICH PRODUCE THE INEQUALITY IN THE DEVELOPMENT OF THE BRANCHES AND BUDS OF A TREE, ILLUSTRATE CLEARLY THE LAWS OF SOCIAL INEQUALITY AND SUBORDINATION IN CIVILIZED COMMUNITIES.

WHEN we see defined against the clear, cold winter's heaven, the leafless branches and branchlets of a tree, it is hardly possible to imagine anything which is apparently so chaotic and irregular.

There are branches and twigs of all possible degrees of growth, mingled together without any apparent order. It is a complete labyrinth of ramification-an inextricable maze, perplexing and without a charm. Yet there is nothing even here that is random or confused. Everything about a tree is constructed according to plan and system. Even this apparent chaos of branches, with their innumerable branchlets and twigs, is no exception.

If we would obtain a clear and satisfactory perception of the causes which have produced all this infinite variety of ramification, and trace out plan and system in every twig, branchlet, and branch, we must go back to first principles. We must study the tree in the earlier periods of its life- 
in the lower stages of its development; we must go back to the first year's growth. The unequal development of the shoots from the sides and summits of the primary vegetable cone, is the cause of a subsequent inequality, which has gone on increasing with the growth and life of the twee. The branches were, the first year, all equally feeble and powerless; sheltered beneath the covering leaves, which kept watchful sentinel over the growing points of the first year's shoot, through many a cold and dreary winter's day and still more stormy night. Then came spring, warm and welcome. The sentinel leaves were removed from the post of duty, the new leaves and shoots were unfolded from the buds. But from the very first there is the same principle of subordination as clearly apparent among the shoots as amongst the leaves. Just as the sap, elaborated in the lower leaves of the first shoot, contributed to the formation of the upper leaves, so the inferior buds either remain sterile or unfold simply as unbranched shoots or leaf-clusters, because they are subordinate to the development of the upper buds which attract the sap away from them. The most considerable growths or shoots are therefore made by the bud at the summit of the first year's shoot and the side-buds situated in immediate neighborhood. It is plain that all the buds of the first year's shoot are equally exposed to the air and the sun's influence. The inequality in their development must therefore originate in a principle of subordination and subserviency in the lower leaf-buds to the upper ones.

Now, these peculiarly abbreviated forms of the shoot play an important part in the building up of the tree-form. All the little twigs which fill up the space between the larger branches, and which are so plainly visible when they are deprived of their leaf ornaments, have proceeded from buds which take a minimum of development, and unfold year after year simply as leaf-clusters. There is no side production. On the contrary, the whole of the vital energy of the leaves is expended in the formation of the enlarged terminal bud, and in supplying the upper and more developed shoots and branches with sap. 
The leaf-clusters which form those rudimentary shoots give a marked character to the foliage of trees. Not only are the Pines indebted to them for the green clothing which covers their branches, but they fill up and relieve the (comparatively speaking) naked intervals of stem, between the more powerfully developed branches, with foliage. The Beech, Cherry, Linden, and Hazel, especially derive their thick leaf-drapery from the copious development of these leaf-clusters or rudimentary side-shoots; and the light and slenderly clad leafage, so characteristic of the Birch, is to be attributed to their early decay and removal from the stem and branches. They appear to be entirely absent from the Willow.

These rudimentary shoots may continue at a minimum of development, and (as in the Beech and Cherry) for ten, twelve, or even twenty years, unfold leaf-clusters from their terminal bud. But when the growth of a branch stagnates in this manner, its life must be necessarily greatly abbreviated. Sooner or later it gradually pines and dies; the terminal bud at last ceasing to have the power to unfold itself. The dead twigs are then removed by the wind or other natural agents, and leave behind them those naked intervals of stem visible between the main branches.

Hence, the peculiarly whorled appearance which branches present on the main axis or stem, which is so well marked on some trees, that an experienced woodman can approximate in some measure to a correct estimate of their age, when he views them from a distance, by counting the intervals of unbranched stem between the several whorls of branches.

The same inequality in the development of the shoots may be traced also, to some extent, on the main side axes or branches, and is to be attributed to the same cause, viz.: the development of the upper buds into shoots, and the unfolding of the lower buds into leaf-clusters; but as the branches and branchlets are necessarily younger than the main axis or stem with which they are connected, the work of removal has not progressed to the same extent, and the dead, as well as the living twigs, still fill up the intervals 
Which separate the more powerfully developed shoots and branches from each other.

The struggle for superiority then commences with the second year's growth. It is at this time that all the branches make the same start in life. At the close of the second year, the upper buds developed from the axillæ of the upper leaves, have produced shoots, the lower only leaf-clusters; the former have therefore got considerably ahead of the latter, during the same period of time. An inequality has been generated, which increases more and more every year. The third year, the terminal bud of the lower shoots unfolds again as a leaf-cluster; but the upper shoots become mother shoots, developing from the buds, at their sides and summits, other shoots like themselves. It is thus they continue progressing from year to year, until they ultimately become those powerful branches which form, as it were, the prop or scaffolding of the crown or spreading top, and no inconsiderable part of the entire tree itself.

The lower buds, on the contrary, developed from the axillæ of the lower leaves, make no headway, but continue in the same fix, year after year, pining in poverty and inactivity. There is no difficulty in finding any quantity of such miserable starveling shoots on the branches of the Beech, the Horse-Chestnut, the Apple, and other trees. The current of sap is drawn away from them by the upper and more powerful branches, and there is not a particle of chance left for them except in the excision or death of the upper branches.

We have seen that the tree, during the first year of its life, has only a poor chance of progress, on account of the few leaves which it has at work in the air, and that, when it has arrived at the stage of development prefigured by one of its branches, it possesses a much greater amount of vitally active leaf-surface, and consequently its growth becomes more rapid, and its chances of arriving at maturity multiplied a thousandfold. Now, the same relative condition of things exists between these pitiful twigs and powerful branches, with reference to their respective means of obtaining food, as existed between the tree and nature during the first year 
of its life, and again at the end of twenty or thirty years. What chance have simple shoots with a few leaves, the normal growth of one year against powerful branches which are, it may be, the growth of centuries, which put forth a hundred shoots, like themselves, from their sides and summit, the leaves of which are all subservient to their development? It is plain that inequality of condition, once engendered, has a tendency to go on increasing, and that the shoots and branches of a tree, when once ahead, are very apt to keep ahead.

And is there nothing analogous to this in the social world? Is not the whole framework of our present social system founded on the eternally unchangeable law of the subordination and subserviency of one human organism to another? In order to be happy, man must be free to develope himself. But individual freedom must necessarily generate inequality so long as one human organism has more life-energy than another. We see the results of this inequality of natural gift in a common school, where all are placed in the same circumstances and on an equal footing. What a remarkable difference in the aptness of boys for particular branches of study! With what rapidity and apparent ease some get through the tasks allotted them! How slow and wearisome the progress made by others! Undoubtedly the diligent and attentive student is generally, at the end of the term, the most advanced in his class. But even in a well-regulated school, where industrious habits are carefully cultivated, where the strictest discipline is rigidly enforced, and where all are not only expected but actually made to study, there is the same variety in the natural capacities of the scholars-the same striking diversity in their intellectual progress. When reference is made to the standing of each at the commencement and then at the close of the session, some boys have got far ahead of the others in the same branch, notwithstanding those who have had the misfortune to fall back in their class, have not unfrequently received the greatest share of the time and attention of their teacher. Thus, notwithstanding the oftcited saying of Euclid, "There is no royal road to learn- 
ing," it is undeniable that there is such a thing as an innate or natural intellectual and moral superiority of capacity possessed by one man over another.

Now what takes place in a school, in a small way, is only carried out on a grander scale in the great school of the world. But here, from the commencement, the most talented are usually the least favored by fortune. They enter on the active duties of life under great pecuniary disadvantages; but superior ability and energy will assuredly, sooner or later, give them pre-eminence. It is not long that the contest remains doubtful. Nothing can withstand their onward progress. In vain you try to keep them down. As well might a fly attempt to stop the advance of the mail train from Washington. Enterprising business men soon learn to know and esteem each other. There is a congeniality of disposition which inspires mutual confidence. It is then that capital combines with capital. Contracts are made, and the most extensive public works are executed. Banking establishments are carried on all over the country; they gain the almost unlimited confidence of the community. It is thus that commercial power is slowly and surely accumulated, until finally merchant princes become a stern reality. Yet every enterprise, great or small, has its master-spirit-the main axis or stem from which the lesser branches proceed; for the laws of nature remain invariably the same. Men will pay homage to merit. They ever will cheerfully subordinate themselves to superior ability.

Nothing, therefore, can be more erroneous than the idea that, in order to preserve the present system of inequality, it is necessary to keep a certain portion of the human race in ignorance. This is very bad policy, as well as a violation of the natural rights of man. Let us look at the tree again ; for nature is best interpreted by a reference to nature. We have, in every tree, a deeply interesting and instructive combination of industrial forces which illustrates clearly a perfect system of mutual dependency and subordination. No part of the tree is unemployed or unimportant. The poorest branch and bud-scales, stipule and 
starveling shoot, as well as the powerful branch with its innumerable branchlets, rich in sap and luxuriant in foliage, have helped to build up that tree. Each has labored to the extent of its capacity, and has done some good to the community, although it may be only a little.

In like manner it is for the interest of society that all the varied talents of its individual members should be called forth and employed. Some authors have written on human perfectibility, as if all men could be made philosophers, statesmen, orators, poets, \&c. But this is contrary to all analogy. Among all the forms of life, there is variety in the degree of development, and man is no exception. All men are subject to the same general laws, yet it is undeniable that there is an individuality about each, and that their mental capabilities and dispositions are as dissimilar as their faces. Life, in fact, is but the unfolding of the peculiar laws of the individual organism.

As we progress in science and civilization, more and more of this individual talent will be evolved. Any institutions which are calculated to call it forth, are a blessing to the world. They ought to be encouraged. The men who found them will live in the memory of mankind. Hence, Public Schools, Lyceums of Natural History, and such institutions as have for their object the dissemination of knowledge amongst the people, are all movements in the right direction. I, et the fountains of knowledge be made as public as possible, so that all may drink freely. Let the healing streams be circulated in all directions, until they impart their treasures to every destitute locality; for it is certain that there is no man, however poorly gifted, who may not be made a useful citizen if those gifts are properly cultivated.

It is not possible that the community should be disturbed in its present social relations by this generous diffusion of information. Depend upon it, inequality of condition is an eternal, unchangeable law of nature. It does not admit of a doubt, that some men are much more richly endowed with native talent and energy than others, and these will always be the leading branches in the social tree; others 
must and will naturally take an inferior and subordinate position. But the branch, if it grows for centuries, will never equal the entire tree in size, and the branchlet must ever continue smaller than the branch. For each has its own limit of growth prescribed by Nature, according to a morphological law which it cannot pass, even under the most favorable circumstances, and by means of which each is rendered subservient to the growth of the other. So, if we suppose all to have the advantages of a liberal education, the variety of gift and intellectual capacity amongst mankind will still remain unchangeably the same, and therefore their social position with reference to each other. There will, however, be this important advantage gained; each will be rendered more capable of discharging the duties of that position in life in which it has pleased Providence to place them; and thus the whole community will be benefited by the prosperity of its individual members.

It has been proved that there will ever be subordination. But as man is naturally a selfish being, blind submission to superior talent and energy is not to be thought of for a moment. It has been well said that "History is Philosophy teaching by example;" now, History teaches most impressively the social evils which were formerly produced by a monopoly of religious and political power. Is it possible to imagine any religious tyranny more execrable than that which existed before the Reformation? Priests were then the jailors of the human mind; they wielded powers so enormous, that the greatest monarchs of the earth trembled before them. When first attacked, terrible were the struggles of this religious despotism! What brute force was employed! What disgraceful and cruel persecutions! Who originated the Inquisition, with its hellish tortures, and dungeons with walls built purposely thick to deaden the shrieks of suffering men and women? The philosopher Copernicus withholding his discoveries through terror of this tyranny, during his lifetime, from mankind, and only consenting to their publication on his death-bed! And the venerable Galileo imprisoned and compelled to adjure as errors, what are now known to be 
truths! Religious liberty! at what an immense sacrifice of life has this precious element of human happiness been purchased! Happily, the monopoly of religious power has been broken down, and the utmost diversity of religious belief now prevails. The claims of different opposing religious sects are carefully examined, and men are becoming daily more tolerant and less fanatic.

Not less instructive is History in reference to that monopoly of political power which formerly prevailed. What numberless calamities has it showered down on the human race! There was a time when the people were inherited like sheep, when they had no significance as individuals. The interests of the most industrious and useful portion of mankind were staked in perpetual games of war, in order to build up the family of the king of the country, and bring new territories under his yoke. But after awhile the wealth. produced by the toiling masses, began to be so important to the comfort and enterprises undertaken by these fighting monarchs, that they were forced gradually to concede them a certain degree of political liberty which they had not previously enjoyed. The grand idea of human rights now forced its way into despotisms, and then came the fierce struggle for political freedom, and on many a battlefield patriotic blood was poured forth like water,-the best and bravest of the human race expired. At last it was conceded that the people had rights and liberties which must be respected: that government exists for the benefit of the people, and not the people for the benefit of the government. That nations are the masters of their own destinies. And now on this continent we have the glorious spectacle of a people governed by one of their own choice, and yet progressing in science and civilization.

Political and religious liberty has been obtained; but human nature has not changed, and there still exist among us the same tendencies to the despotism of bygone ages. It is well known that there is a class of men in our midst, who want to do our religious thinking for us as in former times; and it is also well known that there are those who would abridge popular liberty, who are ever seeking to re- 
cover lost political influence. These powers are extending themselves secretly in all directions, struggling fiercely for pre-eminence. Man has broken his chains, he has escaped from his dungeon, and every effort is now made to effect his recapture. He will not let us think for him now. He considers that he is quite capable of thinking for himself. $\mathrm{He}$ considers that he is at perfect liberty to have an opinion or belief of his own, uncontrolled by any other man or set of men. Such is the language of the foe, as treacherous, despotic, cruel, and unyielding as ever, whose power originated solely in the ignorance and darkness of former ages. Man is no longer a poor degraded captive, devoid of greatness of soul, of reason, and of virtue. He is free now ! He loves science, and nature, and truth! Is he going to surrender the precious rights of religious and political liberty, purchased by the blood of so many patriots and martyrs? Who are these men who wish to do our religious thinking for us? They (and their ancestors before them, about whom they talk so much) are mortal men who sicken and die like ourselves, and the probabilities are that they are, one and all, just as liable to form erroneous opinions as any other men. Religious infallibility on the one hand, and blind submission of the understanding on the other-there has been already too much of it. Surely, the very remembrance of the follies of their fathers, in this respect, has made the present generation wiser. Before the light of science and true religion* these delusions are passing away like a cloud.

But the people are interested in putting down tyrannical monopolies, not only in religion and government, but in commerce. Commercial tyranny is as great a curse as the former despotisms in religion and politics which have been subjugated.

Two hundred years ago, war with its interests absorbed the attention of mankind; but now society has completely changed it character, and become commercial and industrial in its spirit. Strife is therefore transported to this new field; and, as man is still the same fighting animal he ever was,

* "Therefore all things whatsoever ye would that men should do to you, do ye even so to them; for this is the law and the prophets."-Matt. $7: 12$. 
it is now a war of industry and all its elements. Property is the prize for which all are straining their nerves.

But commercial power accumulated in the hands of any one man, or body of men, is ever dangerous to liberty. Who does not know that the love of power is natural to man, and that he is apt to abuse the confidence that is reposed in him? Man is naturally a selfish being. Men do not change their nature when they combine their efforts and become shareholders. Merchant princes are no exception. Personal interest is undoubtedly the moving power of the actions of one and all of them. That they confer benefits on the community is not denied. Their canvas is swelling on every sea, and their merchandise is coming to us from every shore! Yet, is the power thus accumulated in the hands of a few used only for the good of the many? Is it not undeniable that banking and other extensive establishments are not to be trusted? that they are apt to get a little too much ahead? And do not you think, reader, that these leading branches in the Social Tree require to be looked after, and that a little occasional pruning of them would be a public benefit?

No man, or body of men can get much ahead in any pursuit without retarding the progress of others in the same ratio. Every man who commences business in a small way knows that he has, in the large capitalist, a dangerous competitor. And he is quite right. Customers will always go to those places where they can get the cheapest and best goods. They think it is their interest to do so. Hence, they go to the man who has the most money, who can better afford to buy in larger quantities than the small trader, and who is therefore able to accommodate them with better goods at the same or a lower price. It is thus that poor men refuse to stand by each other, bow their necks to tyrants, and kiss the rod of the oppressor. People are attracted to the richly-furnished store; and, for the sake of a temporary advantage, they take their money to those who have more than enough, and refuse to patronize the small trader. Hence, inequality of condition, once engendered, is very apt to go on increasing, until finally 
we see human forms, members of the same great social family, clad in sillss and rags-dwelling in hovels and palaces! Now, this is all wrong! There is no absolute necessity for these social disfigurements. They are a disgrace to Christianity. They show that our present commercial system is not a wisely-ordered one. Starveling shoots! the Social Tree is full of them. Are there not thousands of human beings who toil from earliest morn to latest night, and never make any headway? Do they not con-. tinue in the same fix for life, subservient to the interest of a branch which is more developed than themselves; and this branch holds the same relation to some other branch for which it has to work? And what is society but a tree, an association of branches, where all co-operate in building up its structure and in advancing its arts, its sciences, and civilization? You cannot deny the analogy. Yes, and there are monopolizing branches which get too much sap, and require pruning. For this thing has its foundation in Nature, and we must look to Nature for a remedy. Are there not men in every community with a superabundance of life-energy, whose progress in wealth and in the extension of their business relations has been rapid and unexampled? There is no end to their reckless and insatiable pursuit after wealth! Combined together, they exercise a fearful commercial power. It is these merchant princes in combination who are our masters on the battle-ground of commerce. They are the men who control the markets, who grind down the faces of the poor, who exact at will from the consumer! How beautifully is all this illustrated by the branches of a tree! How faithfully are the laws of society there represented even in all their minutiæ.

But this is not all; for there is a social policy plainly suggested by the leading branches of the tree, and the condition of its branchlets and different varieties of shoots, which all who occupy an inferior and subordinate position in society would do well to study. There is clearly competition among the branches of a tree for sap and sunlight, and in proportion as the leading branches get ahead, in the same proportion is the development of their side-branches 
retarded; whilst, on the contrary, a considerable growth of their side-branches and branchlets is a check on these leading branches.

These facts are strikingly seen in the landscape physiognomy of certain trees. In the Lombardy Poplar (Populus dilatata), the main stem or axis takes a maximum development, and the branches are consequently reduced to a minimum, so that the whole tree, when viewed from a distance, resembles a vast spindle. In other trees, however, such as the Horse-Chestnut (Esculus hippocastanum) and the Linden (Tilia Americana), the branches make an equally powerful growth with the primary axis or stem, and this prevents its elongation. Hence, the main axis or stem is hardly distinguishable from the branches. When uninjured by storms or artificial pruning, the branches of these trees usually spread out equally on all sides, and their top or head is dome-shaped or hemispherical. For this reason these trees make a fine appearance on a lawn or park, in addition to the recommendation of perfect shade which they afford.

Now this competition amongst the leading branches of a tree with their subordinate branchlets and shoots, for sap and sunlight, is a truthful illustration of that struggle for pre-eminence and for the good things of this life, which is perpetually going on through all the ramifications of society. In this respect, rich and poor, employer and employed, meet on terms of equality. Both have hard times; for there is as much competition amongst the great leading branches or master minds of our communities as between their subordinates-the branchlets and little twigs; and the result is that the man who gives employment to hundreds of hands and counts his dollars by thousands, is not unfrequently as hard pushed to meet his numerous obligations as the workman whom he employs. It is the nature of man to seek for power, to struggle for pre-eminence in the profession or branch of labor to which he devotes himself. This produces competition, and as, from the very nature of things, it is impossible that all should be successful, each physician and lawyer, manufacturer, merchant, 
and tradesman sees, in all those who are engaged in the same occupation, competitors who are dangerous in proportion to the amount of their success. A social organization in which there shall be co-operation without competition is clearly an impossibility. It may form a theme for poets and a dream of philanthropy, but as human nature is at present constituted, it is a state of things which can never be realized. A state of warfare appears to be the natural state of man. This may be an unpalatable truth, but it is far better to give true than false views of life.

It would not be difficult to prove that there is antagonism amongst all the inferior forms of animal life, and thus show it to be a universal law of Nature. Even the flowers which decorate our fields and forests, are mutually opposed to each other. Each has to struggle into existence against a host of competitors; for Nature, although she has been prolific of the seeds of life, has limited the supply of room and food. Shrubs and trees prevent, by the extent of soil which they occupy, the vegetation of species of a humbler growth. Millions of seeds are annually produced which never germinate. Borne away from the plants which produced them by the winds or waves, they fall into situations unfavorable to their growth, or upon a soil which is already preoccupied by other plants. A number of ferns growing on a hillside, will successfully maintain their monopoly of the ground for ages against all other intruders, notwithstanding the facilities afforded to the surrounding plants for the dispersion of their seeds. If, for example, a seed from a neighboring thistle or dandelion should fall amongst them, it cannot germinate, because they have possession of the ground, absorb all its food in the struggle amongst themselves, so that it is impossible that any should be afforded for the stranger.

To man, however, the "Minister and Interpreter of $\mathrm{Na}$ ture,"* reason has been given to control those passions

* "Homo naturæ minister et interpres, tantum facit et intelligit, quantum de naturæ ordine re vel mente observaverit, nec amplius scit aut potest."Bacon's Novum Organum. 
and appetites which he has in common with the inferior creatures. Although a social organization cannot exist without competition, yet it does not necessarily follow that we are to oppose each other with the ferocity and cruelty of wild beasts. It is the intention of Providence that we should seek to ennoble each other by mutual rivalry, that the struggle should improve our moral and intellectual nature. As society advances, for the world moves onward, those will be most successful who fight the inevitable battles of life bravely and HoNorably. Even now the tendency of the age is to offer increased inducements to a meritorious line of action. What is a mere millionaire after all? Frail and perishable mortal, whom men so much envy and admire, you shall not survive the grave! To-day your name is in everybody's mouth; to-morrow you will be forgotten! Money never reseued any man's name from oblivion, unless it was expended so as to benefit society. Virtue alone is enduring. The mind is the noblest part of main. What of the mind of the millionaire? Are these the men whose spirits converse with us when their bodies have been mouldering in the grave for ages? Do you rank the millionaire with such men as Newton and Franklin, Clay and Webster, and the venerable Humboldt? These men are not dead; they live, and they will continue to live for ages yet to come. Who remembers the millionaire? Does his picture adorn the poor man's home?

That which is the most remarkable about a tree, is not only the variety, the perfect harmony, and freedom of its individual parts, but that power of centralization by which all these parts are combined together into one harmonious whole. That is only a harmonious ordered whole, whose parts are free, and those parts are only free which unfold their peculiarities subordinate to a common law, and which in their independent forms equally realize the idea of the whole. In the tree, then, we have presented for contemplation an illustration, clear and beautiful as the unclouded sun, of a perfectly natural and equitable social system of labor, combining the highest individual freedom with subordination. The tree shows us a system of harmoniously 
adjusted labor, where not only the branch and branchlet, but even the little twig, leaf, and leaf-scale are all fully employed to the extent of their capacity. Where the individual talent of a community is thus fully and universally developed, there must be freedom.

There always will be individuals pre-eminently gifted, but where talent abounds, there is less danger from the inherent selfishness of those thus liberally endowed by Nature. Let knowledge be diffused on the most enlarged and liberal scale, and the sceptre of tyrants is broken, the throne of delusion crumbles, and individual freedom is fully insured. It is impossible for a people, thoroughly enlightened, ever to be enslaved? Tyranny can never flourish on the soil of this country.

In nothing is the supremacy of America so apparent, as in the fact that when men of talent, accustomed to sway the mind of the ignorant masses in Europe, are exiled to these shores, they have to settle down here after awhile as ordinary men. America extends to them a hospitable welcome, but because they have come to a "free country," they cannot monopolize, for any length of time, any exorbitant share of popular attention and favor. They may be eloquent orators and journalists, but that is nothing in a country where such gifts are abundantly developed. It is true they may contrive to create a local disturbance for awhile, but then it is soon over; their names are forgotten, never mentioned, and they take their ranks as ordinary mortals.

The truth is, that society in America resembles a widespread and well-developed tree, where a great many branches make an equally powerful growth on all sides, so that it is not easy to distinguish amongst them any particular branch which takes the lead. It is not an easy thing for any man to render himself conspicuous by his abilities in a country where there is so much individual talent called forth by education. Now this is all right. It is good policy founded on Nature.

Continue to educate thy children, Columbia! Inspire them with an inextinguishable love of truth and freedom, 
and thy place shall be foremost among the nations in wealth, in science, and in empire! Oh! tyranny, leave these shores forever? There is no chance for thee here! Away with thy dungeons and thy chains! It is not in America that enfranchised humanity can ever be incarcerated! In this country, men are not disposed to cringe before any despotism, however ancient and colossal. Here we live in peace and charity with our neighbor, although we differ in religious opinions. Is this a condition of things to be lamented? Have you the effrontery to deny the fact that men live together more happily, now that religious and political freedom is enjoyed by all? You would have the people to give up this "infidel freedom," (the language of baffled imposture !) those precious liberties claimed for them by their greatest statesmen, and purchased by the blood of heroes! You would revive in our midst the bloody massacres, barbarous cruelties, and inveterate religious hatreds of former ages! Is it possible that you expect a people, now happy, enlightened, and free, making daily advances in science and in all the arts that humanize mankind, to succumb to your wretched, darkening, and enslaving policy? Yet you are moving forward in the dark with slow and stealthy step; but the friends of freedom are on the watch, and the moment you boldly reveal in the broad glare of day the tyranny of your purpose, Columbia will prove, as ever, the bravest defender of the religious and political liberties of mankind. Nothing but benevolence and good-will to the human race is written on her youthful, noble, starry brow.

This then is the true social policy which is plainly indieated by the tree. We see that the sap has a natural tendency to pass to the leading branches from the branchlets and smaller twigs; so power passes away naturally from the hands of the many, who are, comparatively speaking, without energy, to those of the few who possess it in a pre-eminent degree. But power, accumulated in the hands of any one man or body of men, is ever dangerous to liberty. Human nature is not to be trusted with irresponsible power, no matter what the plea. The encroach- 
ments of monopoly, whether political, religious, or commercial, must therefore be withstood. The tree must be made to spread out on all sides. In a world like this it is necessary for people to look out; for the individual liberty of those who occupy a subordinate and inferior position "can only be maintained at the price of eternal vigilance."

We have shown that the tree is a compound plant, built up by the labors of individual phytons or plants, called leaves. One generation of these phytons perishes every year, but not before each individual of the generation has formed a bud, which remains when the leaf falls, through the winter months; the embryo, leaves and stem which it contains, developing on the return of the next vegetative season. If, therefore, the leaves are regarded as phytons or individual plants, the series of buds which they produce and from which comes forth, when circumstances are favorable, new families of leaves, may be correctly regarded as a new generation; and if we consider the first set of leaves as the parent, or the entire shoot, built up by them, as the mother-shoot, the first set of buds produced by them which unfold to shoots and leaves, may be called the daughtershoots or the first generation, and the second set of buds generated by the leaves of the daughter-shoots, the second generation, \&c.

Now if all leaves produced buds the first year, and if all buds, thus produced, unfolded to shoots and leaves the second year, then the number of generations of shoots would exactly correspond with the number of years during which the tree had lived, and we should have an easy but simple method of determining its age. But in reality it is not so, because in the development of the main axis of a branch, often single or numerous seasons occur, during which the growth is greatly retarded, and only such leaves are produced whose axilla remain unfruitful, whilst the growth of the side-shoots is still more retarded, and they, for the same reason, consequently remain unbranched. Hence, the greatest difference predominates between the number of generations of shoots on a branch and its age. Compare in this respect the growth of the first side-shoot 
in Fig. 1, page 31, with that of the whole branch, estimating, in both instances, from the bud-traces marked 53. The age of both shoot and branch is the same, five years; yet how great the difference in the extent to which development has been carried. In five years, there has been no side production from the shoot, with the exception of a single bud, and its entire length is only four inches and six lines, whilst in the same time the primary axis has grown twenty-three inches and three lines, and put forth two generations of shoots, one of which is fifteen inches in length.

It may be stated as a general rule, that, in very favorable conditions, very powerfully growing branches will put forth as many as four or five generations of side-shoots, but the vegetative power here expires, and the last generation of shoots are entirely rudimentary, appearing as mere rosettes or clusters of leaves, no intervals of stem whatever being formed between them.

Hence, the power of a branch to give forth branchlets is not indefinite, but diminishes with each succeeding generation, until the vegetative power ultimately arrives at a minimum. A single glance at the branches of a tree is all that is necessary to satisfy the reader that there is a retarded growth in length and thickness of each successive generation of shoots or branchlets. And this remission of growth is not founded on a difference of age between the branch and branchlet, nor on a cessation of growth at a certain stage of the same, for all axes, so long as they continue to live, grow forth indefinitely; but this circumspection of growth is rather founded on a difference in the intensity of growth from the commencement, on a . positive loss of vegetative energy.

When, therefore, the growth of the axis becomes compound, other considerations must enter into our calculations with reference to the development of any individual axis, such as its relative position on the primary axis, or in regard to the number of successive generations. If it occupies an inferior and subordinate position on the primary axis, or in the chain of successive generations, its growth will be necessarily very limited. 
The reader is again referred to the branch on page 31 , which we must remind him was copied from Nature. The maximum of ramifying power on the main axis of this branch appears to be about the middle, and is seen in the first branch immediately below the bud-traces, marked ' 54 , or the fourth branch from the bottom. This branch is fifteen inches in length. The tenth branch, just under the bud-trace marked 1857, exhibits the minimum of ramifying power, or a growth of only eight lines. It will be seen that the difference of growth amongst the other branches in like manner bears a determinate relative connection with their several positions on the main axis of the branch.

It is very seldom, therefore, that all the axillary buds of an axis are developed. Most frequently the majority of them are suppressed, and this, too, according to a fixed and regular law. In most cases, neither in the axilla of the covering leaves, nor in that of the under leaves, vitally active buds are produced, but only in the leaf-angles of the upper and more powerfully developed part of the year's shoot. Yet this rule is not without exceptions. In the Judas tree (Cercis Canadensis), the maximum of productive power is certainly in the under part of the shoot; the leafaxilla have duplicate buds in the lower part of the shoot, whilst toward its top the axilla of the leaves are sterile.

Sometimes the buds which have thus been rendered rudimentary, retain a sufficient amount of vital activity to carry them forward through the annually deposited layers of wood and bark, so that they continue to maintain their position, year after year, on the outside of the bark, where they remain ready for action, in case the growth of the other buds is checked by untimely frosts or other causes. The disintegration of the bark, which is perpetually going on in old stems, undoubtedly helps to keep them on the surface. But in the majority of instances, the bud either dies, and is detached from the shoot the first year, or it re. tains its life, but continues totally inactive. In the latter case, it necessarily sinks below the surface of the stem, and becomes buried beneath the succeeding annual deposits of bark and wood. Here it may remain for years, in a state 
of passive vitality, entombed in the stem of the tree, like a seed which is buried in the ground. The trunks and branches of trees always contain an immense number of these buried buds. The Beech branch figured on page 31 of this work, may be again referred to; for it furnishes an excellent illustration of this truth. We have proved it to have been constructed by the labors of one hundred and fifty-five leaves, each of which formed, more or less perfectly, a bud in its axilla, before it fell from the stem; yet only twenty-seven of these leaves developed vitally active buds-therefore, the total number of abortive or rudimentary buds in the branch must be $155-27=128$.

The reader will remember that this branch is only six years old, and is a mere twig, comparatively speaking. The length of the primary axis is but twenty-seven inches and three lines, and of its greatest secondary axis fifteen inches. How countless, therefore, must be the number of rudimentary buds in powerful branches, which have been growing for centuries! Each generation of leaves, whose labors brought those branches to their present strength and size, doubtless left behind them buds which now lie concealed in them. The vitality of those buds is not destroyed. Their parent leaves, it may be, have died, and dropped from the tree many years ago ; but they still retain, unimpaired, the life which they then received. It is only necessary for them to be placed in circumstances favorable to their growth, to commence the most energetic life-movements. Let some of the leading branches be broken off by the high winds of Winter, and when Spring comes, they will attract the sap which went to those branches to themselves. This will arouse their dormant energies; and so powerful will be the impulse received, that they will force their way through the wood and bark to the surface, and breakforth into branches, although that wood and bark may be the growth of years. All must be familiar with the sight of willows and other trees, whose main branches have been thus broken off, and whose trunks are nevertheless covered with young branches and shoots, the growth of buds which have been buried in their wood, and for years dormant beneath their surface. 
It is necessary, however, here to make some qualifying observations. Every plant possesses a power of forming buds out of any of its cells, when these cells are placed in suitable conditions. Now, although the normal position of a bud is either at the summit of a shoot, or in the axilla of a leaf, yet buds are frequently found also developing from other parts, such as the leaves and roots; and not unfrequently in the case of trees, where the branches have been pollarded, or cut away, from the cells of the cambium region. It is a fact well known to gardeners, that under the influence of heat and moisture, the leaves of Bryophyllum calycinum, Gloxinia, Gesneria, \&c., may be made to produce buds; and the production of buds on true roots has been frequently observed in Pyrus Japonica, Maclura aurantiaca, and Paulonia imperialis. Portions of the roots of these plants, in a healthy condition, may be made to produce new plants. Hence, in the case of willows and other trees, whose tops have been removed, "it is not always easy to decide, without dissection, whether the buds are really adventitious, or merely latent axillary buds stimulated into development."*

Buds are always formed from the cellular portion of the stem, and in normal cases they may be distinctly traced on young branches to the pith or medullary rays. This fact is illustrated by the dark lines drawn through the centre of the conical ramifications of the diagram on page 59, which represents the pith in the centre of the branch and its branchlets, and shows its connection with their buds or developing points. In those cases where a bud has been formed by a leaf which has died years ago, and has maintained its position on the exterior bark in a latent condition, if a section be made at the point of the stem where it is seen to protrude, the vegetative course of the bud will be marked by a line of pith called the wake of the bud, which traverses the several layers from the centre outward. $\dagger \mathrm{It}$ follows from this, that branches of the same age may have

* An Elementary Course of Botany, Structural, Physiological, and Systematic, by Arthur Henfex, page 69.

$\dagger$ See article "Botany," in Lardner's Cabinet Cyclopædia. 
originated from buds which have been formed at different periods of the life of the tree. Hence, as growth progresses, and the successive conical layers accumulate year after year around the stem and its branches, the original points of development from whence the first vitally active buds proceeded, become deeply seated in the interior of the stem; for the wood of the principal branches of the tree which usually developes from the earliest vitally active buds, can be traced through the successive annual layers down to these original points. This is the cause of those knots which we find in firs and other wood. They are in fact sections across a portion of the branches, which proceed from the interior of the stem, laterally and outwardly. The diagram on page 59, if carefully studied awhile, will also make this fact plain.

But the abundant supply of food existing in the cells of the cambium region of the healthy trunks of trees which have been pollarded, will also stimulate to "unusual activity the cambium cells;" and if there is no wake visible on dissection, it may be decided that the branches have been developed from cells which have originated there, as "vents for the extraordinary vital energy of the plant."*

In society, as in a tree, there is a vast amount of dormant ability, which would manifest itself if circumstances were favorable. So, when a nation is decimated by disease, or depopulated by war, its arts and sciences revive, its poets and philosophers, its statesmen and heroes, are all reproduced. Dormant talent is developed to replace that which has been removed. Men who would have passed through life without notice, fulfilling its ordinary routine of duties in their several callings and professions, become suddenly stimulated to exert themselves. The conditions have become more favorable for their development; their intellectual and moral energies are called forth by the new circumstances in which they find themselves placed, and they prove themselves equal to the performance of the several tasks which have been allotted to them. Their talents are as conspicuous and as highly honored by the

* Henfey's Elementary Course of Botany, page 578. 
community, as those of their predecessors, by the remembrance of whose deeds they are stimulated. Thus death becomes the source of life-nations revive again.

Owing to the imperfect state of our present civilization, the intellectual and moral powers of our nature are unfolded only in a few of our fellow-men, and these few, preeminent for high station and brilliant attainments, are being all the time brought before our notice. These privileged and favored individuals attract universal attention, and in the excess of our admiration we are apt to imagine a great gulf fixed between them and the rest of their race. But it not unfrequently happens that these great men, so conspicuous and illustrious, have had, from the very first start in life, every advantage of education and elevated social position. If so, properly regarded, they should unite us more closely to the multitude of men; for the light which shines in them, shows clearly powers and capabilities now slumbering in thousands around us, awaiting but the influence of favoring circumstances to become manifest.

The starveling shoot only requires sunshine and sap to become a powerful branch; and every poor merchant and tradesman feels his want of capital, and how he could push and extend his business, if he only had the means to do so. How frequently amongst the trees of a forest, does it happen that a powerful branch, rich in sap and sunlight, with its numberless branchlets and leaves all at work in the air, is swept away by a storm, and then the current of sap which it monopolized goes to the starveling shoots; some of them, under its influence, become branches as powerful and luxuriant as that which was removed, and the injury done the tree is thus completely effaced.

It is precisely the same in the social world. Persons now in easy circumstances, well remember the time when they were starveling shoots. Did you not for years bravely battle with the world under every possible disadvantage? You gathered energy and nerve from repeated conflicts, and at last a chance presented itself; and then, in the popular but expressive language of the day, you went 
ahead, and putting forth on all sides, you did an immense business, giving employment to hundreds of hands. And now, having acquired both property and influence in the community, you calmly contemplate the struggles of others now situated as you were years ago. Good deeds done under such circumstances will be to those whom you befriend, like the morning star to the storm-tossed mariner, inexpressibly beautiful and cheering; for they will encourage in them the hope of approaching day, and they will assuredly shine down on you cheerily and brightly as the evening star at the sunset of your life.

\section{CHAPTER VI.}

THE RHYTHMS OR OSCILLATIONS OF GROWTH IN THE DEVELOPMENT OF TREES ARE DURABLY IMPRESSED ON THEIR ORGANISM, AND THE ORGANIZATION OF MAN IS EQUALLY AS SUSCEPTIBLE OF RECEIVING AND RETAINING IMPRESSIONS FROM WITHOUT.

IN the consideration of a tree, we have to deal, not with a product of crystallization, such as the lead tree, or the dendritic formations on a frozen window, but with matter living and organized. Now, although it may be difficult to point out the bounding line between the animal and vegetable kingdom, because a decided characteristic distinction between the animal and vegetable cell is wanted, yet the limit between living and lifeless Nature is easily defined. In living Nature, THe cell predominates as the fundamental organ; its absence characterizes the lifeless creation, whose fundamental form is THE CRYSTAL.

The crystal grows by additions of matter to its surface; the cells grows from within, and not from without. The crystal, throughout its entire mass, consists of the same chemical principles, arranged in the same manner, and in the same proportions; but the walls of the cell and its fluid contents are chemically different from each other. The parts of the crystal, held together by the power of mutual attraction, remain at rest, side by side, without 
exercising any reciprocal influence on each other; but the cells of plants, which united together form their tissues, or the solid substance of their organs, act and react upon each other and upon the sap as it passes through them. Cell and crystal cannot therefore be compared with one another; for the cell lives, but the crystal is dead. The celebrated Naturalist, Linnæus, thus expresses himself in his Philosophical Botany: "Stones grow. Vegetables grow and live. Animals grow, live, and feel."* These definitions, remarkable for their brevity and clearness, have never yet been surpassed. They imply a profound knowledge of Nature, and are worthy the revered memory of a man to whom the world must ever be indebted.

But we have shown THE CELL to be the "lowest and simplest individual elementary organ" employed by Nature in the construction of the tree. Out of the cell springs forth organic life. Each animal and plant begins with a cell, and all the organs of the same are formed out of cells. Therefore, the increase in number of its cells, their individualization and association into tissues, constitute the living building material out of which the entire fabric of the tree is constructed; and the tree is therefore no stiff, unyielding form, but a living, elastic, and easily impressible body, whose movements are, in fact, as fluctuating as those of the mercurial column in the tube of a barometer.

And, first of all, let us contemplate vegetative Nature in her simpler forms. Let us study the life-history of one of those lowly native annuals, besprinkled, as it were, in kindness, in the Spring of the year, over the landscape, by that sublime Providence Who guides all Nature, ruling alike the movements of atoms and the roll of worlds. From the first breaking forth of life in the seed, there is continual motion and activity,-a regular cycle of leaves until growth culminates; the plant then flowers, arrives at the condition of a seed, and enters on the stage of rest. The entire axis, and all its appendages,_its roots, leaves, and flowers-have perished; for into the seed the

* Lapides crescunt. Vegetabilia crescunt et vivunt. Animalia crescunt, vivunt, et sentiunt.-Philosophia Botanica, a Carlos Linnouls. 
exhausted vitality of the plant has retired. Then comes the sleep of Winter, when forest tree and lowly flower alike repose, till the onward march of Nature brings back to earth the heat and light of Spring, re-awakens the dormant life-energies in the seed, which slowly commences the same instructive and ever deeply-interesting life movements.

In forest trees, or woody perennials, there is the same continual change from a state of rest to that of motion. As the tree grows, the life-movements forward are accelerated and then retarded, year after year. These fluctuations of growth in trees may be compared to the rising and the falling of a wave, which attains a certain elevation over the ocean's surface, and then sinks into its depths and disappears.

Now, the trunk of a tree rises at first from the seed as an herbaceous stem; but, as it usually becomes more or less woody before the close of the vegetative season, when it enters on the stage of rest in Winter, it is not destroyed by the severity of the season. Only its foliage perishes. We have seen how the foliage is renewed upon fresh shoots from the terminal and lateral buds of the young stem every season ; in fact, the axis with its branches is the only permanently enduring part of the tree.

In some trees these fluctuations of growth, or vibratory. movements between a state of rest and that of motion, last for hundreds and even thousands of years; but the tree, like every other living organized form, is compelled at last to pay back the debt due to Nature, and yields to the earth and air those borrowed elements out of which it originated.

In order that the reader may form a more definite idea of the nature of these waves of growth, we have ventured to classify them as follows. In the life of a tree, we may distinguish three principal waves of growth, or accelerated and retarded vital movements.

The Annual Wave.-During winter, the trees of temperate climates, like the seeds in the ground, are in a state of passive vitality. Life exists in both, although there is 
no perceptible vital movement; for there is no chemical decomposition or separation of their parts. Alexander von Humboldt defines the power of life as that inward force which dissolves the fetters of the chemical affinities, and prevents the union of the elements or original components of organized bodies. Therefore, there cannot be a more infallible mark of death than corruption. It indicates that the elementary principles or raw material of what was once a plant or an animal, are beginning to obey their pristine laws, and to arrange themselves in accordance with their chemical relations to each other. Therefore, so long as the parts of the organism hold together,

\section{"Before decay's effacing fingers \\ Have swept the lines where beauty lingers,"}

the functions of life, like those of the seed or the tree, may be only suspended for a season, notwithstanding the presence of all the other distressing indications of disease.

Reader, blame me not for this apparent digression. My object in this book is to show "What may be learned from a tree." The above lesson is an important one, and may perhaps be of service some day ; for it is a sad truth, that inevitable separations await us all, and "hours of desolation are on the wing, coming swiftly and straight toward us, soon to overshadow us, and hide us from the light of the sun."*

But Winter has gone with its cold, darkness, and storms, and Spring has come with its warm, bright sun and gentle breezes. The stage of rest is passed. Reinvigorated Nature awakens from repose. Slowly emerges the plant out of the seed, and the tree begins to grow. There is again continual motion and activity amongst all the parts of the growing organs, the same cycle of appendages, - of leaves, flowers, and fruits, - until both arrive again, in the fall, at the stage of rest. The tree is deprived of the leaves and flowers of Spring, and of the fruits of Autumn. Another ring of wood and bark has been formed, and additions

* Discourses by W. H. Furness, Pastor of the First Congregational Unitarian Church, Philadelphia. 
have been made of new growths to the extremities of its branches. These yearly vibrations of growth correspond with the oscillations of the great pendulum of the universe, and are faithfully recorded in the annual wood-rings visible on the cross-section, and in the bud-traces left on the exterior bark of the young shoots and branches.

This however is not all; for when we come to examine carefully the different parts of the tree, when it is denuded of its foliage, we find that each branch, and branchlet, and shoot is characterized by its own peculiar fluctuation. In the annual wave of growth which pervades each shoot, there are three distinct stages which offer themselves for consideration. Toward the bottom of each shoot, we have formed a series of perfectly undeveloped internodes, which support the covering-leaves, and which are visible after their fall in a series of closely approximated annual scars, called, in this work, bud-traces (gemma vestigia). Then follow the partially developed internodes of the lower leaves of the shoot, and then the principal internodes which, through their expansion, form the shoot. But the vitality of the leaves above the centre of the shoot becomes more and more enfeebled, because they come to their perfection later in the season, when the heat and light of the sun-those stimulants of vegetable vitality-decrease. The internodes between the leaves consequently approach each other, until finally we arrive at the terminal bud, where the shoot again enters on the stage of rest.

Now, as the cycle of accelerated and retarded growth is repeated each season, and since there is always as marked a contrast among the shoots as between the internodial developments of the commencing parts and those that follow, the same wave of growth is perceptible amongst the shoots; and therefore we have marked out by Nature, in a manner not less sure, the growth of the year, in cases where the bud-traces are indistinct or wholly absent from the axis of growth, as in the Buckthorn (Rhamnus frangula). In the Beech branch, represented on page 31 , the wave of growth appears to culminate about the centre of each 
year's shoot. The reader will be satisfied of this fact by examining the drawing.

The Daily Wave.-According to Treviranus, the growth of trees is accelerated during the day and retarded in the evening. The principal German physiologists appear to agree as to the fact that there is such a daily acceleration and retardation of growth, though they differ a little as to the precise time of its occurrence. This daily fluctuation is by no means unreasonable; for growth can only take place through the assimilation of formative material, and this mainly depends on the sun's influence. The vital energies of plants may possibly vary, with the degree of the sun's elevation above the horizon, and plants may recuperate to some extent during the night, like the animal creation. For the same reason growth will be more rapid when the sun shines, especially after rain, than when the sky is clouded.

Some of the distinguished microscopists and physiologists of Germany think that these daily pulsations of growth have also left their mark in the interior of the tree, and that the fine layers in the thick walls of the wood and bast tissues, and of the starch granules, are connected with these daily fluctuations in the growth of plants. "Starch granules are the most easily observed in the cells of the potato, where they are very large. The mode of their formation is indicated by the peculiar markings on their outer surface, each grain having a spot at one end

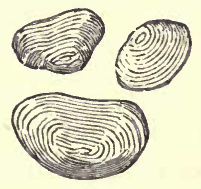

Grains of starch from the potato.

which is called the hilum, or ostiole, with fine concentric lines drawn around it."*

The Life Wave.-This is that grand vibration of growth

* See the author's work entitled "The Plant: an Illustration of the Organic Life of the Animal." 
which extends through the whole period of the life of the tree, and which carries along with it all the smaller fluctuations of each day and each year. We have shown that the growth of the different parts of a tree depends on the amount of leaf-surface put forth by each part into the atmosphere. But there is a continually increasing number of leaves developed during the first period of the life of a tree, and consequently an acceleration of growth, not only of each individual part, but of the entire tree itself in the same ratio, until the tree puts forth its maximum amount of foliage, when the wave of growth culminates. The tree has now obtained its greatest elevation and its widest spread. Thus, precisely the same accelerated and gradually retarded growth which is manifested by the unbranched first year's shoot, pervades the entire fabric of the tree. The law of each part of a tree is thus beautifully and clearly expressed in the whole tree.

It has been intimated that not only the entire tree, but each branch and branchlet has its own independent and characteristic wavelet. It is for this reason, whilst the tree is growing, that it is perpetually changing its form, year after year. The greatest individual freedom predominates. Each shoot, each smaller and greater shoot system, grows after its own fashion. Sometimes here, sometimes there, one or two branches take the lead awhile, to be overgrown and hidden from view in succeeding years by the more powerful development of the lower and surrounding branches. Each year the tree changes its form, yet such is the wonderful power of centralization and the subjection of all its parts to the law impressed on the seed, that the tree always retains the same peculiar landscape character. To nothing is more strikingly applicable than to the tree-form, what Gothe, the German poet said of Nature: "She ereates eternally new forms; what there is, was yet never; what was, comes not again. All is new, and yet always the old."* These fluc-

* "Sie schafft ewig neu Gestalten; was da ist, war noch nie, was war, kommt nicht wieder. Alles ist neu und doch immer das Alte." 
tuations in the landscape figure or outline of a growing tree, resemble the living play of a fountain which is inexhaustible in new forms, and yet remains so similar to itself, that the spectator in the distance might almost believe himself to perceive a solid form hewn out of marble.

This constancy of the form or peculiar characteristic landscape expression of the tree, through all its fluctuations, in the earlier stages of its growth, shows the predominating influence of the grand life-wave, which carries forward all the minor fluctuations of the branches, and affords the highest proof not only of the individuality of the tree, but of the organic unity of all its parts.

There is then in the development of the entire tree, one grand, all-pervading wave of growth, or an acceleration of the yearly growths made by all its parts up to a determined stage of culmination, and from thence, to the end of its life, a progressive remission follows. For the life-wave culminates when the tree has gained its maximum height and spread, and puts forth its reproductive organs or flowers. Its growth is then slowly retarded, for reproduction is always a check upon vegetation,-the vegetative efforts of each season being absorbed by the reproductive.

And now, reader, imagine yourself seated with me beneath the shade of some grand and glorious old tree. I am going to let you into the secret of a few bright guiding thoughts, which cheer me along through life. Spring has covered this tree with another generation of bright, green leaves, all of which are at work on its fabric, and usefully employed. They will soon pass away, and others will take their place, for Nature knows no backward movements. How many such generations of leaves have already expended life in building up this tree!

Reader, your position and mine on this earth resembles that of the leaves on this tree. We are only here for a little space of time. Many generations have preceded us, and coming generations will soon take our place. The wise and good of all ages have been trying to improve this 
world and its inhabitants, and, as the result of their labors, we have now a social organization called civilized society. There certainly can be no question as to the necessity of further improvements. These must be founded on Nature. Whilst we live, then, let us employ ourselves usefully, and help to diffuse science, peace, prosperity, and contentment. Let us try to build up a noble social tree.

If we study the economy of labor amongst these leaves, we shall find that they "help each other along." The lower leaves on the shoot, for instance, prepare the sap or nutrient material for the leaves above them, the little twigs assist to develope the branchlets, and the branchlets aid in the growth of the branches. In point of fact, the whole tree may be regarded as a "Mutual Aid Society;" and thus should it be in this world.

The tree is all the time changing its form, and in like manner society is ever changing its aspect through all its ramifications. Through want of life-energy and industry, some are losing gradually that social position to which they were elevated by their ancestors. They are rapidly losing the sap* for which all are contending. This is now being diverted away from them to other channels, to individual shoots and branches, where there is more vital activity, fo sap is always attracted to these parts; these stranger shoots are becoming more and more conspicuous in the social tree, and will soon overtop and conceal them. It is thus that the rich sometimes become poor, and the poor rich.

But there are other causes which effect great social changes in a community. Sometimes the form of a tree changes in consequence of storms; its branches are broken off by powerful winds. And what man is sure for one moment against calamity! This is so well known, that the words "in prosperity prepare for adversity" have passed into a proverb. How frequently have the fruits of years of toil and privation been lost in a single hour!

\footnotetext{
* Sap, or dollars-that circulating medium so necessary to the develop-
} ment of individuals and societies in civilized communities. 
It has, however, been shown that the injury done to the tree is soon effaced, that when branches are thus removed, those less developed get the sap which they monopolized. And does not precisely the same law obtain in society? If any body suffers in person or pocket, somebody is sure to benefit. Hence the force of the old Scotch proverb, "It's an ill wind that blaws naebody ony luck."

But the most remarkable and interesting feature about a tree is the fact that it is a body so easily impressible. All its periodical changes from a state of rest to that of motion, those waves of growth of which we have spoken, have left an indelible impression in the solid parts of its fabric. All the bright and stormy days of its life, every wind that has shaken its foliage, and every rain-drop that has wetted its roots, have helpéd to mould its physical organization, and make it just what it is. We see, however, that in the figure of its leaves, the form of its branches, and the color of its flowers, it is governed by peculiar laws of life impressed on the seed, and that it possesses an internal organizing power by which it can to a certain extent form itself, notwithstanding the indelible impressions left on its organization by the events of its life.

And is it not thus with the successive generations of man? Like the flowers of the field and the tres of the forest, do not we all develope according to the same general laws running through the same cycle of life-changes-of infancy, maturity, decay, and dissolution? Yet each individual is governed by a peculiar specific law. Is there not an individuality about each of us? Ifence, like the plants around us, do we not possess, to a certain extent, an organizing power within ourselves?' Like the trees, we are inseparably connected with the material world, from whence our organization derives impressions. We are a part of the universe. The matter of which our bodies are composed, like that of trees and flowers, is held together by attraction, and after a while, like them, the present living generation will disappear from the landscape,- -dissolved into earth and air. But not an atom perishes. The same 
matter again reappears in other forms of life and beauty. It is not the first time that the matter which composes the present living organized creation has been vitalized. How then can this grand machine of Nature be without guidance? Who will say that there is no plan or system in this thing? Is it not also plain, that we are connected with the past and future in adamantine chains, and that the species of independency and separation from external nature which we attribute to ourselves is a mere figment?

And if matter is thus imperishable,* then gravity, heat, light, electricity (those forces which control matter), are also eternal. And why should not mind be immortalmind, the highest force in the universe, which now guides the lightnings, and to form and advance which is the design of this vast system of sea and land, air and skies? It is natural for a noble mind to desire immortality. But if man is not immortal, then in vain a nation weeps for its mighty dead, and erects its noblest cenotaphs. Where will they be when the perpetual beat of ocean shall have shattered to ashes these continents, and the Alps and the Andes, those majestic monuments of Nature, lie entombed under its rolling waters? Matter and the forces which govern it are eternal, and human life (I mean that life which we have in common with plants), is a mere integral $\dagger$

* There is not now and, in the author's opinion, never was, a chaos or state of things in which the atoms of material bodies were heterogeneously disposed. All the researches of science tend to show that matter has always been subject to law. It is not impossible for the matter of our earth to have existed in some other form anterior to its attraction together about the earth's centre, and when the earth shall have answered the purposes of its creation, when she shall grow weary in her diurnal march, and the ocean roll its last billow, the winds breathe their last gasp, may not the matter of the earth, like that of one of the beautiful trees and flowers which have disappeared from its surface, still be in existence, and reappear again in some other form, to beautify the heavens and go through another grand cycle of change?

$\dagger$ Integral, the sum of a series of differentials or infinitely small quantities. The moments of human life are its differentials, and human life itself is their sum or integral. 
portion of eternity; yet, why doubt the immortality of that higher manifestation of life called mind, when it can sweep over the vastness of Nature and unfold the principles of things? If the value of man is to be estimated by the duration of his frail and perishable body, then is he of less importance than the tree which he fells for timber, for that frequently outlives him and his successive generations. $\mathrm{Oh}$, let us not think thus meanly of ourselves! The mind is the man; and "one living mind is worth more than a dead universe." Never can I sympathize with those who seek to inspire man with low, reptile feelings, and try to shame him out of his trust in his Creator. What moral good can ever result to the human race from the advocacy of such sentiments?

I see the sun now sinking in the West. He is casting his parting rays on our landscapes. How beautiful the light reflected from the clouds in his neighborhood! Another beat of the great pendulum of the universe! Whence that thought? It arises from my appreciation of the advance of Nature. The landscapes are now enveloped in the earth's shadow. It is night. Why did that sunset give me so much pleasure? Because the sun was made to

- minister to my gratification. I am then of more importance than that sun. Yet it shone myriads of ages before I came to regard its splendors, and it will soon shine on my lowly grave. That will contain my body, but Nот мE. Others shall look on thy setting beauties, thou glorious sun, and read these lines when I am gone, and oh! may they inspire in them my own unfaltering faith in Providence and immortality!

As the tree is connected with the material world and receives impressions from without which mould its character, so with the organism of man. He is bound by inseparable ties to the material creation. Locke in his "Essay on the Human Understanding," has shown us the nature of this connection: that sensation links us with matter, is the germ of intellect, and the avenue of human knowledge. 
Notwithstanding the unbounded liberty which the mind of man seems to possess, it is in reality confined within very narrow limits; for when we carefully analyze our ideas, simple and complex, we can trace them without an exception to past impressions made on our organization. We can form no conception of anything without a reference to ideas previously acquired by the senses. I may conceive of a golden mountain, but it is obvious that if I had not previously acquired, by impressions from external Nature, the ideas of mountain and gold, it would have been impossible to have formed the combination.

We are very frequently compelled to receive ideas independently of our will. I may, for instance, be looking out of my window, and see a man shot down, and a year afterwards recollect the circumstance. I have thus involuntarily acquired an idea. Impressions thus received,

* when powerful and painful, will recur again and again, and influence our conduct through life.

Now if our knowledge of an external object was limited to the moment of perception, and was extinguished forever with the fading sensation which gave it birth, if we had no memory of past impressions, then we should be creatures utterly incapable of reasoning or reflection. But we are so constituted that the knowledge derived from without lives within us. All our past impressions are secured to us. They are associated together according to certain laws, which have evidently been contrived with the most admirable adaptation to our wants, so as to bring again the knowledge previously acquired by the senses at the very time when its return is the most profitable. "A burnt child fears the fire," for example. Hence we are ever expanding ourselves over the long series of our past sensations, for memory is the mind relapsing into a former state, and the use of reason becomes more and more apparent, as these sensations from the external world are increased in number and variety.

How beautifully are the upper and lower extremities of a 
tree organized with reference to the earth and atmosphere! The fibres on the roots and the leaves on the brancheshow different in form and color! Yet both are absorbents beautifully adapted to the media in which they develope. In like manner is the organization of man adapted to the material creation spread around. His eye is beautifully adapted to receive the light, his ear is formed for the reception of sound; his body, in fact, is an apparatus most exquisitely contrived to render him sensible to the nature of external things. Hence, Nature is the great teacher. In childhood we are the most passive and impressible. We spend life in a state of constant and curious excitement. We are perpetually stimulated by the presence of new objects, and every hour brings with it stores of facts and natural appearances, the rich materials of our future knowledge. Nature is pouring in instruction at every avenue of sense. As we advance in years, we become familiar with common objects, and our attention is naturally drawn away from the discovery of what is new to the study and examination of that which is old. The vast variety of phenomena which have made an impression on us are brought under review, and the feverish astonishment of childhood gives place to the calm of manly contemplation. Then commence those first attempts at generalization which mark the dawn of science in the mind, and from the lessons of the past we now draw the materials of our future wisdom.

Every wind and rain-drop has helped to mould the character of this tree. And it is a great truth, which well deserves to be regarded, that not only the peculiarities of their organization, but the circumstances by which they are surrounded, form those endlessly diversified varieties of human character which we meet with in our passage through life. Like the different trees of a forest, the individuality of men is the result of the controlling influence of peculiar laws of organization and the circumstances in which they are placed. 
The tree unfolds from the seed and runs through all the various phases of its life, according to peculiar laws which are ineffaceable, and can never be set aside by circumstances, adverse or otherwise. And, like the trees and flowers, human nature exists under a vast variety of form. We differ from each other, not only in our features, but in our tastes and modes of thought. These differences of character are constitutional, the result of the operation of those peculiar laws of life which have governed us from the commencement of existence. This variety of talent and disposition is a wise and benevolent provision of Nature. It brings men together. It enables them to be of service to each other, and thus strengthens the bonds of mutual dependence, respect, and good-will. Since, then, human nature is so constituted, it shows not only ignorance and narrowness of mind, but a want of courtesy and even common sense, to cherish unkind feelings toward any man for a mere difference of opinion, or a want of sympathy with us in our favorite pursuits. On the contrary, charity and forbearance are indicative of a mind enlightened, expanded, and noble. It is an endorsement of the fact that its possessor appreciates freedom. We cannot all think alike. There are natural antipathies and mutual attractions. If the former were not a reality, the latter could have no existence, and life would be without some of its choicest blessings-the sweet sympathies of mutual love, and the warm and appreciating grasp of the hand of friendship.

A tree cannot flourish in an unfavorable soil, however healthy the germ which the seed encloses. So a man may be richly endowed with natural talent, and yet that talent will continue rudimentary, and ultimately become abortive through the long continuance of unfavorable circumstances. These facts ought ever to be borne in mind if we would form a just appreciation of others. The first duty which a man owes to himself is to develop himself. Circumstances form character. "He that walketh with wise men shall be wise, but a companion of fools shall be destroyed." There must be an affinity for what is true and noble, and then there will be progress. We may extricate ourselves from an unfavorable 
position. By honorable, right-angled or upright behavior, we may awaken sympathy in the bosom of the wise, the just, and the benevolent. We may impress them favorably, and they will necessarily become our friends. It is a law of Nature, that virtue and integrity shall have their reward. Is not this a plain indication of that pathway through life over which men ought to travel?

And let us never forget that we mutually impress each other by every action of our lives. If we violate a contract made with another, we produce a bad impression, and we injure not only the man but the community. That unfavorable impression is retained, and it may be a generous and confiding man has been rendered, for life, penurious and distrustful. But if we keep our contract, we produce a good impression, which is quite as permanent-the man has confidence in us, and we impel him to increased confidence in his species. He meets us with a bright smile because we have done well. If men only reflected thoroughly on the power of external circumstances and individual laws of organization, they would act with greater wisdom and justice toward each other.

Far be it from me to insinuate in these pages that man is ever carried to any line of conduct by physical impulse or necessity. If we suppose this, then man becomes a mere machine; and no longer responsible for his conduct, he is unworthy of either praise or blame. Virtue becomes a figment. Every action of his life is the result of choice, and that choice connects itself with a degree of moral responsibility proportioned to the extent to which he has a clear and adequate perception of his obligations. The very idea of virtue implies resistance to temptation and an enlightened and willing fulfillment of duty. 


\section{CHAPTER VII.}

The Leaf With THE ENTIRE EDge is ALONe TO BE REGARDED AS A SIMPLE LEAF-THE LEAF TAKES A HIGHER FORM OF ORGANIZATION, AND BECOMES COMPOUND IN PROPORTION TO THE DEVELOPMENT OF THE FIBROUS PORTION OF ITS LAMINA-ALL THE IRREGULARITIES OF ITS MARGIN, SUCH AS LOBES, TEETH, CRENATURES, SERRATURES, RESULT FROM AN EFFORT AT NEW LEAFLETFORMATION ARRESTED IN ITS FIRST STAGES.

THE commonest leaf-form in the vegetable world, which must therefore be regarded as the fundamental type or normal form, consists of two parts-a stalk or support, called the petiole, and an expanded part called the lamina or blade. To such organs the term leaf was formerly restricted. But it is now admitted by all physiologists, that this term is equally applicable to all the organs of the periphery of the plant which develop laterally during the growth of the axis, and which are distinguished from the ordinary stem leaves by the use of the terms bud-scales, stipules, bracts, sepals, petals, stamens, and pistils. All these different varieties of leaf-form pass by intermediate gradations into one another, so that this classification is wholly arbitrary, and the terms are merely used as convenient references to those varieties which are the most decidedly marked. Now, what is the evidence on which this doctrine rests? Is it not transition forms? Does not the whole science of Vegetable Morphology rest on this foundation? The following facts presented in this chapter are only the fruit of a careful application of precisely the same principles of research. Transition forms show ties of relationship subsisting between the most dissimilar organs and often lead to conclusions at which Naturalists themselves 
are at first completely astounded. Nature herself by this means teaches us her own processes, and this too by such evidence as none can gainsay or deny.

The reproductive always exhausts the vegetative force. All physiologists will concede me this ground unhesitatingly. It is well known that this is one of those grand laws which govern every form of organized matter. Animals âd plants must first vegetate before they can reproduce; and reproduction in both always checks growth and exhausts the vital powers of the organism. Hence leaves take a simpler form in the neighborhood of the flower. They are not so highly organized, because their development is gradually arrested, and the vegetative force diminishes in intensity as the repro. ductive force becomes manifest. There is a mutual antagonism between these'two forces. There can be no doubt as to the influence exercised by this law in modifying the foliage of plants. It is only necessary to compare the leaves in the neighborhood of the flower with those at some distance from it, in the vegetative region, to see the gradual simplification of leaf-structure, as we pass from the vegetative to the floral region.

Now, such investigations are exceedingly instructive; for if we carefully examine the leaves of plants at different points of height along the stem, it will be seen that they present notable differences of form, and that the most intimate ties of relationship subsist between lobes, crenatures, teeth, etc. Generally speaking, the leaves attached toward the inferior portion of the stem are cut into teeth or lobes more or less numerous, and are connected with the stem by a petiole or stalk; but in proportion as they are situated near the flower, they become smaller, lose their stalk"or support, and become sessile, the teeth, lobes and other irregularities disappear from the margin of their lamina, which becomes entire, and they gradually approach the floral leaves in form, until'finally they cannot be distinguished from them except by their position around the stem. The gradul disappearance of the serratures from the margin of the leaves in proportion to their proximity to the flowers, may be seen to advantage in the different 
species of Solidago, or Golden-rod, and the passage of lobes into crenatures in the Swamp mallow (Hibiscus moscheutos).

The stem leaves, however, not only vary in form in proportion as we pass from the vegetative to the reproductive region, but they vary in the midst of the vegetative region 1tself. The polymorphous condition of the foliage of the paper mulberry (Brousonettia papyrifera), and the common Sassafras (Sassafras officinalis), is well known. On these trees scarcely any two leaves can be collected which have precisely the same figure. The variability of the foliage in this case cannot arise, as in the former, from the gradual decrease in the vegetative tendencies of the leaves in consequence of the tendency to the exercise of the reproductive function-there must be some other cause.

In Chapter VI. we have shown that the growth of trees may be compared, not to the steady and continuous flow of a stream, but to the rising and falling of a wave; and that the tree, whilst growing, is in a state of continual oscillation, as it were, between a condition of progress and one of stand-still. Now, the difference of growth amongst the shoots, not only during the same year, but for a succession of years, may be traced to this accelerated and retarded wave of growth, or the ever-varying condition of the vegetative force throughout the season; and the fluctuations of the same wave leave their traces in the foliage of the shoots. In herbaceous annuals and perennials this wave obtains its maximum elevation where the leaves are most developed, and is depressed to a minimum in the flower. The same wave is visible in the leaves of ligneous perennials or trees, which are generally much smaller toward the bottom of each new shoot, and larger toward its centre and summit.

Now, when polymorphous leaves appear on such of the shoots and branches of a tree as are purely vegetative, this wave of growth must be taken into consideration in comparing them with each other. It will be found that the leaves with the greatest number of lobes and other marginal irregularities are invariably developed at those points of the shoot where the vegetative force is the greatest, or where the wave 
of growth is at its maximum, and that they take a simpler form, their fibrous portion or framework being less developed, as the vegetative force diminishes in intensity, or the wave of growth is gradually depressed along the axis of the shoot. Hence, this variability in the form of the leaves on such shoots and branches as are purely vegetative, arises from the operation of the same common laws of accelerated and retarded growth which pervades the branches.

On some trees, such as the sassafras and paper mulberry, with polymorphous foliage, if we collect and compare the different varieties of leaf we shall find that they invariably take a higher form of organization in proportion to the development of the fibrous portion of their lamina. The truly simple leaf is in fact the one with an entire edge, and all other varieties of leaf having irregularities of margin, such as lobes, dentations, crenatures, serratures, must be regarded as leaves in a certain stage of progress to a compound condition, for the above marginal irregularities are in reality an effort at new leaflet formation arrested in its first stages.

We commence this demonstration with the case of lobed leaves, which is the most obvious.

The lobed variety of leaf is caused by two or more partially formed leaflets, which are organically united with each other and develop in the same plane. The upper part of the lamina of these leaflets is the only portion of them which is fully formed, and it is this which gives to such leaves their lobed appearance.

For let the polymorphous foliage of the common blackberry (Rubus villosus), see Plate III., be carefully studied, and a com. parison instituted between the different varieties of its leaves. Every intermediate grade of development may be traced between lobes and leaflets, the various vegetative stages in the passage of the former into the latter having been left visible in the leaves of this plant. We have monographed a few of the more prominent forms to show their connection, and give the reader an idea of our method of observing Nature. But all the intermediate varieties can be collected, and thus the truth of the above proposition may be verified. 
FROM SIMPLE LEAVES.
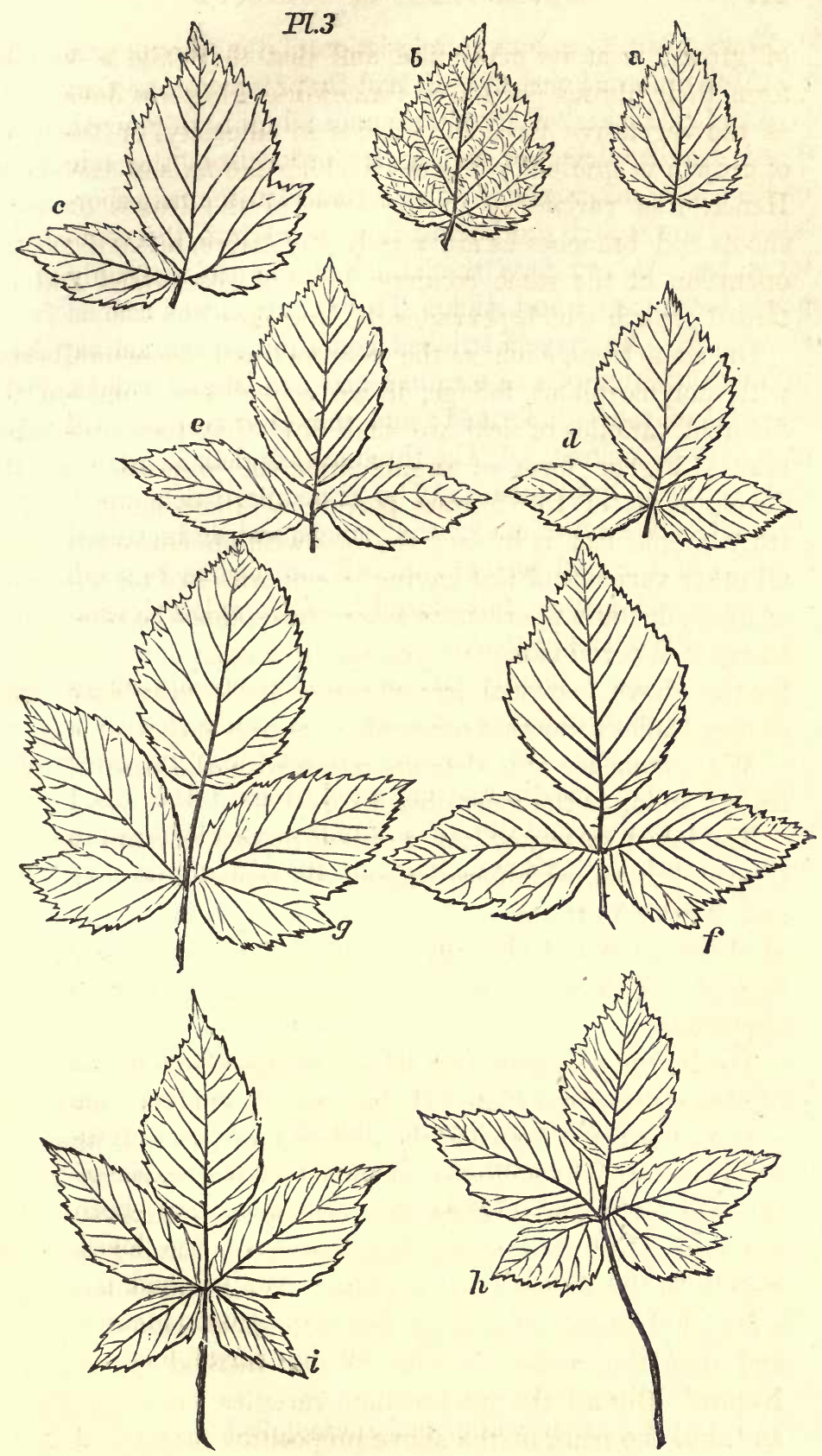
Now, it is plain, from simple inspection of the fibrous part of these different varieties of leaf, that in proportion as that is developed, the leaf itself becomes more highly organized. These leaves were detached in regular order from the side of the shoot, commencing with those situated in the neighborhood of the flower and proceeding downward into the vegetative region. At $a$ we have the lamina of the leaf with only a biserrate margin, and no petiole. This specimen was nearest the flower. At $b$ we have a trilobed condition of the lamina, or a partial formation of one terminal and two lateral leaflets. At $c$ one of the leaflets is formed; and the other two are still in a state of anastomosis. $d$, The three leaflets detached from each other and fully formed. $e$, The same more developed. $f$, A bilobed condition of one of the leaflets, and an increased development of the petiole. $g$, Both of the leaflets bilobed. $h$, One of the new leaflets fully formed. $i$, Complete formation of both of the new leaflets.

Here, then, we have plainly visible the intermediate stages in the formation of the lamina or blade of a leaf with only a biserrate margin, into five distinct leaflets. Surely, after such a lesson from Nature, we may safely regard the lobed variety of leaf as the condition of a lamina whose leaflets are in a state of partial formation, and remain still organically united with each other.

The leaves of the swamp maple (Acer rubrum), the sugar maple (Acer saccharinum), the Plane-tree maple (Acer pseudoplatanus), and the Castor-oil (Ricinus communis), Plate IV., Figs. 1, 2, 3, 4, may therefore be regarded as transition forms between simple and compound leaves. In all these cases the lamina of the leaf consists of several partially-formed anastomosing leaflets, whose number is indicated by the number of lobes, and the extent to which their formation has been carried, by the depth of the divisions between the lobes, precisely as the number of petals and sepals united and the extent of their union is shown in the gamopetalous and gamosepalous envelopes of the flower, by the number of lobes or teeth on their superior margin.

When the fibrous ramifications of these lobed leaves are 
prominent on their under surface, as in the Castor-oil plant, by simple inspection of that under surface, we can easily trace out the fibrous portion of each forming leaflet in the blade of the leaf, and thus satisfactorily arrive at the same conclusion, that the entire blade itself is a composition of partially formed and organically united leaflets. Because the lateral veins given off by the midrib of each forming leaflet may be traced below the point where the division between the lobes or blades of the leaflets ceases, and they become as it were blended together; for notwithstanding the confluence of the fibre and parenchyma of the leaflets below this point, their lateral veins still continue to be given off with the utmost regularity, even down to their point of divergence at the apex of the common petiole. The fibrous portion or framework of the forming leaflets is therefore perceptible in the common lamina or blade of the Castor-oil leaf; and it is not difficult to imagine the form that the leaflet would assume when fully developed and detached from its neighbor, as in the above case of Rubus villosus. But the further development of the leaflets of the Castor-oil leaf is arrested at this stage, and therefore they are never found separate.

The coalescence or union of leaves or leaflets with each other in all instances results from a want of developmental vigor in that fibrous portion of their lamina, which constitutes their skeleton or framework; hence, the most frequent cases of union or coalescence, occur among the floral leaves where the vegetative powers of the plant are gradually expiring. Thus, when the sepals or leaves of the calyx, as also the petals or leaves of the corolla, coalesce, we have produced what is technically termed a monosepalous (or gamosepalous) calyx, and a monopetalous (or gamopetalous) corolla, as in the Bellflower (Campanula Americana); so, also, the metamorphosed pollen-bearing leaves termed stamens, situated immediately within the corolla, may unite with each other by their filaments and become monadelphous, as in the Mallow and Geranium, or by their anthers and become syngenesious, as in the Dandelion; or the filaments and anthers of all the stamens may unite and form a single organ, a sort of vagina 
or sheath enclosing the pistil, as in the Cardinal flower (Lobelia Cardinalis). In like manner, the still more highly organized pollen-receiving leaves called pistils, which are the organs of the flower most centrally situated, coalesce sometimes by their ovaries, as in the Pink, or by their ovaries and styles, as in the Lily. And not only may there be a coalescence among the floral leaves of the same circle, but the different floral whorls or circles may themselves coalesce, or unite with each other, as is the case in the Asclepias, or Silk-weed, where the union of the stamens and pistils forms the solid column in the centre of the flower.

Hence plants whose floral leaves are still in a state of coalescence, and therefore only partially developed, are very properly considered in the Natural System of Botany as ranking lower than those whose floral leaves are free from each other and fully formed. It is evident that flowers whose sepals, petals, stamens, and pistils are each individually and completely formed and free from each other, and which develop on the same common rudimentary axis or receptacle, must be more highly organized than flowers whose petals and sepals, stamens and pistils are only half-developed, and therefore still organically united with each other.

That the leaf should develop new leaflets from its margin, and that the new leaflets should remain connected with the parent foliole in different stages of formation, is only in accordance with the same laws to which all the other organs of the plant are subjected. Thus if we regard the different species of CELL or simple elementary parts of plants, we find that they generate cellules of the same nature as themselves, and that these cellules associated form the tissues of their more complex organs, such as their shoots and branches, which possess the same capacity for self-multiplication. For the first year's shoot produces from its lateral and terminal buds, shoots which are constructed in precisely the same manner; and these again become individually parent shoots, until we have associated about a common axis a series of families of shoots or branches all actively engaged in reproduction. The whole tree is therefore only a continuous series 
of successive generations of shoots, which remain connected with each other and which have developed on the first year's shoot. Where is now that once slender and flexible shoot which formed the growth of the first year and the basis or foundation of all the succeeding growths? It has been metamorphosed, through the labors of its numerous progeny, into a stem massive and unyjelding, and the buds which adhered to its surface, after the fall of its leaves, have been replaced by wide-spread and powerful branches! It is thus that the matter of the earth and atmosphere is attracted about a seed or germinating point, and successively moulded into cells, leaves, shoots, branchlets, and branches, until at length a form majestic and beautiful-a noble Tree is constructed. How far surpassing all the works of man, this wondrous living architecture of Nature! Ah! man, thou canst go to Nature for instruction, copy her faithfully with thy pencil-but, mould thy material imitations as thou wilt, thou canst not give them life! These are secrets which Nature has hidden from thee!

There is a wonderful unity and harmony pervading all the parts of these works of Nature, which result from the influences of the same general laws to which the cell, the leaf, the branch, and in fact the entire tree, are alike subject. Just as the whole tree consists of a union of branches of various growths, as the branches themselves are formed by a union of shoots which show an equal amount of variability in the extent of their development, so the leaves themselves, which construct the shoots, when simple, with an entire edge, fully formed and free from each, vary in figure and size on the same shoot. Even those leaves which manifest a disposition to self-multiplication, and which must be regarded as transitional between the compound and simple, in the different sizes of their lobes, teeth, crenatures, serratures, plainly show that the forming leaflets are endowed even from the beginning with a tendency to that variety of vegetative energy and impulse which is so well-marked a feature in the other organs. This is the cause of that pleasing and infinite variety of form assumed by the foliage of trees-that green and graceful drapery with which they are annually adorned. 
Therefore the truly simple leaf is the one with the entire edge, and all other leaves with any irregularities of margin, such as lobes, teeth, crenatures, etc., are transitional forms between simple and compound leaves. For such irregularities are in reality so many incipient advances to the compound condition of the lamina or blade of the leaf.

It has been shown (page 112) that a leaf can develop other leaflets from its margin, and thus become a compound leaf. Now, when this process ceases in its first stages, and the apices of the new leaflets are only just visible on the margin of the parent leaf, then that margin is rendered serrulate, crenulate, denticulate; or if the formative process is carried a little further, so as to render the summits of the new leaflets rather more apparent, then the leaf-margin is said to be serrate, crenate, dentate.

In the lobed variety of leaf, the upper portion of the lamina of each leaflet is fully formed, and the number of forming leaflets, as well as the extent to which their formation has been carried, is expressed botanically by the terms bilobed, trilobed, quinque-lobed, etc.; the words bipartite, tripartite, and quinque-partite are expressive of a still higher degree of development, and indicative of the formation of the greater portion of the lamina of the leaflets, and that their detach. ment from each other has been nearly carried down to their main petiole or support.

If the reader compares the leaf of the False sycamore (Acer pseudo-platanus), Plate IV., Fig. 3, with that of the Castor-oil plant (Ricinus communis), Fig. 4 , he will see that the transition from the one form of leaf to the other has been brought about by the partial development of the lamina of an additional leaflet, and that the extra lobe thus formed fills up that sinus or opening which is left between the two lower lobes of the Sycamore leaf, and thus produces in the Castor-oil leaf the palmately lobed variety. The terms palmately-cleft and palmately-parted, point out a still further formation of the lamina of the leaflets, whose several bases nevertheless still remain in a state of coalescence.

But in the digitate leaf of the Horse Chestnut (Esculus 
Pl. 1
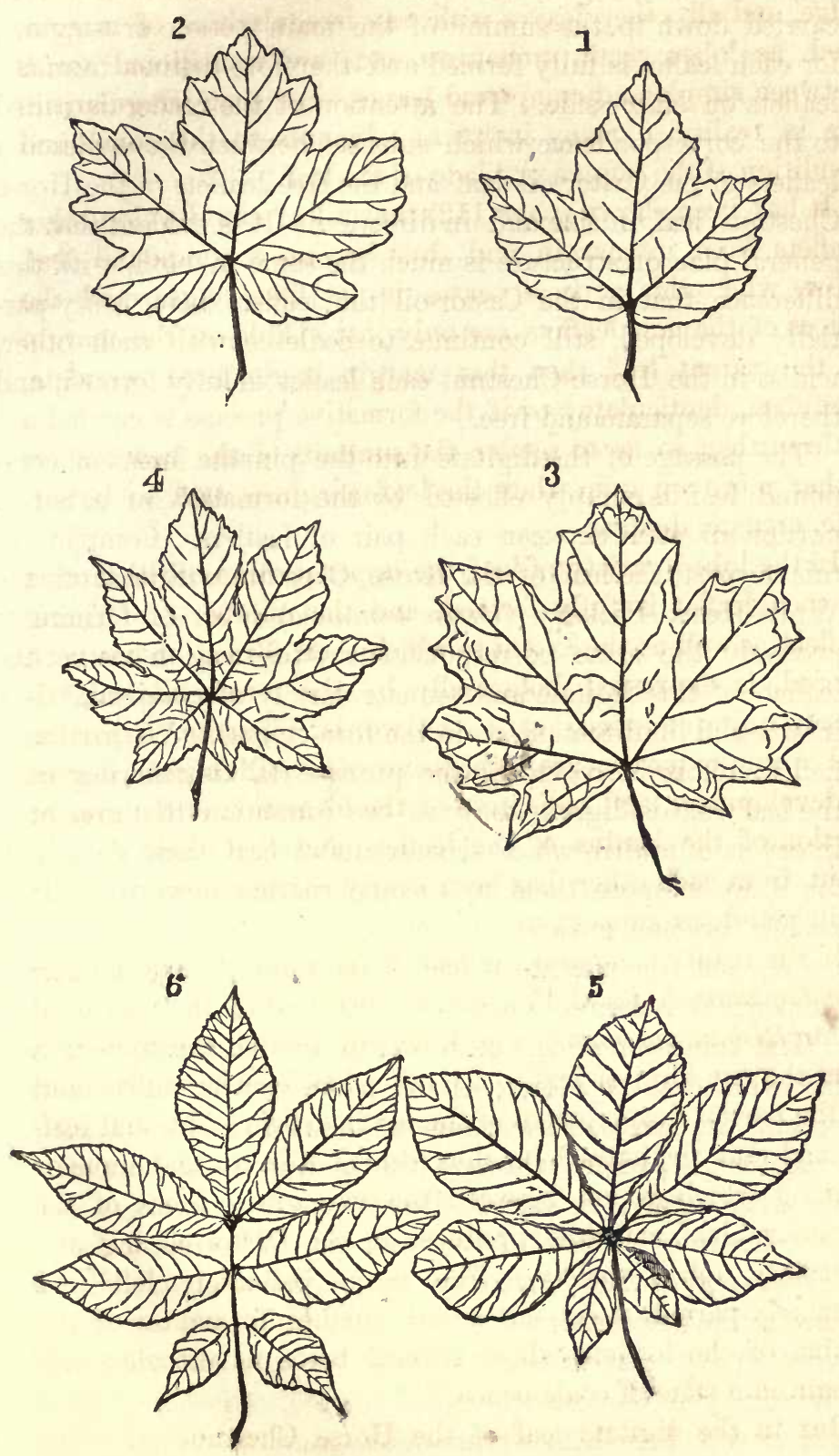
hippocastanum), Fig. 5, the separation of the leaflets has been carried down to the summit of the main petiole or support, for each leaflet is fully formed and therefore distinct from the leaflets on either side. The attention of the reader is called to the correspondence which subsists between the coalescing leaflets of the Castor-oil leaf and the free leaflets of the Horse Chestnut leaf, in size and in direction. It is evident that the general plan of structure is much the same in both, with this difference, that in the Castor-oil the leaflets, being only partially developed, still continue to coalesce with each other, whilst in the Horse Chestnut each leaflet is fully formed, and therefore separate and free.

The passage of the digitate into the pinnate forms of compound leaf, is simply effected by the formation of a naked portion of stem between each pair of leaflets. Compare, in this respect, the leaf of the Horse Chestnut with that of the White-Heart Hickory (Carya tomentosa), Fig. 6. There is precisely the same correspondence subsisting between the leaflets of this digitate and pinnate variety of compound leaf, in size and in direction, as in the former case. We are justified therefore in regarding the pinnate leaf as differing from the leaf that is digitate, only in the formation of those little intervals of midrib which separate its several pairs of leaflets; for if we suppose them to become rudimentary, then these leaflets become crowded together at the top of a common petiole, and the pinnate at once passes into the digitate form, from which it can no longer be distinguished.

The transition of the pinnate into the bipinnate form is a fact which has been long known to the world. This is well seen in the leaves of the common Locust-tree (Robinia pseudacacia), Fig. 7, where, through the increased development of the costa, $\alpha$, and its lateral fibres, $b$, the new costæ, $c$, and a second set of leaflets, $d$, is produced. This second set of leaflets may in like manner produce another set, which is the case in the tripinnate variety of compound leaf; but here the vegetative power reaches its limit, for it is seldom. that the division goes beyond the third degree, although tripinnate leaves with their leaflets pinnatified are not uncommon. 
But the most instructive foliage is that of the Honey-Locust (Gleditchia triacanthos), Fig. 8. Among the highly compound leaves of this plant, the intermediate transitional forms between a pinnate, bipinnate, and tripinnate division of the lamina may be readily found. We have had one of them drawn. It will be seen, at $a$, that one side of the lamina of an individual of one of the pairs of pinnæ has developed three new pinnules, and that two of them are only partially formed, whilst the other side of the lamina retains its original appearance. The individual which is thus nearly half-formed into new pinnules differs hardly at all from the new pairs of pinnæ in size; and the reader will perceive at once that these pinnules are five in number, and that this exactly corresponds with the number of pairs of pinnules into which the terminal and lower pairs of pinnæ of the leaf have been developed. Surely such proof as this makes it clear enough, that the costa and side veins of a leaf may so develop that the former shall become a common axis or support for the latter, which shall constitute the midribs of new leaflets.

Hitkerto we have endeavored to prove that the irregularities along the margin of leaves, described by the technical terms serrate, crenate, dentate, etc., are to be attributed to an incipient effort at new leaflet-formation by the evidence of transitional forms, a mode of reasoning which we think Naturalists generally admit to be correct. But the same position may be established by showing the intimate nature of that connection which subsists between the leaf and the other organs of the plant. that it is only a peculiar modification of the fibre and parenchyma of the branch to which it is attached, and governed by the same general laws in its development.

According to Dr. McCosh, the celebrated author of the work entitled, "Typical Forms and Special Ends in Creation," there is a correspondence between "stem ramification and leaf ramification" in "the disposition and distribution of the branches, and the disposition and distribution of the leaf veins," and also "in the angle at which the branch goes off" from the stem, "and that at which the lateral veins go off" from the costa or midrib of the leaf. If this theory be true, 
then the same general laws which govern the development of the branch and its ramifications give form to its leaves, which exhibit in their midrib and its ramifications through the parenchyma of the blade, a miniature copy of the branch itself

- $t$ is undeniable that this theory of Dr. McCosh has been received with ccidness and distrust by scientific men, although Professor Balfsur, of Edinburg, has very properly given it a notice in his "Class Book of Botany," but without committing himself as to its general soundness. In science it is not permitted to yield to imagination. If we would give currency to new truths, and obtain their endorsement as such by men filling a high and responsible public position, it must be seen that we have been guided solely by well-known and established facts in their development. There must be a stern determination to give a true and faithful portraiture of Nature and her operations, which, the more they are studied, the more they delight us by their grandeur and simplicity.

But do we interpret Nature correctly when we say that the leaf is nothing but an expansion of the fibre and parenchyma of the branch, that the ramifications of its fibrous portion or skeleton follow the same general laws as branch ramifications, that the leaf and branch are, in fact, homotypal?

Of course it is understood that these general laws of stem or branch ramification are somewhat modified in the leaf. Thus in every tree there is a certain normal angle at which branches are given off from the stem, and this angle varies in different trees. For instance, in the Norway Spruce Fir (Abies excelsa) the branches are drooping or pendulous, in the Hemlock Spruce (Abies Canadensis) they grow out horizontally from the stem, and in the Lombardy Poplar (Populus dilatata) their growth is almost vertical. Moreover, the angle which the branches make with the stem varies even in the same individual tree, for it not only increases with the age of the branch, but it is greatly modified by the position of the branches and the influence of surrounding agents. As a general rule, the lower branches of a tree grow more horizon- 
tally than those situated toward its top. All branches naturally tend to the light, and the inferior branches necessarily take this direction on account of the overshadowed position which they occupy. If the reader looks at the beech branch figured on page 33 , he will see that the upper twigs or branch. lets develop from the main axis of the branch at an acuter angle than the lower twigs; and let him at the same time bear in mind the fact, that the branch repeats, on a smaller scale, the type of the tree itself.

If we regard the costa or midrib of the leaf as corresponding to the stem or principal axis of ramification of the tree, then the first and most prominent sets of fibrous fasciculi, which separate themselves from the midrib or principal fasciculus of the lamina or blade of the leaf, will correspond to the strongest and largest side-branches of the tree; and it is obvious that in both instances the general figure or outline of both tree and leaf is determined by them. But whilst in a tree the angular inclination of the branches to the stem varies, in a leaf whose lamina or blade is not formed into distinct leaflets there is no such variation of the angular inclination of the principal veins to the costa or midrib, because the veinlets which would seem to correspond to the branchlets of the branch coalesce among themselves. Therefore there can be no change in the angle formed by the principal leafveins and costr, at any epoch in the development of the leaf, in such cases of leaf-organization, whatever correspondence there may be in other respects between their angular direction and that of the leading branches of the tree.

In compound leaves, however, which make a much nearer approach to the organization of the branch in their structure, where the lamina of the principal leaf is developed into one or more generations of leaflets, light causes the angular inclinations of these leaflets or foliaceous branchlets to vary slowly and continuously at different periods of the day, with reference to the midrib of the leaf, just as the same agent, acting for years on the main branches of a tree, changes their original angular inclination with reference to the tree stem. Thus the leaves of the American Senna (Cassia Marilandica) and of the Honey. 
Locust (Gleditschia triacanthos) hang down with the coming of the evening shades, and continue drooping through the night; but as soon as

\footnotetext{
"Night's candles have burned out, and jocund day Stands tiptoe on the misty mountain's top,"
}

they gradually elevate themselves to their usual horizontal position.

Another obvious distinction between stem ramification and leaf ramification, lies in the fact that the branches and branchlets of a tree are all radially arranged or grow concentrically about its stem, whilst the veins and veinlets of a leaf take a symmetrical, bilateral arrangement on either side of its costæ or midrib, and develop in the same plane, or, more correctly speaking, in a series of closely approximated planes.

But in trees of a low order of organization, such as the Coniferæ, or cone-bearing family, to which the Pine, Fir, and Larch belong, the main stem is well-defined, and the branches, although disposed about it concentrically, are nevertheless arranged symmetrically. The branches of the Pine and Fir, for example, grow from their main trunk in verticils or whorls, because they develop from the axils of closely-succeeding, spirally-arranged leaves, situated in the immediate neighborhood of the terminal bud, from which the main trunk proceeds each season. In consequence of the urging of the formative power toward the top of each year's growth of the leading axis, all its inferior lateral buds are suppressed, and whorls of branches are produced with naked intervals of stem between them. Now, if we imagine a vertical plane to descend through the main axis or stem of one of these trees, we will suppose it to be the Norway Spruce (Abies excelsa), so as to divide the tree exactly from top to bottom, it is evident that this tree, like the body of man or of an animal, would be divided into two perfectly symmetrical halves, which joined together would make one complete symmetrical whole.

In addition to this, the branchlets which proceed from the 
branches thus concentrically disposed about the main trunk are arranged not only symmetrically but bilaterally, the two sides of each branch, like those of the leaf, being counterparts of each other. This remark applies to branches with drooping branchlets, as well as to those which spread out horizontally from the sides of the branch. For the leaves which are arranged concentrically about the trunk assume a bilateral distribution on the branches in proportion to the increase in the amount of their horizontal development; and in the lowest branches, whose growth is most horizontal, the leaves drop from the under surface, or such as remain there curve round to the sides of the branch for light, so that they are mainly confined to its upper surface and two sides. Now it is plain enough that the axillæ of the leaves situated on the upper side of the branches would be bad starting points for growing shoots; and for this reason the upper side leaves remain sterile. Therefore this bilateral arrangement of the branchlets or side-growths of the branches, is the natural result of their horizontal growth and their overshadowed position, for branches always develop their branchlets in those directions where there is the most space and light.

Again, in the Beech, Linden, Hazel, Elm, and Hornbeam, this bilateral symmetry of the branches holds not only for the ramifications of the secondary axis but for the whole tree during the first years of its life. For these branches proceed from buds which are developed by alternate, distichous, or two-ranked leaves; hence, in the Spring of the second year they will necessarily lie in one plane, like the beard of a feather. This is well seen in the second year's growth of the Linden (Tilia Americana); but in the Beech this branch symmetry is preserved still longer, even until the tree has attained a considerable height above the ground. Nevertheless, as the tree continues to grow, it is subjected on all sides to the influence of surrounding agents, especially light, and the result is that the branches depart from their original symmetrical position, and tend to arrange themselves concentrically so as to receive the greatest amount of its influence. 
The symmetrical bilateral arrangement of the branches therefore disappears as the tree gets older, and it is still further concealed by the tendency of the concentric growth of the whole tree to repeat itself in the leading branches. This tendency very frequently manifests itself. Cases where two or more similarly-formed stems spring from the same common stock, whose branches are all concentrically disposed, are quite common in the woods. In fact, whenever a Beechtree (Fagus ferruginea) is old and well-developed, two principal forms or prototypes may be distinguished within the crown. The one, the form of the tree itself, only less developed, in the concentric growth of the leading branches into which its smooth, silvery-gray yet massive stem divides; the other, the form of the leaf: for the fibrous portion or skeleton of that organ, only greatly enlarged and developed, has its counterpart in the symmetrical, flattened, spread-out, but less powerful branches of the tree.

These facts would seem to indicate that the leaf, whose existence and development in relation to the axis is entirely secondary and subordinate, is in reality the prototype according to which the tree itself is constructed, which type repeats itself in each individual branch-that is to say, each branch represents, prefigures, and copies it.

The leaf may therefore be regarded as nothing but a peculiar modification of the fibre and parenchyma of the branch which it is engaged in constructing; and the fibre ramifies through its parenchyma as the branch ramifies through the atmosphere-the same general laws being followed in the distribution of the veins and veinlets.

This truth will be more apparent if we consider the scheme of a system of shoots or of branch ramifications, and the law of their development and association. In the first place, the primary axis of such a system preponderates in length over the first generation of side axes; and there is also a proportionate decrease, not only in the length of the side axes, but also in the number of vitally-active buds which they produce, and consequently in the extent to which their ramifications are carried. The vegetative power of the branch in fact 
diminishes with each succeeding generation of shoots, until at length it approaches its limit in buds, which unfold year after year into mere clusters of leaves. The bud traces on such shoots follow each other in close order, the leaf scars are reduced in size, and finally the terminal bud becomes abortive, and all further growth in that direction is necessarily arrested. There is also a well-marked remission of growth in the direction of the main axis of the branch. For after a certain point of time in the development of the main axis, the growth it makes each year becomes less and less; and this is accompanied by a loss of ramifying power in the families of shoots which it developes laterally, so that there is an exact correspondence subsisting between the loss of vegetative power in the branches of the upper region of the principal axis, and in the second and third generation of shoots developed by the branches of its lower region.

The same laws of remission of growth from one generation to another manifest themselves in the structure of herbaceous plants, which branch or repeat themselves in the axilla of their leaves, one, two, or even three generations of branches being developed during the same season. If this process of ramification is examined in the common St. John's Wort (Hypericum perforatum), or any other branching herbaceous plant, it will be evident that these successive side-productions are only repetitions of the whole plant on a constantly diminishing scale of magnitude, and that there is a beautiful symmetry apparent throughout the whole of them. For the branches given off from the axilla of the opposite pairs of leaves which clothe the stem of the primary axis, not only meet the axis at the same angle, but the lower branches are less developed than the upper branches, whose leaves are carried forward to the highest stage of vegetative metamorphoses and terminate in flowers. Hence there is only one generation of branches developed from the axillæ of the lower leaves of the primary axis, whilst the leaves situated toward its summit develop two generations; and as each branch terminates in a flower, its growth necessarily ceases. Herbaceous plants therefore follow precisely the same laws of ramification as the trees which 
overshadow them. They differ, however, in one particular. The first and subsequent generations of side shoots in trees are formed in embryo the first year, enveloped beneath the covering leaves of a winter's bud through the cold season, and develop as shoots the second year; but herbaceous plants are without these covering leaves. They need them not, because they develop all their branches in one season. This activity of the ramifying process the first season undoubtedly must tend to exhaust the vegetative powers of the herbaceous axis, so that the period of puberty arrives in a few weeks or months, and the plant flowers, forms its seed, and thus rapidly passes through the same cycle of life-changes which, in trees, it takes centuries to perfect and fulfill.

We are now fairly in a position to show that leaf ramification is governed by the same general laws as stem ramification. Assuming that the midrib and petiole of the leaf, when it possesses one, corresponds to the leading or primary axis of the branch, then the first and most prominent sets of fibrous fasciculi which separate themselves from the midrib will also correspond with the powerful side axes of the first order in the branch; and where the fibrous portion of the leaf takes a high degree of development, as is the case in compound leaves, there is in the leaf precisely the same tendency to a repetition of itself, on a smaller scale of architecture, as there is in the branch, and one or more generations of lcaflets will be formed, whose fibrous ramifications, like those of successive generations of branchlets, are more and more retarded, until finally the vegetative powers of both leaf and branch are reduced to zero.

Again, the stem and branches of the tree are all conically constructed, tapering toward their extremities. In like manner, the bundles of fibre which ramify through the green bark or parenchyma of leaves are equally tapering. The midrib or main fasciculus of fibres decreases in diameter from the base to the apex of the leaf, as the enveloping layers of fibre separate from each other. In such leaves as those of the Chestnut, all further ramification is at once stopped by the anastomosis of the fibres amongst themselves, the parenchy 
matous areola or interspaces between the fibres becoming continually smaller as they approach their ultimate ramifications; but where development is carried further, as in pinnate and bipinnate forms, there is the same conical and attenuated fibrous structure, and the same ultimate anastomosis of the fibre when the developmental power of the leaflet has reached its limit, just as in the simple leaf with the entire edge, where the vegetative power of the fibre of the leaf is reduced to a minimum, and the fibres, by consequence, anastomose among themselves before they come to the margin of the leaf.

The same laws of lateral or marginal leaf development manifest themselves amongst leaves even when they are still in a state of anastomosis, or only partially formed and separated from each other. One, two, or even three generations of partially-formed folioles may develop and remain associated with each other, producing the bipinnated or tripinnated forms, as is the case in the leaves of Ambrosia artemisioefolia, or Roman Wormwood. And just as the branch is only the tree itself on a smaller scale, representing a certain stage of development through which the tree has already passed, and, if severed from the stem and planted in the soil, would represent its exact condition during one period of its life, so a careful comparison of the entire foliole with its collaterals, proves that these collaterals are only incipient repetitions of the entire foliole, and that they hold to it the same relationship as the branchlets owe to the parent branch, and follow the same law of retarded development-and which is alike visible in the rugged and gigantic branches of the lofty tree which endures for centuries, despite the fiercest onsets of the elements, and in the delicate fibrous ramifications of the leaf, which a single night's frost can kill. Such is the grandeur and simplicity of natural law. Correctly interpreted, we see in the fibrous ramifications of the leaf a miniature or rather model exemplification of those very natural laws which, operating on a more enlarged scale, build up the powerful branches of the tree, with their innumerable branchlets.

The accuracy of this reasoning will be rendered clear and intelligible by Fig. 9, which represents a leaf of Kolveuteria 
paniculata, a beautiful Chinese shrub, cultivated in sheltered situations, for the sake of its elegant leaves and panicles of yellow flowers. In the leaves of this plant, the different stages in the process of new leaflet-formation may be traced at a glance. There is apparent that retarded development of the leaf ramifications in the first, second, and third generations of forming leaflets (Figs. 1, 2,3), which spring from the primary axis or costæ of the leaf; it will also be perceived that the outline figure of the side leaflets corresponds to that of the primary or parent leaf, from which they differ only in size, being only a repetition of the parent leaf on a smaller scale. Thus the lateral fibres given off from the primary costa or main foliaceous axis of the leaf, gradually decrease in size from the middle to the apex and base of the leaf; it is the same with the fibrous bundles given off from the secondary costæ: these are the most developed toward the middle of each leaflet; hence, toward their summits, the leaflets of the second generation are still in a state of anastomosis, or only partially formed. The lowest leaflets of this generation are the most completely developed; but they are sessile, their petiole is rudimentary, and the vegetative power is so enfeebled in the upper Ieaflets, that the parenchyma is increasingly decurrent along the line of the costæ. These lower lateral leaflets are therefore clearly only the secondary leaflets arrested at a still lower stage of their development. If we examine them carefully, we shall find that the lateral fibres proceeding from their costæ or midribs produce the sharp incisions of their margin. These sharp points are therefore the tops of the new leaflets of the third generation, and by consequence the last expiring efforts at new leaflet-formation. The marginal development of new leaflets, like the lateral development of new branchlets, is here reduced to a minimum, being arrested in its first stages.

There is a Comparative Anatomy of Plants as well as of Animals, which has yet been only indifferently studied. More careful researches are necessary in this interesting field. The gradual simplification of leaf-structure in the neighborhood of the flower, the result of a loss of vegetative energy in the leaf, and the antagonism of reproduction, is a fact in Vegetable 


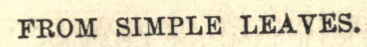

\section{PLV}
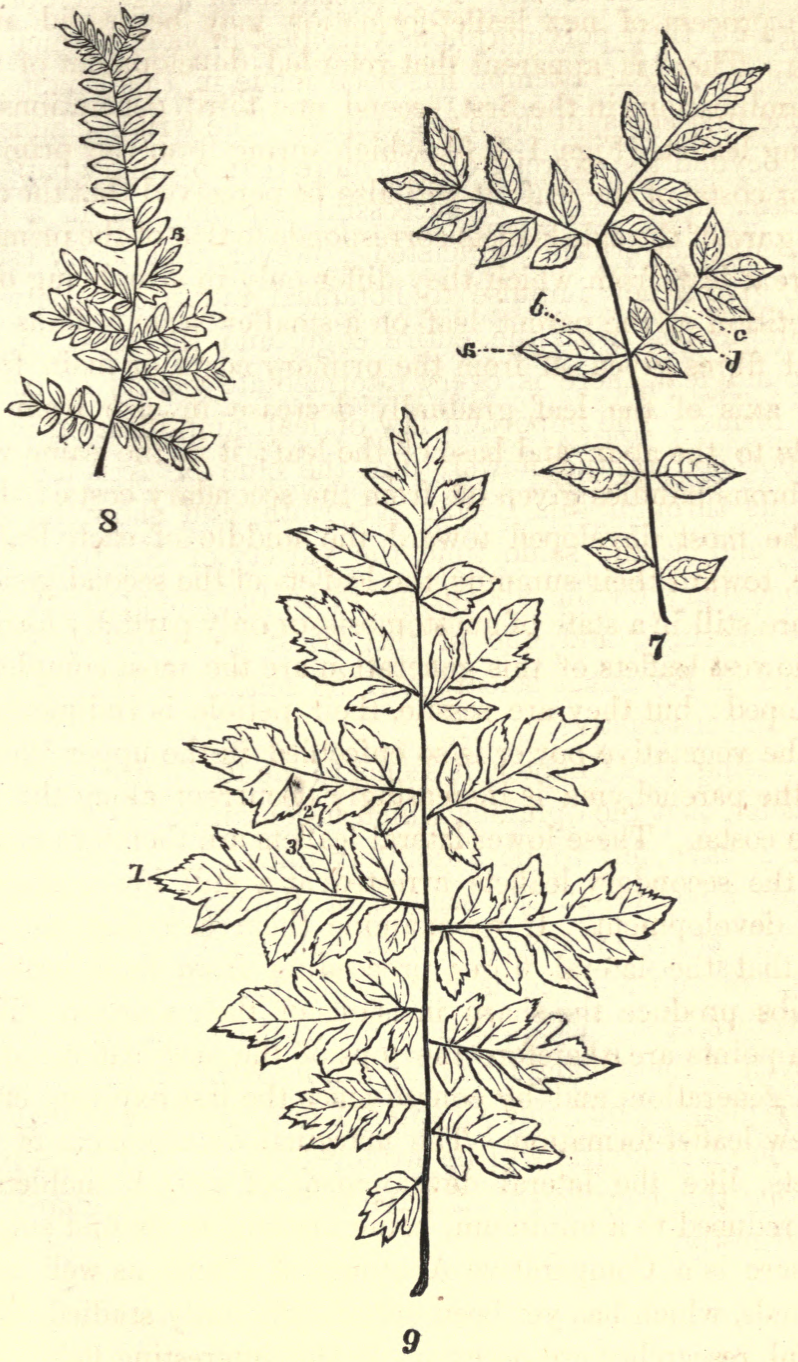
Morphology which has never yet been traced out to its legitimate consequences. It has an important bearing on our knowledge of leaf forms. It connects them with each other, through all their polymorphous varieties, in bonds which are indissoluble. An attempt has been made in this Chapter to take the first steps in these researches. The writer claims no credit beyond the exercise of that more than ordinary patience and care, so necessary to successful explorations in a new field. May the truths enunciated, however imperfectly established, give a new impulse to botanical inquiries. Between the simple leaf with the entire edge, and the most highly compound leaf, there is every intermediate variety of transitional forms. The important law of leaf simplification in the neighborhood of the flower, like the clue of Ariadne, will guide us through this Cretan labyrinth, and show the simplicity, and, at the same time, the variety of Nature. It is only necessary for the above law to be fully apppreciated in all its bearings, and one of the driest and most technical portions of Botanical science will be rendered deeply interesting and instructive.

In closing this Chapter, it seems to me to be proper to tell the reader, that the opinions which it contains are conclusions which I have felt to be absolutely unavoidable. They are certainly novelties in the science of Botany, the boundaries of which are very susceptible of enlargement, if a greater amount of self-reliance is exercised, patience is cultivated, and Nature is studied. These new truths are so interesting, that even if there should be only a minimum of scientific and literary merit about this Chapter, I have no doubt that the attention of Botanists will be attracted to the subject. I only hope that this may be so. I have written, I trust, guardedly and earnestly. 


\section{CHAPTER VIII.}

A SKETCH OF THE HISTORY OF THE CREATION AS RECORDED IN THE STRATA OF THE EARTH, SHOWING THAT THE TREES WHICH NOW COVER ITS SURFACE WERE NOT ALL CREATED AT THE SAME TIME, BUT WERE INTRODUCED AS THE EARTH BECAME FITTED FOR THEIR RECEPTION-TREES WERE CREATED IN SUCCESSION-THOSE OF A LOW TYPE OF ORGANIZATION ARE THE MOST ANCIENT INHABITANTS OF THE GLOBE-THE MORE HIGHLY ORGANIZED TREES HAVE BEEN INTRODUCED AT A COMPARATIVELY SPEAKLNG MODERN GEOLOGICAL EPOCH.

Just as a tree contains in the woody layers of its stem a record of its progressive life-history through the past years of its existence, so with the organism of the earth. We have recorded, in its strata, a faithful account of the progress of Creation, a history of those physical and organic changes which the earth has undergone, with this difference, that the time expended in producing them is to be estimated not by years, but by myriads of ages, periods of duration all but infinite - fragments of eternity. The History of Creation has, in fact, been written in the rocks, which may be regarded as so many separate volumes laid up in the library of Nature. To interpret correctly the language in which this history is written, requires the highest attainments in Natural History and Physics. It has up to the present time been only partially interpreted. The following facts have, however, been fully elicited.

All the elements which enter into the composition of the solid and fluid parts of the earth once existed uncombined, and in the gaseous form. The earth was, during this epoch, an immense sphere of gaseous matter. In the course of vast 
periods of time, the attractive forces gradually predominated over the repulsive, the nebulous matter condensed about a common centre, evolved heat and light, and the earth became a radiant star or self-luminous body. Another cycle of ages elapsed, during which there was a continual loss of heat from the surface by free radiation into the stellar spaces; and that surface was ultimately cooled down to the solid crust which now envelopes the fiery nucleus. The earth is therefore an opaque or dark body; and if these views be correct, it is an extinguished star.

About the time that the solid mantle of rock was formed through the cooling of the earth's crust, the air and water were probably separated, the atmosphere was charged with carbonic acid, and the clouds burst in violent showers of rain, originating a hot salt sea. The rind continued to grow thicker as the cooling process went on. In the meanwhile, it became necessarily fissured or cracked in many places, and an uneven surface thus originated, with elevations and depressions and openings, through which poured itself a part of the fiery contents of the earth's nucleus. The earth during this period was covered with an immense number of volcanoes, which were constantly engaged in throwing up showers of ashes, incandescent rocks and melted lava, thus increasing the inequalities of the surface, and forming, in connection with the operation of the boiling waters of these ancient seas, the laminated or slaty rocks known to Geologists as gneiss, micaslate, and talcose-slate. Their formation closed the first great geological period, the Azoic period.

Sublime and terrible must have been the scenery during this epoch; innumerable active volcanoes incessantly thundering, and illuminating the darkened heavens with their raging fires. In such a condition of things, it was impossible that organic bodies, animals and plants, should exist, and accordingly we find no traces of them in these ancient rocks.

In order for living beings to diffuse themselves over the earth, the temperature must be lessened, and an earthy soil must be created, on which plants can grow, and through them animals be nourished. Plants live on inorganic matter, on 
water, carbonic acid, ammonia, and certain salts; animals, on the contrary, require plants and other animals for their existence. Such a soil forms itself only in the course of ages, out of the underlying rocks. Through the chemical influence of the air, and the solvent and mechanical power of the rains, the rocky surface was gradually broken up, and the loose material was either left lying on the surface, or, driven along by torrents of water, was deposited in other places at a distance. Rocks composed of matter which has thus been deposited from water are called sedimentary rocks, and we find first in the most ancient of these rocks the remains of plants and animals, the so-called fossils.

The time occupied in the formation of these ancient deposits is called for this reason by Geologists the Palæozoic period, because they contain the first germs of higher organic forms, and are the repository of its most ancient life. The Cambrian, Silurian, and Devonian formations are the oldest historical rocks, and the fossils which they contain prove that the earth was at this time no Eden, but, on the contrary, a monstrous muddy swamp. Water appears to have predominated over the land. Among animals the fish held the highest rank. There was an abundance of shell-fish and corals, and a crustaceous swimming animal called a trilobite. The air contained a great amount of carbonic acid gas.

The plants belong to the Cryptogamous or flowerless division, and are decidedly low in organization. They consist of gigantic calamites, plants allied to the horsetail (Equisetum), ferns, and arborescent club-mosses (Lycopodium), called Lepidodendra-in fact, such plants as are found now in swamps, and whose size is at present very diminutive. An almost endless ocean yet covered the earth's surface. Only here and there an island was visible, rugged and torn, and which the first offspring of the young creation covered. Land was, indeed, created, and the waves of these ancient seas broke against the rocks as now, and plowed out for themselves gulfs and bays. In the interior of the earth the wild efforts and strength of the fire had, in some measure, abated. The vol. canoes were less numerous. Yet the blue heavens were not 
visible through the cloudy atmosphere. Dense vapors arose from the ocean, and fell in violent showers over the land, returning back to that reservoir in ten thousand roaring torrents. This period has been called by Agassiz the Age of Fishes. There were neither reptiles, birds, nor mammals then in existence.

Toward the close of the Palæozoic period, the earth appears to have presented the appearance of one vast archipelago, or collection of islands, and vegetation was developed on the grandest scale. It was during this epoch that the coal was deposited, as only on the coasts of tropical islands could such plants grow as are found fossil in the coal formation. The vegetable remains are mostly found, not in the coal, but in the accompanying clayey and sandy soil with which the coal is interstratified.

From these remains it can be proved that splendid forests grew on the boggy soil of these islands. Here elevated itself a tree fern, its summit penetrating the dark clouds which obscured the heavens; there, a gigantic lycopodium or club moss. Calamites and equisetaceæ were abundant; and, in addition to this, we find traces of coniferous plants, or plants allied to the Fir tree, and resembling the Norfolk Island Pine, (Araugaria excelsa.) Barren uniformity, however, marked the character of these forests. Only seven hundred and fifty plants are at present known to Naturalists, which were at this time diffused over the whole earth; whilst to-day, in Europe, one of the smallest dvisions of the earth, more than ten thousand species are known. The earth at the time of the stonecoal formation was yet too warm for the sun's rays to produce any essential influence on the climatic conditions. The temperature was pretty much the same all over the earth. Hence the stone-coal plants are the same, although found in countries thousands of miles apart. Even the poles of the earth were covered with a tropical vegetation, although now cooled down so as to be covered with a mantle of everlasting ice and snow. This opinion has been advanced by some Naturalists; but as light is nessary to the formation of plants, and as the poles are deprived of its influence during a part of the 
year, this opinion must be received with some degree of restriction.

The animals of the Stone-coal period resemble in many respects those of the preceding formations. The crustaceans have, however, improved. In addition to the trilobites, we have the horse-shoe crabs, and other gigantic forms. We also meet with traces of insects and scorpions. These appear to have been the only inhabitants of these swampy forests. No mammalia pastured beneath their shade; no birds warbled forth their melody, or nestled amongst the branches of these leafless, flowerless trees. Trees with true leaves and flowers had not made their appearance. The atmosphere was not yet fitted for their growth. With the exception of the Fir-trees, with their needle-shaped leaves, the vegetation was wholly cryptogamous, and decidedly low in organization. Every Botanist who examines the coal plants is necessarily impelled to this conclusion. There is no denying the evidence of the rocks.

The Palæozoic rocks, which contain the fossil remains of the first inhabitants of the earth, extend from the Cambrian formation as far as the Magnesian limestone, which lies above the coal, and, together with the Old Red Sandstone, constitutes the Zechstein formation of the German geologists.

A careful examination of the fossil remains found in these rocks, by the most distinguished Naturalists, has developed the interesting fact, that the first inhabitants of the world were a few sea-weed zoophytes and shell-fish, and that, throughout the whole of the immense period of time occupied in the formation of these rocks, vegetation did not advance further than the Coniferæ or Pine family, the highest rank of the animal creation being a low order of fishes.

The period immediately succeeding the Stone-coal era was characterized by great volcanic activity: the rocks were upheaved, and storm and annihilation swept over the islandforests of the Stone-coal landscape, millions of gigantic trees being buried beneath the raging floods.

The great amount of carbonic acid removed from the atmosphere by the luxuriant vegetation thus entombed, rendered 
the air purer and fitted for the respiration of a higher order of animals. At length appeared the first inhabitant of the land-a reptile! It is well known to Naturalists that in reptiles and fishes the venous and arterial blood become mixed together, the former being only partially returned to the lungs. The respiration in these creatures is therefore imperfect, or the blood is only partially oxygenated. Now, as the condition of the atmosphere was such as to furnish life only to reptiles, which do not require much oxygen, the presumption is, that carbonic acid was still the predominating element. Man would have been stifled at once in such a world. And this state of things appears to have continued throughout the whole of that vast interval of time immediately succeeding the deposition of the Palæozoic rocks, which is called by Geologists the Secondary Formation, and which Agassiz has very appropriately termed the "Age of Reptiles." This period includes all the rock-formations from the New Red Sandstone to the Chalk.

During all this time, the land was not continental, but the earth continued to exhibit the appearance of an archipelago of greater and smaller islands, which were generally without mountains, presenting a low, flat surface. Naturalists are forced to these conclusions by the consideration of the fossil remains of plants and animals contained in the Secondary rocks. This swampy condition of things undoubtedly prevailed throughout the early part of the Secondary era; but afterward elevated table-lands, mountains, and hills diversified the features of the landscape, the land continually encroaching on the territories of the watery element, which, nevertheless, still occupied the greater portion of the earth's surface.

Hence it is that the predominant forms are amphibious reptiles of monstrous size, which probably took their maximum development during the Oolitic period, creatures fitted to inhabit both land and water. The birds, too, appear to have been gigantic, and to have belonged to the class of waders, which at present tenant low, swampy grounds on the margin of rivers and bays. This is proved by their long bones and immense strides. Professor Hitchcock discovered 
the impression of the feet of the wading birds in the New Red Sandstone of Connecticut. These impressions are some of them eighteen inches in length and five feet apart, so that the birds making them must have far exceeded in size the largest African ostrich. All traces of mammalia are totally absent from the New Red Sandstone, the Muschelchalk, and Keuper, and are first found in the slates of Stone fields, in the upper stages of the Oolitic formations.

The plants found in the Secondary rocks must be regarded as a flora intermediate between the plants of the Palæozoic rocks and the Tertiary formation. Ferns and club-mosses are not so abundant, and less gigantic in their growth; and, in addition to these, we meet with a great number of Coniferæ and Cycadaceæ, or plants allied to the Cicas revoluta, or Sago Palm, which is a common though somewhat costly ornament of the conservatory. The stems of the Cycadaceæ reached at this time a height of from four to thirty-six feet, for stems as long as that have been found; but at present three feet is the maximum length of the stems of these plants, which are not so numerous as formerly, as they have been to some extent superseded by the Palm, a plant which is related to them but far more highly organized.

We have clear proof, from vegetable remains found in the Lias and Oolitic rocks, of a landscape diversified by hills and valleys. The remains of Pine-trees, which usually develop on a dry, poor soil, are found, along with the fruit and leaves of Zamias plants belonging to the Cycadaceæ, which require moisture and heat in order to grow, by which we are forcibly reminded of a hilly if not mountainous landscape within the tropics. The Pines would grow on the hills, or elevated lands of the islands, which were probably wooded to their summit, whilst the Cycadacex, the ferns, club-mosses, and horse-tails, would grow on the low lands which surrounded them.

In the Chalk rocks especially are the vegetable remains interesting. We find here the remains of plants with true leaves, and the first trees of this kind turn out to be Willows! which it is well known will develop in a poor soil provided 
there is the requisite amount of moisture. In addition to the leaves of the Willow, those of the Elm and Maple trees have been found. We also meet with fragments of dicotyledonous wood, marked by perforations of marine animals.

With the Chalk we close, as it were, the second great series of volumes of the history of the animal and vegetable creation. Every thing up to this point belongs to the past. The fossils, both animal and vegetable, all belong to species no longer in existence; they are the fossil remains of extinct species. With the commencement of the Tertiary formation a new condition of things obtains, and new forms of life make their appearance, beautifully adapted to the ever-changing landscape, some of them belonging to species now in existence, and occupy the places of that organized life which has forever passed away.

We have shown that in the earlier periods of the earth's formation the climate was nearly uniform over the whole earth, because it was not determined by the sun, but by the interior heat of the earth. In the Secondary epoch the influence of the sun was hardly yet felt, although the earth had so far cooled as to be more susceptible to outward influences, and the atmosphere had become, comparatively speaking, clearer and more pure. But at the time of the formation of the Tertiary beds, the earth had cooled to such a degree that the effects produced by its internal heat had almost entirely ceased, and the heat received by its surface was mainly derived from the sun. Then arose that diversity of climate which is characteristic of the present creation. The sun gradually acquired his rightful empire over the world, and all Nature became dependent on his kindly influences.

The poles of the earth, which obtain the least amount of sunlight, were necessarily cooled more rapidly than the beds of land at the equator, where the greatest amount of light and heat is received, whilst the zone intermediate between the polar and equatorial regions, where the conditions calculated to develope a superior race most abound, became, in course of time, fitted for the reception of humanity, science, and civilization. 
With this gradual increase in the variety of the external conditions, the dull uniformity of former creations passed away; and as the difference of temperature in the several regions of the earth slowly increased, there became gradually organized that immense variety of animals and plants which now occupy the air, the earth, and the water.

Hence it is that the Tertiary fossils consist of the remains of species now in existence, intermingled with such as have become extinct. Sir Charles Lyell, the English geologist, has proposed a classification of the Tertiary beds, based on the relative proportion of extinct and recent species found among the fossils of each formation, which has been generally adopted. He divides the Tertiary group into the Eocene, Miocene, and Pliocene formations. These three words originate from the Greek. Eocene is derived from Gr. eos twilight and kainos recent, which designates very beautifully the commencement of this new geological period, as the morning rays of the present creation. Miocene from Gr. meion less, and kainos; and Pleiocene from Gr. pleion more and kainos.

It is probable that there was very little ice formed in the northern hemisphere until about the close of the Tertiary epoch; because the plants found in the Tertiary beds clearly indicate the prevalence of a much higher temperature within the temperate zones than that which now exists there. Both London and Paris stand on the Tertiary strata. The same formations are also met with in Hampshire, and in the Isle of Wight, England, and in the South of Europe, Asia, and America.

The plants found in the Tertiary beds are totally different from those which are obtained from the Palæozoic and Second. ary rocks. The land appears to have been richly clothed with a vegetation not very different from that which prevails in warm climates at the present day. The leaves of the EIm, Maple, Beech, Poplar, Oak, and other modern forest trees have been found; also pieces of wood which present the structure of pepper plants and palms. The fossil plants of the Isle of Sheppey, which is situated near the English coast, have been examined by Bowerbank, and have led to the determination 
of several hundred species of plants, all of them extinct, and all resembling plants of warmer climates.

During these geological periods, the marine or amphibian reptiles of the Secondary rocks were replaced by numerous mammalia of enormous size. This era has therefore been called by Agassiz, the "AgE of Mammals."

If we would form for ourselves an idea approximating to a true conception of the appearance which the earth presented during this era, we must consider the land as still partially insular, or a loosely-connected group of islands, covered with low volcanoes. The problem, what is it? To unite more and more the solid land and to restrain the oceanic life. Through the influence of air and light shall the life on the land be increased, and the life developed by the waters be circumscribed; and through the influence of a diversity of climate, a greater variety in creation shall be produced, and thus the regular powers of Nature be brought to work together harmoniously.

The climate of the northern hemisphere, which had been, during the Tertiary epoch, considerably warmer than now, so as to allow the growth of palm trees in our present temperate zones, became much colder toward the end of that period, in consequence of the gradual accumulation of snow and ice at the poles. The ice formation began manifestly about this time, for as we go further back into the history of the earth, through the Tertiary deposits to the time of the Chalk formation, we find neither erratic blocks, nor any indications of the marks of glaciers; on the contrary, the proofs become more and more apparent, that the earth in these earlier epochs was much warmer than it is at present. Hence the appearance of ice at the poles and on the summits of mountains must be regarded as comparatively speaking a recent event in the history of creation, and is contemporaneous with some of the last revolutions to which the earth has been subjected.

The glacial or ice period is considered to have produced those numerous detached fragments of foreign rocks which we find scattered over the surface of the soil, and which are known under the name of erratics, boulders, or grey-heads. These drift materials are called Diluvium, as their transporta- 
tion to their several locations was erroneously attributed to the Noachian deluge, which name they nevertheless still retain, although it is now certain that they have been conveyed thither by icebergs, or glaciers, which have been borne by the currents of the ocean southward from the poles, or have descended from the summit of the mountains into the adjacent valleys. These glaciers are always loaded with heaps of gravel or blocks of stone, and as they come down from the regions of perpetual frost and snow into warmer countries, the ice necssarily melts, and the gravel and blocks are left lying on the earth's surface.

The commencement of the Diluvial epoch was probably ushered in by the volcano and earthquake. The sea showed its gigantic power, covering with its waves the land, which was now torn and uplifted into mountain chains, whose lofty summits were whitened with the snows of a perpetual winter. The glaciers or deposits of snow on these mountains descended much further into the valleys than at the present time, and the polar glaciers probably advanced further South. The temperature of the North pole was about the same as the present temperature of the South pole, which is described by all Arctic explorers to be the most inaccessible.

The prodigious forces then called into exercise at this era are seen in the unusual majesty of these mountain chains; forces, in comparison with which, the physical power put forth by the mightiest nations of the earth is as the feebleness of infancy.

When volcanoes thunder and blaze-when earthquakes rend and pile up granite rocks above the region of the clouds, in such a presence shall mortal man boast of his exertions of physical power? What mathematician can even begin to calculate the vast forces of nature which have been called into exercise in the formation of a mountainous landscape? Stand under the uplifted rocks, and contrast the mightiest displays of human power with these exhibitions of the secret energies of Nature! Amid such manifestations of Almighty power, humility of mind and silent adoration is true philosophy. To a mind capable of appreciating these forces in their grandeur, 
such a state of feeling is the inevitable result of these sublime "Aspects of Nature."

The annual melting of the snows on the summits of the mountains furnished perpetual supplies of water, which in the form of springs, rivulets, or mountain cataracts, descended to lower levels, irrigating the richly-wooded valleys; or a thousand little tributary streamlets, which are always governed in the directions which they take by the inequalities of the ground over which they move, all poured together their tributary waters, until finally they formed the great rivers of the earth which now perpetually roll along to the ocean. Many of the animals of this period, such as the hyena and bear, lived in caves. In the famous cavern at Kirkdale, in Yorkshire, England, "parts of the skeletons of from two to three hundred hyenas have been detected, mixed with portions of the osseous framework of the cave-tiger, the cave-bear, the ox, the deer, the mammoth, and the rhinoceros."*

So far no human remains have been discovered, no skeletons except those of the hitherto irrational denizens of the earth. Human skeletons are only found in modern fluviatile and ma. rine deposits, along with the bones of the existing species of animals, and of the leaves and branches of plants now growing on the earth's surface, or they occur in those ancient repositories of the dead called, by antiquarians, barrows or tumuli. Man is therefore, comparatively speaking, a recent creation.

The occurrence of human skeletons in modern fluviatile deposits, accompanied by coins and works of art, the preservation of the bones of the existing species of animals, and of the leaves and branches of plants now growing on the earth's surface, in the various geological formations now in progress, shows the immutability of Nature, and proves that the same enduring monuments of the present state of things will be transmitted to future ages as we possess of the former conditions of the earth.

The earth was created for man. To him the whole of these changes point from the first appearance of life in the Palæozoic

"The Testimony of the Rocks," by Hugh MiLler. 1857. 
rocks. His first appearance, which is thought to be so mysterious, is no more difficult to understand than the appearance of any other organism. He was introduced at the time when the earth was ready for him. His existence on the earth, if it is to be accounted for scientifically, is a question of Natural History, which at present is not sufficiently advanced to explain the introduction of any of the forms of life which have appeared at the several geological eras. He is undoubtedly the noblest which has yet tenanted the earth, the crown of the creation; and as his appearance is quite a recent event, and the earth has been so many ages preparing for him, the probabilities are that it will continue to endure for myriads of ages yet to come. The conviction of the constancy of Nature deepens with every footstep which is taken in physical investigations. The system of things is perpetually changing, yet the laws which govern these changes remain invariably the same. When viewed by the light of the eternity that is past, or seen through those vast periods contemplated in Geology, the land loses its attribute of fixity and becomes as movable as the ocean. These grand and more worthy views of the Works of the Creator are the result of the investigations of Science. It is not stating more than is strictly true, when we affirm that there is physical proof in the rocky strata of our globe, and the organic remains which they contain, of changes which must have taken thousands of millions of years to bring about, and this necessarily impresses on the mind the conviction that Nature will remain subject to the same laws for myriads of ages yet to come. Why should we doubt the constancy of Nature through coming duration, when she has left us such irresistible proof of her invariability through the eternity that is past?

"The study of vegetable fossils," says Professor Henfrey, "is far less satisfactory than that of animal remains, since, in the great majority of cases, the structures most distinctive of the subordinate groups of plants are formed of very perish. able matter. Genera and even species of animals may be recognized by bones and shells, which are of a very persistent nature, and are found abundantly in stratified rocks. The, 
vegetable bodies which can resist the long-continued action of water are few, and these mostly afford only characters of large sections of the Vegetable Kingdom, without furnishing generic, far less specific distinctions."

It is therefore probable, that the fossil plants which have hitherto been found, only partially represent the floras of these remote ages; and there is no denying that ideas obtained from fossil plants, must be necessarily superficial and very speculative. But there is a sufficient amount of evidence furnished by them to show satisfactorily that the first plants did not originate frrm seed but from spores. They were undoubtedly Cryptogams. And the first land plants were certainly swamp plants. Mosses, fitted to live in water as to-day Bog-mosses are accustomed, gigantic Calamites and Lepidodendra. For ever since land existed there have been plants of tree-like proportions and bulk. It is not necessary that there should be a rich and varied flora for this result to be produced. Were there no other plants in existence now but those belonging to the Natural Order Rosaceæ, we should still have herbs, shrubs, and trees covering the landscape. The yellow cinquefoil (Potentilla Canadensis), and the wild strawberry (Fragaria Virginiana), are lowly herbaceous plants; the common blackberry (Rubus villosus), and the swamp rose (Rosa lucida), are shrubs; and the apple, pear, plum, and cherry are the fruits of trees, yet the whole of these are Rosaceous plants. Therefore, notwithstanding the great sameness of the plants which covered these ancient landscapes, they were not without their trees.

As the land became more elevated and free from water, Cycadaceæ, Coniferæ, and a plant allied to the Pandanus or Screw Pine of the tropics, were added to these primeval forests; then Dicotyledonous trees with true leaves, such as the Willow and Maple, and along with them we find the first evidence of the creation of flowers, for Nature is always consistent with herself, flowers being, as is now universally admitted, nothing but the ordinary leaves of the stem, brought together in consequence of a loss of vegetative power in the branch on which they are borne, and metamorphosed with reference 
to the reproductive function. The first bee makes its appearance in the amber or fossil resin of the Pines of the Eocene period; the fragments of the wings of butterflies and other flower-sucking insects are also frequently met with enclosed in the same substance. Dicotyledonous trees of a low order of organization, such as the Birch, Beech, Oak, Poplar, Chestnut, and Hornbeam, were probably as abundant in the forests of the Eocene period as they are now in our present woods. But there is no proof of the creation of Rosaceous plants. These seem to be coeval with the first appearance of man.

Our forest trees were therefore not all created at the same time, but are the product of different geological eras; and the present plant-covering is only a fragment of many antecedent plant-creations. Coniferous trees with needle-shaped leaves, such as the Pine, Fir, and Larch; also Ferns, Horsetails, and Club-mosses, are among the most ancient and persistent types. They have descended down to us from the oldest periods of the creation. This remark applies especially to the Natural Order Coniferæ, which from the most ancient times even until now, in new varieties and splendors, has continued to develope. The first flowers among herbaceous plants appear to have been land and water lilies, and plants belonging to the Natural Order Ericaceæ or the Heath tribe, such as the Whortleberry (Vaccinium), and the Alpine Rose (Rhododendron). Among trees bearing true leaves and conspicuous flowers, the Tulip Poplar (Liriodendron tulipera), appears to be an ancient forest form, so also trees belonging to the Natural Order Leguminosæ or the Pea tribe, such as the False Acacia (Robinia Pseudo-Acacia), and the Honey Locust (Gleditschia triacanthos). These trees all preceded Rosaceous plants in the plan of creation. Trees bearing edible fruits, as well as beautiful blossoms, such as the Peach, Apricot, Apple, Pear, Plum, and Cherry, were introduced when the earth was fitted for the reception of man, their remains are only found in the modern Geological formations now in progress, and therefore like him they must be regarded as among the recent creations.

The most important fact taught by this Geological history of the plant world, is that the organic and inorganic creation 
slowly assumed its present appearance, and the evidence would seem to lead us irresistibly to the conclusion, that changes have taken place in the organization of plants, by which their forms have been gradually and contemporaneously adapted to the ever changing landscape. Hence the history of the development of plants is intimately associated with the history of those physical changes which the earth's surface has undergone. Just as the present form of a grand and venerable tree, which appears to us to be fixed, but in reality is as fleeting as all the other forms through which that tree has passed from its first life-movement in the seed, is the final result of a long series of antecedent changes, so with the globe which we inhabit. The present appearance or, more truthfully speaking, phase of creation, is the necessary result of a long succession of antecedent changes of which the earth's crust has preserved the memorial. This world, what is it but a great and ancient theatre, where the scenery of life is ever changing? And who dare say that the present arrangements of land and water, the forms of our modern forest trees, and of the entire animal creation, sra sow any more fixed and unalterable than at any previous epoch? Nothing on earth is permanent, if there is any truth in the teachings of the past, and any constancy in Nature.

When a traveler at the foot of a mountain in the tropics ascends toward its summit, he remarks the same change in the features of the landscape as in advancing from the equator to the poles. In both instances he finds that the temperature declines, that water, whether in the form of vapor or fluid, changes to eternal ice, and with this loss of heat the vegetable kingdom diminishes and becomes substantially altered. The plant-covering of the earth, from this point of observation, may therefore be regarded as a living geographical thermometer. The condition of vegetation at the equator and the poles form in this respect a striking contrast. At the equator the quicksilver in the tube of the thermometer reaches its maximum elevation; at the poles it is depressed to a minimum. So with the vegetable kingdom. At the equator, its types reach their highest expansion; the stem, leaves, and 
flowers of plants are gigantic, and their colors are splendid and dazzling. At the poles, the plants sink down to the condition of dwarfs; their foliage is tough and coriaceous, and of a dark and sombre green, gloomy as the long night of the polar world. In some cases even here the northern lights, and the reflection of the wonderful midnight sun, produce in some of the plants an unexpected splendor of coloring. In the steady light which comes from the sun as he circulates about the horizon for weeks, the grasses and other plants assumed a softened green. But far purer and higher are the colors of the flowers. The Trientalis and Anemone, which in temperate climates produce white flowers, steep themselves in the beams of the midnight sun of the deepest red.

Now if the organism of the plants thus varies on the earth's surface, from the valley to the mountain summit, and from the equator to the poles, then it is plain that any physical revolutions which shall, in the course of ages, change the features of the land, must at the same time produce a change in its flora. We know that when forests are cut down in America, the plants which grew beneath their shade become exhausted and die out; so, also, swamp plants and trees disappear when the soil is drained of its superfluous water. Would not the same results take place if such changes were brought about in the course of ages through the operation of the ordinary forces of Nature? It is certain that land cannot be first elevated and then depressed below the surface of old Ocean, without great changes in temperature, and that many species would in this way naturally perish when the conditions became unsuited to their growth. Fossil plants may be truly regarded as the remains of a system of vegetable life, developed under external conditions which are no longer the same in any part of the world.

But there are indestructible organic features which connect the flora of the present with that of former ages. Not only individuals, but even species, genera, and whole orders, have perished; but there prevail, in the present Creation, forms or types which existed in the most remote geological periods. This proves indisputably that there are certain persistent 
features in plants which have not been affected by the physical revolutions which the earth has undergone. Surely there is nothing unreasonable in believing, that in such cases there is, to a certain extent, power given to vegetable matter to adapt itself to a gradual change of circumstances. We know that great changes may be effected in a brief space of time in the organization of plants by cultivation, or a change in their external circumstances, and why should not an organic change be brought about in plants when their external circumstances are altered by Nature in the course of ages?

"If," says Prof. Draper," "we expose some spring water to the sunshine, though it may have been clear and transparent at first, it presently begins to assume a greenish tinge, and after a while flocks of green matter collect on the sides of the vessel in which it is contained; in these flocks, when. ever the sun is shining, bubbles of gas may be seen, which if collected prove to be a mixture of oxygen and nitrogen, the proportions of the two being variable. In the mean time the green matter rapidly grows; its new parts, as they are developed, being all day long covered with air bells, which disappear as soon as the sun has set. Similar green flocks to these of which we speak, are also found on the surfaces of rocks exposed to the sea, damp walls, and other places where there is constant moisture. These plants belong to the Algæ or sea-weed tribe. This green matter thus formed is produced from the gaseous matter, Oxygen, Nitrogen, and Carbonic acid, contained in the water in a state of solution. It is necessary, however, to admit the existence of some germ or objective-point on which the light can act. As we have already said, a bubble of gas soon makes its appearance, and growth with the development of the green color takes place. If we examine the changes now occurring in the water, we find that the Carbonic acid is disappearing and Oxygen and Nitrogen are evolved. Contemporaneously with the development of this green matter that of animal life begins, and thousands of aquatic animals are formed which live on it as food.

* "A Treatise on the Forces which produce the Organization of Plants," by JoHN W. Draper. 1844. 
Hence it is the object of vegetable matter to form from inorganic matter, organic molecules, as food for animals."

In a similar manner, probably, originated in old Ocean the first plants. Scarcely were the solid parts of the earth created, than the procreative power of its organic germs was called forth. Vegetable life was at first entirely aquatic, then amphibious, and lastly terrestrial. It was the same with the animal world: first fishes, then swamp reptiles and aquatic birds, and lastly land and air life-mammalia and man. So plants must have been created before herbivorous animals, and these last before those carnivorous races which prey upon them, and the whole of whose habits, instincts, and organs are most wonderfully and beautifully adapted for their destruction as sources of food. Lastly appeared man, Omnivorous. So, from the first plant to man-creation is one continuous chain; and the present glorious and variegated vegetable carpet which covers the earth, with its beautiful flowers and grand forest trees, is only a fragment of former plant-creations which have been conducted on plan and system by a Providence whom mankind must learn to look up to as THE UNIVERSAL FATHER. A proof that, in the whole of Nature, all creatures are continuous and inseparably connected with each other, so that the earth, with all its living forms, constitutes one entire whole, in which each plant and animal has its place, which it necessarily occupies and fills.

It seems therefore plain that the earth, with its atmospheric covering, its continents and ever-sounding seas, with all their rich variety of life, is as much an organism as any tree on its surface. There is the same continuity and mutual dependency of all its parts, the same system of perpetual change on its surface, and the same record of its progress and past changes preserved in its interior.

Reader, if you cultivate a garden, as I hope you do, you can see the beginning and end of the lowly plants growing around your dwelling, and you know that they put forth a regular cycle of organic appendages, of leaves, flowers, and fruits; and it is the same with the forest trees, whose lifehistory covers a longer period of time. Now if the cycle of 
changes which form collectively the life of a flower or tree are conducted on a plan and system, why not those of this world? Does it not necessarily follow, when all Nature is thus bound together in adamantine links? I confess to you, reader, that this assemblage of facts connected with the development of life on the surface of our planet, this mutual dependency which pervades all Nature, and this order and mechanism which ever surrounds me, inspires me with the profoundest of all convictions, that there is plan and system pervading the whole of these onward movements. I have thought on this subject until I feel myself to be a part of Nature, linked on the one hand with the lichen on the rock, and, on the other, with the most distant star, for I know not where to break the chain.

I am connected with the whole of Creation, and with a system of things conducted on a plan so vast that I see neither the beginning nor the end.* I know that the parts of a tree are put together with matchless skill and beauty, and my impression is, that things are just as well and wisely ordered in this world. We meet with much that is dark and distressing in life; but let us place a cheerful trust in Divine Providence, and rest assured that ALL IS FOR THE BEST.

For my own part, I have been very happy in tracing out these beautiful harmonies in Creation. Nature is a library from which no man can be excluded. I have come to look upon her lowly flowers and lofty trees as my books. Seated beneath some shadowy beech or venerable oak, I have an infinite variety of choice volumes in the flowers spread at my

* "The Author of Nature has not given laws to the Universe which, like the Institutions of man, carry in themselves the elements of their own destruction. He has not permitted in his works any symptoms of infancy or of old age, or any sign by which we might estimate either their future or their past duration. He may put an end, as he no doubt gave a beginning, to the present system at some determinate period, but we may safely conclude that this great catastrophe will not be brought about by any of the laws now in existence, and that it is not indicated by any thing which we perceive."- "Illustrations of the Huttonian Theory of the Earth," by John Playfair. 1802. 
feet. I take out my note-book and make my extracts. And I always feel happier when returning from reading my books in my library, for I can always find something new in them.

"Nature never did betray

The heart that loved her; 'tis her privilege

Through all the years of this our life to lead

From joy to joy; for she can so inform

The mind that is within us, so impress

With quietness and beauty, and so feed

With lofty thoughts, that neither evil tongues,

Rash judgments, nor the sneers of selfish men,

Nor greetings where no kindness is, nor all

The dreary intercourse of daily life,

Shall e'er prevail against us, or disturb

Our cheerful faith that all that we behold

Is full of blessings." 


\section{CHAPTER IX.}

Change Which takes place in the constitution of TREES AT THE PERIOD OF PUBERTY, ORGANIC METAMORPHOSIS OF THEIR LEAVES INTO FLOWERS AND FRUIT, AND RELATIVE PHYSIOLOGICAL RANK OF THE FLORAL ORGANS.

HITHerto our remarks have been confined entirely to the vegetative stages in the development of the tree; and therein we have endeavored to point out the interesting fact, that it is a plant of a highly compound nature, built up by the labors of simple individual plants or phytons, commonly called leaves. At first a certain number of these leaves associated together form individual plants of a higher order called shoots; then these shoots, by reproduction and association of themselves, produce in the same manner plants still more highly compound, called shoot families; next, these families of shoots, developing about a common axis, form branches, and finally these branches unite together in one common trunk, and thus construct the one individual Tree, which is therefore the last and most highly compound plant in the series, and the noble descendant of an unbroken line of ancestors, of which the first phyton or leaf, nourished to maturity by the nursing leaves, was the lowly but illustrious parent.

Now, among the numberless shoots and branches of a tree, a great many retain, through all the stages of its life, their purely vegetative character; and their phytons or leaves, without ever experiencing any further metamorphosis, oscillate forever between the two opposite conditions of leaves and bud scales. The leaves of the remainder, however, are carried forward to the highest stage of vegetable metamorphosis, that of flowers and fruit. This takes place generally (152) 
after the vegetative powers of the main stem and its branches have been exhausted by the development of branchlets and twigs; for, as a general rule, anything that checks vegetation increases the tendency to reproduction.

It has been proved, in Chapter VI, that the vegetative powers of the whole tree, in common with those of each leaf, shoot, and branch, have a period of acceleration and retardation like the rising and the falling of a wave. It is at that period, emphatically called the "change of life,"-when these powers have just passed their culminating point, when the vegetative vigor of the tree begins gradually to decline,- - that we notice a peculiar alteration in its habits and structure, for the sap of the tree is no longer totally expended in the formation of new shoots and leaves, but partly in the production of flowers and fruit.

In herbaceous -plants, no flowers manifest themselves until the organization has first acquired the degree of strength which is necessary to produce them, by passing through a certain series of vegetative stages. The time required for this purpose depends upon the peculiar constitution of the plant: in some, a few days or weeks is all that is necessary to form a vegetative foundation for the flowers: the stage of puberty is reached, and the plant unfolds its flowers, forms its seed, and then dies.

This is the case with some of our native annuals, such as the Whitlow Grass (Draba verna), which covers the ground with a profusion of small white flowers, through the months of March and April. I have always felt an especial interest in this plant, on account of the beauty and simplicity of its organization, and the brevity of its life. The radical leaves, which are disposed about the scape, or flower-stem, in a stellate manner, make quite a graceful appearance on the ground; the scape itself rises from their centre to a height varying from one to three inches, and supports from eight to twelve small white flowers, which form little, smooth, ovate-lanceolate seed-pods. This lowly plant lives about two or three weeks; it then 
passes away, and other flowers occupy its place. Its form is seen no more until the cold, moist conditions of the early part of the year again prevail. Then, from those germs which Nature ever carefully preserves, it again springs into being to perform its allotted part in the great organism of the Universe.

In works on descriptive botany, it is usual to employ certain signs to designate the different duration of plants. These signs are those used by astronomers to represent some of the heavenly bodies. Thus, annual plants are represented by the sign of the sun $\omega$, because the earth revolves around that star in a year; biennial plants by the sign of Mars $\delta$, because that planet performs its revolution about the sun in two years; perennial plants by the sign of Jupiter $\varkappa$, because Jupiter is nearly twelve years in going round the sun; and ligneous plants by the sign of Saturn $々$, whose revolution about the sun is accomplished in about twenty-nine and a half of our years.

Now, herbaceous plants, whether annuals, biennials, or perennials, like the trees which overshadow them, during the vegetative period of their life, ramify and branch; and there is the same continual loss of vegetative power by their branches from generation to generation until the ramifying power is exhausted; so also their branches, like those of trees, are only repetitions of the whole plant on a smaller scale. Their branches, however, differ from those of trees in this particular, that they are without the folia tegmentia, or covering-leaves, and have therefore, no means of security organized to protect them during the winter months. To herbaceous plants, a humbler task has been allotted in the household of Nature. It is not her intention to preserve them, or consolidate their fabrics, and therefore the frosts of winter are permitted to despoil them of their beauty, and to sweep them into one common grave. Their branches develope from what Henfey has very properly called "open buds,"-one, two, and sometimes even three generations being formed during the same season. This necessarily rapidly exhausts the vegetative powers of the organism, 
calls forth more speedily the reproductive energies, and brings the life of the plant to an early close. If the plant is an annual, the whole organism perishes the first year; but if it be a perennial, the part of the organism developed into the atmosphere alone dies: for, as we have seen, it is without the means of protecting itself against the inclemency of the weather; but the part of the organism still below the soil is protected, and lives securely sheltered by its friendly covering till warm weather comes again, and then from that still living underground rhizome, or subterranean stem, the same plant springs forth in the renewed beauty and freshness of youth, to go through the same brief but interesting life-changes.

It is otherwise with ligneous plants, such as shrubs and forest trees; in them we see the working of the same natural laws, but in a somewhat modified manner, and on a far grander scale. It is the intention of Nature, in the case of trees, that her work should be preserved, and therefore she seeks to consolidate their fabric, by the preservation, through the winter months, of the amount of work done by the leaves of each season. In trees, under ordinary circumstances, only one generation of shoots is produced in a year, and these shoots do not branch any further than the formation of buds in the axilla of their leaves. These buds, or vegetative points, are always more or less perfectly formed by the leaves before the tree becomes defoliated. Like the original seed out of which the whole tree has been gradually developed, they individually contain, in an embryonic condition, a shoot and leaves precisely like the first year's growth from the seed.

An additional set of organs, usually called bud-scales, is therefore furnished to trees, in order to protect their young rudimentary branches. These I have ventured to call in this work, folia tegmentia, covering-leaves. These leaves are assisted in their protective function in some instances, by a covering of hard, dry varnish; and, in not a few cases, they have, internally, a warm, woolly lining. Every pore is thus sealed up, and the atmosphere of winter 
carefully excluded. Under such circumstances, the numerous fully-formed embryo-growths of the next year on the branches, are as secure under the covering-leaves of the bud, as was the solitary embryonic shoot and leaves of the first year under the wrappers of the seed.

To the tree, as well as to the annual, winter is the season of rest; and exhausted vitality, in both instances, has time given for recuperation. In annuals, the exhausted vitality of the roots, stem, leaves, flowers, and seed-vessel, or pericarp, retires into the seed; and, as the whole plant perishes, these seeds become detached from it, and the embryos which they inclose develope into new and separate plants on the soil. But in trees the exhausted vitality, not only of the leaves but of the new layer of bark and wood-cells, which they have constructed (see page 64 ), retires into the buds, from which the new plants develope on the return of Spring. Now, although there are cases amongst herbaceous plants, as for example, Lilium bulbiferum, in which axillary buds are formed by the leaves which become detached from the stem and grow into separate and independent plants on the soil, no such instance occurs in trees. The buds of trees, formed by the leaves of each season, do not separate from the tree; and hence the new plants which they contain, remain organically united with each other about a common axis. This is the reason why the vegetative period in trees is so greatly prolonged, and why they attain such a superior altitude and spread. They rest each winter, and through perennial associations of new growths, Nature carries on her work much further than in herbaceous plants. Trees are, therefore, composite plants, developed on the grandest scale. They cover a far greater extent of ground than herbaceous plants. Hence their giant forms, when gathered together into communities, are most strikingly seen in the landscape pictures of the earth. A firmer, more enduring foundation is thus laid, in the organism of trees, for the exercise of the reproductive function; and when once the state of puberty is reached, they are necessarily covered with the utmost profusion of flowers, and 
continue to flower and fruit for a number of years, without showing any signs of decay, or any indications whatever of diminished vitality.

Each species of tree, however, has its own period of time during which it vegetates, so as to gain the requisite strength for reproduction, although the time varies with the favorable or unfavorable circumstances in which the tree may be placed, such as suitable soil, and exposure to the sun's influence. The following examples will illustrate the difference in the maximum growth and age, at the time of flowering, of some of our principal trees :-

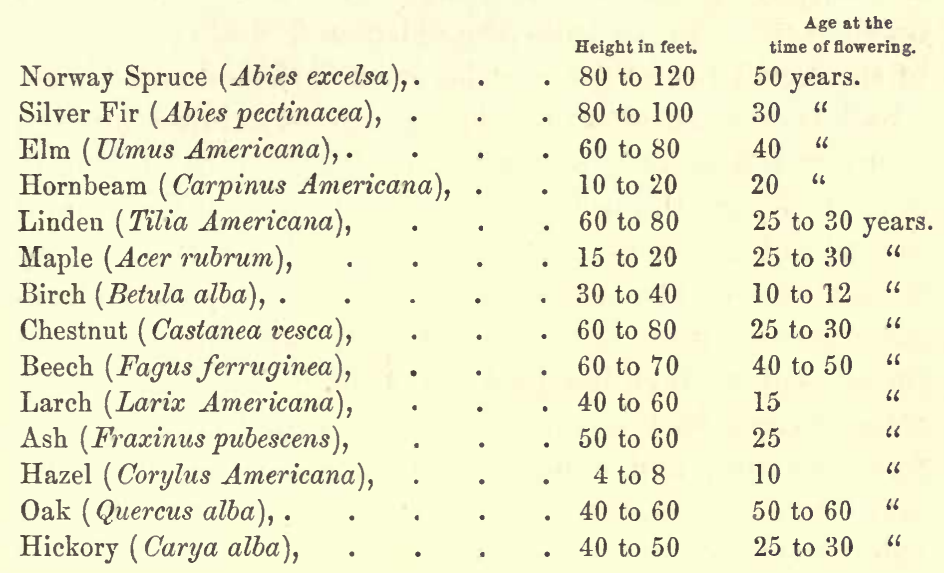

The above numbers give the mean ages and height of these trees at the time of flowering under the most favorable conditions, especially where the tree has plenty of room for development, and the soil is suitable.

In trees, as well as in herbaceous plants, vegetation is checked by reproduction. Those branches which are destined to exercise this function, take, at this time, a short, stunted appearance, growing only a few inches or lines in length in the same time that they formerly grew as many feet; the bud-traces on the outside of the branches (gemma vestigia), the intervals between, which mark the annual growths, thus become crowded together. Ulti- 
mately, the branches ccase to elongate altogether, and the leaf-buds become metamorphosed into flower-buds. When these flower-buds unfold themselves, they disclose a number of leaves totally different in appearance from the ordinary stem-leaves,-certain changes having been made in their structure by which they are adapted for reproduction.

As in the flower, the vegetative powers of the leaves are reduced to zero, the axis of the floral leaves necessarily retains its rudimentary condition, and no intervals of stem form between them; they therefore remain crowded together into a sort of rosette, analogous to that which is formed by the ordinary stem-leaves, which remain in clusters without metamorphosis when the branch or axis to which they are attached continues undeveloped.

If we examine the leaves which have been thus converted into floral organs, we shall soon be satisfied that, despite of the various forms under which they present themselves, they are identical with the ordinary stem-leaves, and that the alteration in their appearance is the necessary consequence of the gradual expiration of the vegetative powers of the branch on which they are borne.

In many plants, - those with axillary inflorescences, as, for example, the moth mullein (Verbascum blattaria), where the primary axis remains permanently vegetative, and where the buds formed in the axilla of the upper leaves are metamorphosed into flower-buds, the passage of the ordinary green leaves of the stem into bracts or floral leaves, is so gradual, that it is impossible to distinguish between the bract and the leaf; and, in like manner, the bracts slide, as it were, almost imperceptibly into the sepals or leaves of the calyx. In such cases, there is no difficulty in verifying the fact, that leaf, bract, and sepal, are one and the same organ; for we plainly see how the leaves diminish in size as we pass from the vegetative to the reproductive region, and the successive steps made in the metamorphoses of the ordinary green leaves of the stem into the sepals or leaves of the calyx or flower-cup.

But in cases where the inflorescence is terminal, that is 
to say, where the development of the main stem and branches of the plant are suddenly arrested by the metamorphosis of the leaf-buds at their summit into flowerbuds, no such gradual metamorphosis in the leaves is to be seen; and this makes the task of identifying the flowerleaves with the ordinary green leaves of the stem far more difficult. Yet even here we are not without indications of that common family relationship which subsists amongst all the leaf-organs. There is the same rudimentary condition of the floral axis which we observe amongst the common green leaf-clusters on the branchlets when their vegetative powers are enfeebled; the same spiral arrangement; for, if we consider the leaves of the flower carefully, we shall find that they alternate with each other, the sepals or leaves of the calyx occupying an intermediate position between the petals. We observe, also, that these floral leaves deviate more widely from the ordinary type of stemleaf, in proportion as they are situated toward the superior portion of the axis; this change of structure increasing as the vegetative forces become enfeebled. Thus, whilst the sepals or leaves of the calyx retain almost all the characters of leaves, these characters are less apparent in the petals and stamens, until finally, in the carpels, or pistils, which

FIG. 1.

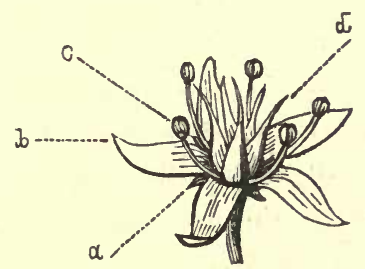

The different parts of a flower: $a$, the calyx; $b$, the corolla; $c$, the stamens; $d$, the pistils.

occupy the summit of the axis, the departure from the ordinary leaf-type is the widest.

Transitional forms, between sepals and petals, and be- 
tween petals and stamens, may be obtained in many flowers, especially in the common spatterdock of the pools (Nuphar advena), and the white water lily (Nymphoea $a l b a)$. These terms may furnish the botanist with convenient artificial distinctions, which are very available in botanical diagnosis; but absolute boundaries between sepals, petals, stamens, and pistils, do not exist in Nature; there is the utmost latitude and freedom of form, and we seek in vain to confine her in the fetters of an artificial nomenclature.

Examine the flowers of the yellow lily or spatterdock, and you will find that the sepals or leaves of the calyx, although green externally, are yellow internally, and thus approximate in appearance to the petals; that the petals, which are arranged in a closely-approximated spiral, gradually become smaller as they are more centrally situated; for the anthers become visible on their upper side, and the lower portion of the petal contracts into a filament. The curious pollen-bearing leaves, called stamens, are thus identified as metamorphosed petals; for such transitional forms remove every shadow of doubt from the mind.

In the pistil or central organ of the flower, there appears to be the greatest departure from the primitive leaf-type; yet it is not difficult to trace it even in this instance. The analogy of the pistil to the leaves is easily demonstrated in the flower of the Iris, the pistils of which are petaloid, or petal-like. In general, the pistil is nothing but a leaf which remains folded on its midrib, the two sides of the lamina continuing together instead of separating, as in ordinary cases. Whilst in this condition, the margins of the lamina anastomose, or grow together, and thus form a placenta or point of attachment for the ovules in its interior. The folded condition of the leaf in the young state may be observed in the leaves of the Cherry tree and common Garden Rose. Examples, too, are not uncommon of the development of stunted green leaves in the centre of the flower, in the place of the pistils, as in the Double 
Cherry and Garden Rose; although, as a general rule, when once the development of the axis has reached its limit in flowers, there is no recurrence again of the vegetative period.

And here it is necessary to appreciate fully the relative physiological rank or importance of the floral organs. To understand this, we must study not only the subordination of function which subsists amongst the floral organs, but also their presence or absence in the greater number of flowers; for it may be very safely concluded that those floral organs which are present the most frequently in flowers, and the last to disappear, are in reality the most necessary to the exercise of the reproductive function.

The popular idea of a flower is usually associated with something showy and colored, and hence the flowers of the Judas Tree (Cercis Canadensis), the Dogwood (Cornus Florida), and the Tulip Tree (Liriodendron tulipifera), are easily recognized; but not the flowers of the Larch, Cedar, or Pine. The flowers of these trees take a lower form of development, and require the searching eye of the Naturalist to detect them. Such humble forms of floral structure are, in reality, the most attractive and interesting to the philosophical Botanist. He can admire the rich colors of a Camelia or Geranium, but there is something quite as pleasing when he recognizes simplicity of structure, where calyx and corolla have disappeared, and nothing remains but the stamens and pistils, the parts absolutely necessary to reproduction. These are the most highly metamorphosed of the leaf-organs of the plant, to which all the others are simply accessory. Propagation cannot be effected without them, hence they are the very last to disappear from the organism, in descending from the higher to the lower orders of the Phanerogamia or flowering plants; and wherever they are present, there is a true flower. Stamens and pistils may be distinctly seen, at certain seasons of the year, in grasses, sedges, and rushes, which are therefore very properly regarded by Botanists as flowering plants, notwithstanding their sombre appear- 
ance, the term being quite as applicable to them as to a rose or lily. Brilliant and highly-colored floral envelopes must be regarded as characteristic of the more highly organized flowers. These gradually lose their bright attractions, as we descend in Nature, until they become green and inconspicuous, as in Nettles, and in the Pigweed (Amaranthus hybridus); and, finally, their place is supplied by rudimentary leaves or bracts, as in Grasses and Birch trees; or they are suppressed altogether, as in the Lizard's Tail (Saururus cernuous) and Willow.

A few brief remarks may now be made in reference more immediately to the reproductive functions exercised by the stamens and pistils. Let us take, as an example, the Apple tree. This tree is beautiful in spring, when covered with blossoms, and still more attractive in autumn, when loaded with fruit; and it is desirable, in this place, to say something about the way in which both the flowers and fruit are formed.

When the period of puberty arrives, the branches of this tree cease to elongate, and their terminal buds assume a swollen appearance, and give birth to a cluster of little twigs, or stalks, each supporting a flower-bud. These flower-buds unfold themselves about the same time as the regular leaf-buds; but the leaves which they contain do not separate like those developed by the leaf-buds; on the contrary, they remain crowded together in clusters at the summit of each flower-stalk, or peduncle.

If we examine the leaves of the flower which have been thus crowded together, we shall be struck with admiration at the simplicity and beauty of the means which Nature has adopted to effect her object. The outer leaves of this floral cluster, although greatly diminished in size, still retain their green hue, and form a sort of cup-like envelope, called, for that reason, by Botanists, the calyx. Situated immediately next are the leaves of the corolla, or garland, so called on account of their ornamental appearance. These are the most showy leaves in each set; they are slightly tinged with pink, and of a dazzling whiteness. 
Now Apple trees are hermaphrodite, that is to say, they are self-impregnating, the male and female organs being situated in the same flowers. These organs are called, by Botanists, stamens and pistils, and we must look for them immediately within the apple-blossom, or corolla. The stamens, or male sexual organs, are very numerous, and surround the pistils or female sexual organs. All these organs must be regarded as altered stem-leaves, beautifully organized with reference to the new and important functions which they have to perform. In the stamen, the stalk of the leaf is converted into a filament, and the dilated portion, or blade, contracted into a little club-like body, called an anther. This will be better understood by referring to

Fig. 2.

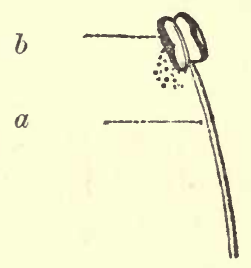

Fig. 2, which represents one of the stamens of the Apple tree. The filament is marked $a$, and the anther $b$, which is seen discharging its fecundating matter, or pollen. It is because the anther prepares and discharges the pollen, that we call it the male sexual organ of a flower. The female sexual organ, or pistils, occupy the central portion of the flower. They are so called because they receive the impregnating matter, or pollen, a process which, in plants, is indispensable to reproduction. The reader will form a very good idea of a pistil, by looking for a few moments at Fig. 3, which shows one in section, or cut open. $C$ is the stigma, or summit, of the pistil, to which the pollen adheres when fertilization takes place; $b$ is the style of the pistil; $a$ the ovary, containing the young ovules, which are 
pointed out by the letter $d$. The pistils of the apple-blossom are somewhat different from the one figured here.

Fig. 3.

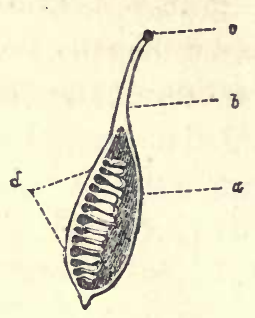

There are usually five pistils, with free styles and stigmas; the ovaries are, however, united; each contains two ovules, surrounded by cartilaginous walls, forming what is called the core of the apple, and the whole is inclosed in the fleshy tube of the calyx, which, by subsequent enlargement, becomes the fruit.

It is not the beauty and fragrance of apple-blossoms, so much as the plan on which they are constructed, which is the chief point of attraction about them. This terminal rosette of sweet-scented, ornamental leaves, is, in reality, nothing but the ordinary green leaves of the stem, whose organization has been altered, and is most admirably adapted to the discharge of a new and important function, that of reproduction. For the mind is necessarily filled with admiration at that matchless skill which thus, by a modification in the same typical organ, the leaf, adapts it to the exercise of the reproductive functions. "The contraction of a branch and its leaves forms a flower; the disintegration of the internal tissue of a petal forms pollen; the folding inwards of a leaf constitutes a pistil; and, finally, the gorging of the pistil with a fluid, with which it cannot part, produces a fruit."*

The function exercised by the two outer sets of floral

* Lindley's "Introduction to Botany." 
leaves is purely a protective one, and they are placed in close proximity to the stamens, in order that they may fold over them, and thus shelter them from the falling rain and the dews of night. All must have noticed this folding-up of the calyx and corolla in wet weather, or at sunset. The leaves of the calyx, and especially the petals of the corolla, also aid in the preparation of the sap for the stamens, and

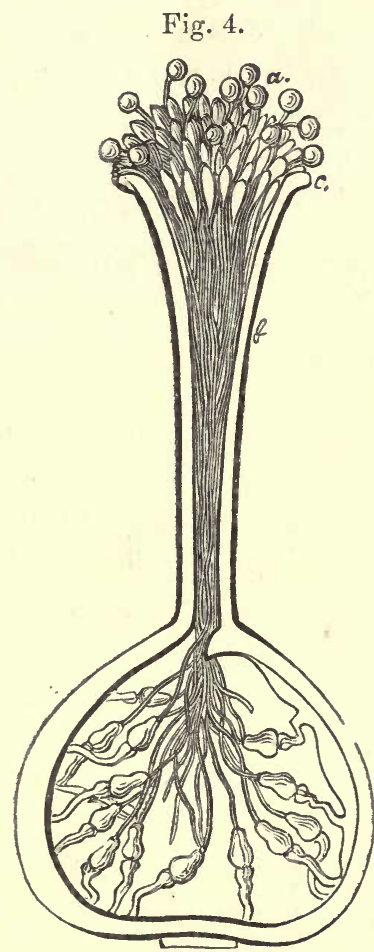

Longitudinal section of the pistil of Helianthum denticulatum, showing the ovules in the interior of the ovary, attached to the placenta by means of the funiculus, or vegetable umbilicus; $b$, style; $c$, stigma; $a$, pollen granules, the tubes of which have descended the style, and entered the micropyle of the ovules.-Schleiden.

help to form that saccharine matter which the bee collects so industriously, and which nourishes the stamens and pistils. 
The function of the stamens and pistils is purely reproductive. At first the anthers are unruptured, moist, and closed; but, as they approach maturity, they become dry, open their cells, and discharge their pollen on the stigmatic surface of the pistil, which, about this time, becomes bedewed with a clammy fluid, which serves to retain the pollen. The grains of pollen absorb the moisture of the stigma and emit delicate tubes, which penetrate the loose cellular tissue of the style, and act as a conduit of the fecundating matter of the pollen grains to the ovules, which these tubes finally enter by means of their micropyle (Greek $\mu \iota x \rho o s$, little, and $\pi v \lambda \eta$, gate). The ovules, having received the impregnating matter, the embryos, or miniature plants, begin to form in them, and are gradually transformed into seed.

The sap is now drawn to the forming fruit, away from the petals and stamens, which fade and fall off, having fulfilled their important but ephemeral functions. The stigmas and styles of the pistils being now useless to the plant, disappear equally with the other parts. The ovaries alone remain to aid in the ripening of the seed contained within their cavities.

The sap elaborated in the ordinary green leaves of the stem, passes through the peduncle, or what was formerly the flower-stalk, into the fleshy tube of the calyx, by which it is retained, and which now gradually enlarges and continues to increase in size as long as the sap continues to enter it. The gorged and swollen cellular tissue or substance of the apple is formed from this sap about the cartilaginous walls of the ovaries. The surface of the apple, whilst green, acts like an ordinary green stem-leaf on the atmosphere, absorbing carbonic acid gas, and giving out oxygen. As it slowly loses its green color, and assumes a ripe and ruddy appearance, it ceases to do this, absorbing the oxygen instead of giving it out. At maturity the stalk ceases to afford any further passage for the fluids, and becomes finally unequal to the task of supporting the fruit, so that it falls to the ground. Here it lies, unless eaten by cattle, till it decays. On the approach of Spring, the seeds 
contained within the ovaries, stimulated into life by the heat, put forth roots in the mass of nourishing, decaying matter which surrounds them, and which was provided by Nature for this very purpose, and develope into new plants; which, should circumstances favor their growth, pass again through the same life-changes as the parent tree on which they originated.

Such are the progressive phenomena in the growth not only of the Apple tree, but of all the trees which are natives of northern climates, modified, of course, by peculiarities of structure and constitution; but all grow in a similar manner, - their forms gradually unfolding from the seed, according to the same laws.

The tree exhibits a picture of the whole of Nature, and of the way in which Nature works. In its building up, it shows that the grand is always preceded by the apparently insignificant, and complexity of structure by extreme organic simplicity. Cell and fibre, leaf-scale and leaf, shoot, branchlet, and branch, all preceded each other, and their united labors produced the blossom and fruit, the highest, the culminating point of organic perfection and metamorphosis. So that no part of the tree is insignificant, and all its organs are mutually dependent on each other; for is there not a centralization of their forces, a unity of their organic action, in the labors necessary to form the blossom and the fruit?

In the early part of this chapter, I spoke somewhat enthusiastically of a little, apparently insignificant, Spring flower, popularly called Whitlow Grass (Drabaverna), whose blossoms cover the ground, in the utmost profusion, in the months of March and April. Now, vulgarly speaking, this plant is nothing but a "common weed." Will you believe, reader, that I have watched this plant, through all the phases of its brief life-history, for several years, with an interest ever on the increase! Let me tell you a few of the thoughts which it has suggested. I have marked the care with which Nature preserves its germs, and the constancy with which it appears on the earth's surface at the 
appointed time. Surely this flower, so humble, unattractive, and short-lived, like the leaf-scales of a tree, has its place assigned in the organism of the universe, which would probably be no unimportant one, if the wondrous mechanism of life were only better understood. And it is the same with the every individual of all that troop of bright and smiling ones with which the earth is annually garlanded, especially when, like my welcome little friend, Draba verna, they decorate the earth in countless numbers. Regarded as a part of the organism of living Nature, such plants lose their insignificance; and there is no genus, however brief its life-span and unattractive its appearance, which is beneath the consideration of Naturalists.

Nor is the above lesson without its moral. What shall be said of those who despise the honest and industrious man, because he occupies an inferior position in society? Such conduct is certainly not sanctioned by Nature, or her teachings, when we see what is lowly and apparently insignificant at the foundation of her grandest operations. 


\section{CHAPTER X}

CONTAINS A DESCRIPTION OF TREES REMARKABLE FOR THEIR GIGANTIC GROWTH AND GREAT AGE, FOUND IN DIFFERENT PARTS OF THE WORLD.

Every country possesses these vegetable giants, and this, too, from the most different groups of trees. India has its Banyan; Africa, its Baobab ; Germany, its Linden ; England, its ancient Oaks and Yews; and California, its magnificent mammoth trees, which belong to the natural order Coniferæ, and which are upwards of three hundred feet in height.

A Chestnut tree is now growing on the side of Mount Etna, in Sicily, the stem of which is hollow, and one hundred and eighty feet in circumference. It consists, in reality, of several stems, which have grown together at their base, and whose crowns are concealed within one another. It is called by the natives, "Castagna di cento cavalla ;" because a hundred horsemen can find shelter in its interior. The age of this tree is unknown, but its immense size proves its great antiquity. It is indeed a noble tree, which has outlived and sheltered successive generations.

By Neustadt, in the kingdom of Wurtemberg, in Germany, stands a Linden tree, which must have been very old in 1229; for an old tradition says that the city, which formerly was called Helmbundt, was destroyed in 1226, and was again rebuilt in 1229, "near the Great Linden." This Linden was so remarkable and well known, that for centuries the Germans were accustomed to speak of Neu- 
stadt as the city "near the Great Linden." In a poem written in 1408, it is described as growing near the gate of the city, its branches being supported by sixty-seven pillars. In the year 1664, there were eighty-two, and in 1832, one hundred and six of them. They were built of stone, and erected just as they were required, in accordance with the increase in the horizontal growth of the branches. The oldest inscriptions on these pillars bear the respective dates of 1558,1562 , and 1583 , with the name and escutcheons of those who erected them. In the year 1832, the stem of this tree was, at a height of six feet above the ground, thirty-seven feet six inches in circumference. It must, therefore, have been from seven hundred and fifty to eight hundred years old, at the lowest estimate. Since 1832, it has suffered so much by tempests, that it is now almost, comparatively speaking, a complete ruin.

Walnut trees, also, occasionally reach a great age. There is one in the Baidar Valley, near Balaklava, in the Crimea, which is at least a thousand years old. It yields annually from eighty thousand to one hundred thousand nuts, and belongs to five Tartar families, who share its produce peacefully amongst themselves.

Cedars are yet found on Mount Lebanon, in Syria, supposed to be the remains of the forest which furnished Solomon with timber for the Jewish Temple, three thousand years ago. They were examined by Belonius in 1550, who found them twenty-eight in number. In 1696, Maundrell counted only sixteen; and in 1818, according to Dr. Richardson, there were still seven of them left. There can be no doubt as to the great age of these trees. Maundrell mentions the size of one of them, which was thirty feet six inches in circumference, and one hundred and seventeen feet in the spread of its boughs.

There are Oaks now growing in England, which were planted before the time of the Norman conquest, in 1066, and which are therefore more than eight hundred years old.

The Yew trees (Taxus baccata) are still oldęr. One of these trees, located at Fountain's Abbey, near Ripon, in 
Yorkshire, was examined by Pennant, in 1770, and was then more than twelve hundred years old; and another, in the churchyard of Braburn, in Kent, according to the measurement of Evelyn, in 1660, had then attained an age of two thousand eight hundred and eighty years, and consequently is now more than three thousand years old.

The so-called American Cypress (Taxodium distichum), found in Florida, in southern Louisiana, and in Mexico, has not unfrequently, at a height of one hundred and twenty feet above the ground, a circumference of forty feet, and must, therefore, be very old. A fine specimen of this tree now grows in the garden of Chapultepec, Mexico, which was of an immense size at the time of the conquest of Mexico by the Spaniards, in 1520, and was then known as Montezuma's Cypress ; and in the province of Oaxaca, in the same country, still stands the same Cypress which sheltered the troops of Ferdinando Cortez. These trees are at least four thousand years old; in fact, De Candolle considers them to be much older.

But by far the most remarkable trees in the world are found in California. The Sequoia gigantea, popularly known in the district where it grows as the "Mammoth Washington Tree," was first discovered by the English traveller and Naturalist, Lob, on the Sierra Nevada, at an elevation of five thousand feet, and near the source of the rivers Stanislaus and San Antonio. These trees belong to the Natural Order Coniferce, or the Pine family, and grow two hundred and fifty and even four hundred feet in height. The bark, which is of a cinnamon color, is from twelve to eighteen inches thick; the wood reddish, but soft and light; and the stem is from ten to twenty feet in diameter. The branches grow almost horizontally from the stem; their foliage resembles that of the Cypress; yet, notwithstanding the monstrous size of these trees, their cones are only two inches and a half in length, resembling those of the Weymouth Pine (Pinus strobus); whilst the Auracauria, or South American Pine, although far infe- 
rior in size to the Sequoia, produces cones of the form and magnitude of a child's head.

The Sequoias stand together in groups on a black, fruitful soil, which is watered by a brook. The miners have given some of them their especial consideration. One has been called "The Miner's Cabin." It is a hollow tree, about three hundred feet in height,- - the excavation being seventeen feet in breadth, and nearly fifty feet in circumference. "The Three Sisters" have all sprung from the same root. "The Old Bachelor," worried by storms, leads a solitary life. "The Family" consists of a group of trees, two large ones,-"The Parents,"-and twenty-four small ones,"The Children." "The Riding School" is an immense tree, which has been overturned by a storm, in the hollow stem of which a man can ride on horseback for a distance of seventy-five feet.

In standing before these giant forms of the forest, we naturally try to calculate the time which was necessary to bring together such vast masses of vegetable matter, and then think of our own short lives and diminutiveness. Judging from their rings, these trees are at least from two to three thousand years old. The following description of one of them, recently felled for timber, is taken from a work published by the United States Government. It will be read with interest, as it furnishes reliable information:-

"As considerable discussion has already been had with regard to the age of this tree," says Dr. Bigelow, "I may state that when I visited it in May last, at a section of it, eighteen feet from the stump, it was fourteen and a half feet in diameter. As the diminution of the annual rings of growth, from the heart or centre to the circumference, or isap-wood, appeared pretty regular, I placed my hand midway, roughly measuring six inches, and carefully counted the rings on that space, which numbered one hundred and thirty, making the tree $\mathbf{1 8 8 5}$ years old.

"A verbal or written description of this tree, however accurate, cannot give one an adequate idea of its dimensions. It required thirty-one of my paces, of three feet 
each, to measure thus rudely its circumference at the stump. The only way it could be felled, was by boring repeatedly with pump augers. It required five men, twenty-two days, to perform the operation. After they had succeeded in severing it at the stump, the shoulders were so broad, and the tree so perfectly equipoised, that it took the same five men two days in driving wedges with a battering-ram, on one side of the cut, to throw it out of its equilibrium sufficiently to make it fall. The mere felling of the tree, at California prices for wages, cost the sum of $\$ 550$.

"A short distance from this tree was another of larger dimensions, which, apparently, had been overthrown by accident, some forty or fifty years ago. It was hollow for some distance; and, when I was there, quite a rivulet was running through its cavity. The trunk was three hundred feet in length; the top broken off, and by some agency (probably fire), was destroyed. At the distance of three hundred feet from the butt, the trunk was forty feet in circumference, or more than twelve feet in diameter. Fragments of the same kind of tree, which had apparently been exposed to the vicissitudes of climate and the weather the same length of time, and supposed to be from the individual tree that lies prostrate, are to be found projected in a line with the main body, one hundred and fifty feet from the top; proving to a degree of moral certainty, that the tree, when standing alive, must have attained the height of four hundred and fifty or five hundred feet! At the butt it is one hundred and ten feet in circumference, or about thirty-six feet in diameter.

"These mammoth trees, by their stately and majestic bearing, striking the beholder with awe and wonder, and cause him almost involuntarily to bow before them as the kings of the forest. Their whole number does not exceed five hundred, and all are comprised within an area of about fifty acres. Only eighty or ninety of them are of gigantic size. Their extremely limited locality and number, forcibly impress the traveller with the belief that the species will 
soon be extinct, as is further evinced by their slow reproduction. Indeed, these giants of the forest are so marked in their rusty habits from their present associates, that we can hardly view them in their present relations, except as links connecting us with ages so long past, that they seem but reminiscences of an eternal bygone. They seem to require but the process of petrifaction to establish a complete paleontological era."*

But the Baobab (Adansonia digitata) surpasses even the trees of California in grandeur and antiquity. It is the oldest vegetable monyment on earth. Its stem is only from ten to twelve feetin height, but of immense proportions, for it is thirty-four feet in diameter. This colossal circumference is an absolute necessity; because, from its summit it unfolds so vast a leaf-crown, that it can only be supported on such a massive foundation. The main branch rises perpendicularly to a height of sixty feet, and from it branches extend themselves to a distance of from fifty to sixty feet horizontally on all sides; so that they form a noble leaf-crown, whose diameter is more than one hundred and sixty feet, giving to a single tree the appearance of a whole forest. The leaves of the Baobab are palmate, and forcibly remind us of the Horse-Chestnut,-being divided to the leaf-stalk. It is covered with great Malvaceous-like flowers, which droop on their peduncles. The fruit is about the size of a small gourd.

In its native country, this tree bears a name which signifies "a thousand years ;" and, contrary to what is generally the case, this name expresses what is, in reality, far short of the truth. Adanson noticed one in the Cape de Verd Islands, off the coast of Africa, which had been observed by two English travellers three centuries earlier; he found within its trunk the inscription which they had graven there, covered over with three hundred woody layers, and

* See "Reports of Explorations and Surveys, to ascertain the most practicable and economical route for a railroad from the Mississippi River to the Pacific Ocean," Vol. IV. 
thus was enabled to estimate the rate of the increase of the stem in three centuries. With this measure he succeeded in estimating the number of year's growth of the entire stem, and in ascertaining the age of the tree, which he found to be 5150 years.

But, although some trees live for thousands of years, yet the life of all must sooner or later terminate; for, to each tree, equally with the lowly plants which grow beneath its shade, a limited period of life has been allotted. This period may vary with the favorable or unfavorable circumstances in which the tree is placed, and depends also on the greater or less amount of life-force with which the embryo was endowed in the beginning; but, nevertheless, the life of all trees has its appointed period, like their form, altitude, and other specific peculiarities.

We close this chapter with the following catalogue of trees, which is designed to show how the age of the same tree may vary:-The

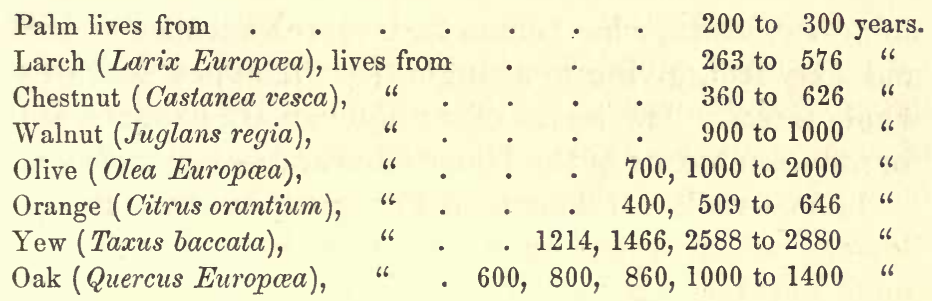




\section{CHAPTER XI.}

THE WOODS TAKE THE FIRST RANK IN THE COMMUNITIES OF THE VEGETABLE KINGDOM-RECIPROCITY OF ACTION AMONGST PLANTS-A COOL ATMOSPHERE PRODUCED BY WOODS-THEIR REMOVAL IS FOLLOWED BY A WARMER, DRIER CLIMATE, AND IS BENEFICIAL IN SOME CASES-WOODS ON MOUNTAINS MUST NOT BE CUT DOWN-PERNICIOUS RESULTS OF THEIR REMOVAL IN ITALX-WOODS USEFUL ALONG THE SEA-SHORE WHERE THE COAST IS LOW AND SANDY-CONCLUDING REMARKS.

THE plant.covering of the earth is very properly called the Vegetable Kingdom. It is indeed a state in the kingdom of Nature, which, like the state under the government of man, is divided into communities of the greatest difference and variety. The orders of plants in the natural system of botany, are a rough draught or attempted sketch of these communities, and among them the woods take the first rank. The magnitude of trees, and the extent which they cover when they form forests, makes them quite a prominent feature in the landscape ; and they are quite as important as their conspicuous appearance would seem to intimate. The woods are indeed the supreme rulers of the plant-world, and the life of the other plants ; and the prosperity of man himself is, as we shall now proceed to prove, most intimately connected with their existence.

The woods show us, in the clearest and most direct manner, that the earth would be perfectly uninhabitable if plants did not grow together in communities. Without these natural associations, their life, as individuals, would 
be in the highest degree endangered. United together, they mutually shelter each other on all sides against storms and the drying effect of the sun's rays. This reciprocity of action is highly interesting. Thus, herbaceous plants and grasses envelope the earth with a protective covering. They allow the sunbeams access to the young scedlings, and also give them a sufficient amount of shade, so that the sun's rays are prevented from drying the soil, and thus injuring their young life. It is thus that trees grow up at first under the shadow of the smallest members of the vegetable kingdom, only to reciprocate, as they approximate to the period of their maturity and strength, the favors which they received in the hour of weakness and infancy. Under their summits the shadowed earth retains its moisture, and the poorer plant-children of Nature are thus fed,whose tender rootlets have not the ability, like the roots of trees, to draw their moisture deeply out of the earth. Besides, a moss carpet forms on the ground in woods, at least in temperate and cool climates, which preserves the soil moist much longer, or lets it slowly penetrate to the deeper lying basins among the hills. So also, when showers of rain fall on forests, the leaves of the trees catch the drops, break the force of their descent, and the plants thus shel. tered gently drink in the moisture of the storm, whilst they escape its violence. The moss-covering, too, retains the moisture long after the storm has passed and sun-smiles brighten the earth, whilst the shadow of the trees prevents its evaporation.

It follows that a wooded soil is favorable to the production of springs; also, that the continued existence of moisture in woods, and the constant evaporation from them, will produce a cooler atmosphere, and therefore a lower degree of temperature in a country where they abound. It is not difficult to make this intelligible to the reader. The ocean, winds, and woods, may be regarded as the several parts of a grand distillatory apparatus. The sea is the boiler in which vapor is raised by the solar heat, the winds are the guiding tubes which carry the vapor with them to the 
forests, where a lower temperature prevails. This naturally condenses the vapor, and showers of rain are thus distilled from the cloud-masses, which float in the atmosphere, by the woods beneath them. The grateful moisture descends on the thirsty landscape, replenishing its numerous springs. The little streamlets which issue from them continue to flow, and a confluence of their waters forms brooks and rivers, the natural arteries of a country, and the first natural means of intercourse and commerce possessed by a people in an early stage of civilization.

The Turks, although only a semi-civilized people, seem to be aware of the cooling influences which forests exercise on the spot where they are located. There is, to day, in the neighborhood of Constantinople, a splendid woods of the finest beech and oak, which is protected by law; because it feeds a spring, the water of which supplies the whole city. It is conducted there by an aqueduct.

The history of any nation traced back to its origin, will attest that springs and rivers have ever been an inducement for man to forsake his roving habits and commence a regular life. Examine the map of any part of the earth where man is settled and civilized, and you will find that its most important cities and towns are located near its rivers. Springs and rivers will ever be to man a source of wealth and power. His condition, centuries ago, when he was without the experience and knowledge of Nature which he has now acquired, was such as to make him gladly avail himself of these great natural aids. Their waters supplied him with fish, and their banks with herbage for his animals; they facilitated commercial transactions, to which he appears to have a natural tendency, and they furnished him with a natural mechanical power for driving his earlier efforts at machinery. Science has now given him the steam-engine; how great an advance on his rude watermills! No wonder that springs and rivers were adored, and that they were supposed to be frequented by Nymphs, who protected and presided over them. These beautiful myths show how their value was appreciated. 
When a country is deprived of its forests, the springs and rivulets are exhausted, and the climate is rendered warmer and drier. This explains the reason why the climate of ancient England and Germany, at the time of the Roman Emperor Cæsar, resembled that which Sweden now possesses. The forests were then extensive, and the woodcock, stag, wolf, bear, and wild boar, made them a home, as now we find them in the woods of Sweden. So also, the climate of Greece, in Homer's time, was like that of modern Germany, which now produces the orange and the grape.

The industry of England has removed its native forests, and its meadows are the richest and most luxuriant in Europe; but it must be borne in mind that, in thisinstance, the climate is insular, and therefore the clearing has been effected without any injurious consequences. It is the same with countries about the North Sea and the Baltic. Where, as here, there is a temperate zone and an incessant supply of moisture from the neighboring seas, the woods are of less consequence, in fact it is far better to cut them down; for they make the climate too moist and cold, and prevent the successful cultivation of the soil. The present agricultural condition of Finland, in Northern Russia, establishes this fact; for the removal of its woods has dried up its swamps and forwarded cultivation, whilst it has rendered the climate milder and more habitable. So in laying the railroad across the Isthmus of Panama, the country was found to be unhealthy because too thickly wooded. Its swampy condition and the heat of the climate caused it to reek with malaria and to abound with noxious reptiles and venomous insects, whilst hundreds of workmen employed on the road died of yellow fever. A place was selected for a burial-ground soon after the work was commenced. It is now called Hope Cemetery. It is surrounded by dense foliage on every side, marked by the mourning plumes of the cocoa-nut and the palm. Here those who fell victims to the unhealthiness of the climate whilst constructing the road, were buried by their heavy-hearted comrades. It 
follows, from these facts, that a too great expansion of woods, as well as their removal, has its limits. The geographical position of Panama, lying in the neighborhood of two oceans, shows that good effects will result from the clearing of its dense sun-exeluding forests and the thorough cultivation of its soil; for its marshes and malaria will disappear and its climate improve.

But where the country is not situated near seas or oceans, and the climate is continental, then man must be careful, in cutting down the woods, not to transgress the limits which Nature has prescribed. Where there are mountains, the woods must be allowed to stand, for they cannot be removed without the most pernicious consequences.

The relative dependency subsisting amongst the different plants of a landscape, and their relation to the soil, can only be understood by a reference to first principles. A wood, through the roots of its trees, as well as by its thick moss or grass covering, binds together the soil on the declivities of the mountains, and thus in the most natural and simple manner strengthens them. If we take the wood away, the springs are dried up, and the moss or grass covering disappears. The power of the rain, no longer broken by millions of leaves and by the grassy mantle, comes down in unrestrained violence, and the loose soil torn from the mountain side is carried down into the subjacent valleys. Here it settles as sand and mud, which fills up the brooks and rivers, and renders their waters turbid, so that they overflow their banks and inundate the plains. This sand and mud is left on the grass-covering of the plains when the storm subsides, and the waters return to their accustomed channels. But every farmer knows that crops of hay raised on meadows frequently inundated, are worthless as food for cattle. At length, in the course of years, these swampy pastures become overspread with sand; the former riches and prosperity of the inhabitants slowly disappear, and the once happy valley becomes uninhabitable.

But this is not all. The whole landscape gradually changes, an entirely new plant-covering is produced, and, 
in warmer climates, poisonous gases are developed from the swamps, as in those of Panama and in the Pontine marshes of Italy. It is thus that mischief done to the woods on mountains, is a bequest of destruction to coming generations.

No country in the world was formerly more healthy or more richly cultivated than Italy, once the "garden of Europe," now only an extensive morass. Where at one time the richest life prevailed, gloomy Death threatens to extinguish its fresh torch. $\mathrm{He}$ is aided by malaria, a disease whose existence is to be attributed wholly to the unhealthy decomposition of animal and vegetable matter in the stagnant marshes so abundant in the country. The poisonous effluvia spreads slowly among the few inhabitants whom iron necessity alone compels to remain. Ague, liver and hypochondriacal affections, are in its train. Pale and yellow complexions, with weak eyes, a swollen abdomen, and a wearisome gait, the accompaniments of these diseases, are everywhere to be seen among the poor inhabitants. Behind them lurks a malignant fever, which carries off the greater portion of them prematurely. What has made this once prosperous, healthy, and populous country, so poor, diseased, and deserted? The woods have been removed from its mountains! Look at the map, and you will see that these run through the central and northwestern portions of the Italian peninsula. The Appenines are at present almost entirely denuded of the noble forests which once flanked and protected their sides, and all travellers agree that there is now no country so sorrowful as that which is included in what is called the States of the Church, and which lies along the Appenine chain, between Genoa and Naples. Unhappy Italy, thy serene and sunny skies are now darkened by storms, but free nations are with thee in their sympathies, and a free press whose influences are already visible in all the movements of thy enemies! For why that concealed and stealthy step? Is it not because despotism fears this fearful weapon, and would avoid its effects, well knowing that it is quite as sure in its.aim as 
rifled cannon, while it possesses a far longer range? Is there any painting or sculpture in the world which rivals that of Italy? What music is so sweet as the Italian song? It has now lost its softness, its gentle, mournful cadence; its tones are spirit-inspiring and martial. Surely brighter and better days are in store for Italy. May we live to see this interesting people, so long the victims of religious and political despotism, free from their enemies and selfgoverned. "For a nation to be free, it is sufficient that she wills it."

Leaving Italy for Germany, we find even this country, which has produced so many reformers and philosophers, is not exempt from the terrible consequences of the removal of its mountain forests. A journey amongst the forests of Thuringia and the Hartz Mountains furnishes innumerable vouchers of this fact.

Woods are also useful along the sea-shore, where the coasts are low and sandy, as their roots bind together the loose sand, and prevent its being drifted inland by the seabreezes. One or two examples will show this in a striking light.

The sea-sand having overflowed the country situated in the neighborhood of the Gulf of Gascogne, on the western coast of France, and threatened to make it valueless and uninhabitable; Bremontier, a resident of the province, succeeded in opposing an effectual barrier to its further progress by planting a wood. He first of all planted the sand-loving Broom-Rush (Sarothamnus scoparius), and produced in its shade young Pine-trees, and so brought the overflow of the sea-sand to a stand still.

By reference to the map of Prussia, it will be seen that there is situated in eastern Prussia, between latitude $54^{\circ}$ $15^{\prime}$ and $54^{\circ} 45^{\prime}$ North, and longitude $19^{\circ} 15^{\prime}$ and $20^{\circ} 25^{\prime}$ East, an extensive lagoon, called the Frische-Haff, or Fresh Gulf, which is separated from the Baltic by the FrischeNehrung, or Fresh Beach, a tongue of land thirty-eight miles in length by one in breadth, the northeast extremity of which communicates with the Baltic by a channel half 
a mile across. The low shores along this line of coast are washed by the waters of the Gulf of Dantzig, and in the middle ages its Dunes, or hills of blown sand, which stretch almost from Dantzig to Pillan, were covered with a thick pine forest and an undergrowth of heath'.

"King Frederick William, of Prussia, wanted money. One of his noblemen, wishing to secure his favor, promised to procure it him without loan or tax, if he would permit these forests to be removed. The King not only allowed the forests in Prussia to be cleared, which, at that time, were certainly of little value, but he also permitted the whole of the woods on the Frische-Nehrung to be felled, so far as they were Prussian. The finaneial operation was perfectly prosperous; the King had money. But in the elementary operations which followed therefrom, the State received such an injury that its effects remain even to this day. The sea-winds can now sweep unimpeded over the denuded hills, the Frische-Haff is already half-filled with sand,-its depth being now in no place more than twelve feet,-and sedges grow for some distance in its shallowing waters, threatening to convert it into a monstrous swamp; the anchorage extending between Elbing, the sea, and Konigsberg is endangered, and the fishing in the Haff injured. In vain have all possible efforts been made, through sand-heaps and pastures of coarse sea-grass, to cover again these hills with matted roots. The wind mocks at every exertion. The operation of the Prussian nobleman brought the King two hundred thousand thalers; now the people would give millions if they had the woods back again."**

The woods, in their united might, are truly a natural faseine or fortification, which serves to withstand the perpetual encroachments of the sand-hills on low, exposed shores; growing on the side of the mountains, they stay the further progress of glaciers, and protect the inhabitants of the valleys against the avalanche or mountain snow-ball,

* Das Buch der pflanzenwelt, von Dr. Karl Muller. Leipzig, 1857. 
which loosening on the lofty Alpine summit, comes thundering with gradually accumulating power down the mountain-side, and spends its fury on the crashing but conquering forests of hardy Coniferce.

In America we are in danger of losing sight of the utility of the woods. We want the land which they cover for agricultural purposes, we look on them as an incumbrance on the soil, and their cutting down is a mere question of cents and dollars. Witness the disgraceful vandalism which felled the noble Sequoias of California. Hence, the woods are disappearing on all sides, and this, too, on the most formidable scale.

But it is plain that other considerations ought to enter into our calculations as to the removal of a woods, besides its mere value as timber. If we remove trees from the mountain-side, from a low sandy coast, or from an inland district only scantily supplied with water, there is no end to the mischievous consequences which will ensue. By such ignorant work as this, the equilibrium in the Household of Nature is fearfully disturbed, and her wise and beneficent arrangements for our own good are completely frustrated.

\section{CHAPTER XII.}

THE DEATH OF THE TREE IS FOUNDED ON AN INNER LAW OF ITS ORGANISM, AND IS NOT THE RESULT OF ACCIDENTAL CAUSES.

WE have, in the preceding chapters, traced the development of the tree, from the first appearance of life in the germinating seed, till the period when it arrives at an adult state, so as to be capable of flowering and reproduction. But this history would be incomplete if we did not consider trees in the decline of life, and review those causes which produce their old age, decay, and the ultimate dissolution of the several parts of their fabric. 
The individual existence of a plant usually terminates with the formation of its flowers and seed. This law applies at least to annuals and biennials. In herbaceous perennials and shrubs, on the contrary, those branches only die which terminate in flowers, or in an inflorescence. With trees, at length, death extends not to the whole flowering axis, but only to its upper part, which dies down to the origin of the last side-shoots. And the reason is plain: the mother-shoot is nourished and its life secured by the daughter-shoots to which it gives birth. If the reader also take the fact into consideration, that of the numerous axes of a tree, only a small number, in proportion to the others, terminate in flowers, he will clearly perceive that the tree has, despite the formation of its flowers, ample means of an independent continuance of its growth and life.

But, we see that, notwithstanding the numerous permanently vegetative branches which the tree possesses, as a preservative against the exhausting influences of its flowers, or reproductive organs, yet nevertheless, it dies sooner or later; and this question arises for consideration: Is the death of the tree brought about in accordance with a regular law to which its organism is subjected? or does it possess a natural tendency to an unlimited duration of life, which is only brought to an end, accidentally, through storms and other hurtful outward influences? The former appears to me to be the correct view, and I am sustained in this opinion by Unger* and Mohl, $\uparrow$ both eminent physiologists.

We have seen that every part of the tree is a representative of a certain stage of development through which the tree has passed, whether it be leaf, shoot, or branch. But each of these parts passes through certain regular stages of infancy, maturity, decay, and death.

Now the growth of all the leaf-forms temporarily put forth by the tree, as well as the shoots and branches which

\footnotetext{
* Grundz. d. Anat. u. Phy. S. 131.

$\dagger$ Vegetabilische Zelle, S. 65 .
} 
remain permanently connected with its structure is accelerated during the earlier part of their life, and retarded as they arrive at maturity and towards its close. Thus the growths made yearly are accelerated during the early part of the vegetative season, when the conditions are the most favorable, and gradually retarded as the season advances; till, finally, the growths cease altogether, and the tree continues in a state of passive vitality through the winter months, being in precisely the same condition as a seed before it germinates. With the return of Spring and warm weather, the vitality of the seed and tree again becomes active; the former germinates, and the latter puts forth new leaves and shoots, and is again covered with its usual exuberance of foliage. This we have called, in Chapter VI, " the annual wave."

But there is also a "grand life-wave." For these yearly growths themselves, I mean those made by the main stem and branches of the tree, are subject to the same law of fluctuation. At first we have powerful year's growths, a rapid increase of shoots and broad wood-rings, until the tree gains its maximum height and spread; then follows a remission of growth, the year's shoots become always shorter and more circumscribed, the increase of shoots disappears, and the year's ring, or growth in thickness, becomes smaller and smaller.

In the gradual expiration of growth at the extremities of the branches, when the tree has attained its greatest altitude and passed the period of its prime, the following stages of remission may be distinctly observed: 1 . A little annular development, with some branching, yet so that the lateral shoots appear as clusters of leaves, no internodes being formed between them. 2. Only single shoots, a little developed, with here and there a bud formed. 3. Lengthening of the annular growths or shoots only through a bud-trace, with the formation of one or two leaves each year: no side productions whatever, and a vermicular curving of the branches, yet with powerful terminal buds. 4. The terminal bud pines, gradually 
loses the power of unfolding itself, and finally dies. With the death of the terminal bud, and the cessation of the formation of any more leaves, the further growth of the branch is necessarily completely arrested.

The same remission of growth shows itself in the development of the branches, whose growth is gradually retarded from one generation to another. The power of any branch to give forth branchlets is not indefinite, but has its appointed limits. New shoots are annually put forth by the terminal and lateral buds of the branches, until the vegetative powers of the branch are completely exhausted. That, in each succeeding generation of shoots, these powers are more and more enfeebled, is evident if we cast only a momentary glance at the branch and its branchlets. We see that the branchlets become gradually smaller and finer in proportion as their connection with the parent branch is more remote, until finally the leaves which they put forth are too enfeebled in their vitality to produce buds, their axils remaining unfruitful, and all further ramification is thus necessarily arrested.

It is the nature of all living organisms, whether animal or vegetable, to be running through one perpetually recurring cycle of the same life-changes, of infancy, maturity, decay, and dissolution. The compound plant called a tree, is no exception to this universal law of Nature. We have seen that, in the earlier portions of its life, it is represented by each of its parts. These parts do not all die at the same time, and their individuality is strikingly indicated by their different periods of life. Thus, the cells of the wood and bark, together with the different varieties of leafforms, called by botanists bud-scales, stipules, bracts, sepals, petals, stamens, and pistils, have all a life peculiar to themselves. The bud-scales have arrived at the close of life when the green leaves of the stem are in their infancy, and in spring make their appearance, and throw off their winter envelopes; and the petals and stamens die when the pistils begin to mature. Even the vitality of the walls of the ovary, or seed-vessel itself, is exhausted in the forma- 
tion of the seed, and dies after nourishing into life the embryo plant which is contained within its folds.

Not only the leaves, but the shoots, branches, and branchlets, arrive at their maximum development, and then manifest all the symptoms of a gradually expiring vitality; and this, too, at different periods of time. It is not always that leaves form buds, or buds become mothershoots or branches. The leaves situated towards the upper part of the shoot usually form the finest buds; and from these shoots proceed, which develope other shoots, at their sides and summits, and thus become mother-shoots or branches; and these branches develope another generation of shoots or branchlets; and so on, until the vital powers of the branch are exhausted, which happens sometimes in the second, third, and occasionally in the fourth generation. But the buds produced by the under leaves either form rudimentary shoots, or mere clusters of leaves; or, if the leaves should have a sufficiency of vital power to form internodes, and thus become separated from each other, yet the buds produced by them remain inactive, and the shoots thus formed never become mother-shoots, but their term of life speedily draws to its close. Every year may be perceived, especially on the under part of the stem and branches of trees, these primary branches thus gradually expiring, or absolutely dead. They are quite as easily detached from the stem as an ordinary leaf, and are generally removed by the wind.

And the fate which thus overtakes the individual parts of the tree, or the tree in the lower stages of its development, will finally overtake the tree itself, when fully developed; for the same law which gives form to the tree and its several parts, the law of the decrease of growth in the upper parts of the main stem or axis, as also in the successive generations of branches, is that which must finally set bounds to the existence of the tree itself.

An animal may continue to live after it ceases to grow, but with the tree it is otherwise; for the tree continues to grow as long as it lives, and when it ceases to grow in any 
of its parts, the life of those parts must inevitably and necessarily terminate. This gradually expiring growth at its extremities is, therefore, significant of the fact that the tree has passed its prime, and that its life is gradually drawing to its close. The death of the tree, therefore, takes place from within to without, or from its centre to its circumference, and from above to below; or it dies downwardly, from the extremities of its branches to its roots.

Schleiden, Gray, De Candolle, and others, have indeed advanced the doctrine that the tree can only perish through storms or other mechanical injuries, and that there is nothing in its organization to intimate that it may not continue to vegetate for an indefinite period of time. But, although we freely admit that it is difficult to point out clearly the several stages of vegetative inactivity, till the life and growth of the whole tree forever ceases, and that in most cases the death of the tree is brought about by violent interruptions to the natural life-processes, or a want of those conditions which are necessary to their continuance, yet we do not altogether agree with the views of these distinguished physiologists, for the reason we have already assigned.

The growth of the tree in the air, and that of the coralreef in the ocean, is somewhat analogous. The first is built up by a community of plants, the last by a society of animals; leaves are the architects in the former, and polypi in the latter instance. Both are equally substantial and enduring monuments of the skill of architects alike perishable and insignificant, capable of withstanding the storms of the elements from which they draw their life, and which thus rage for hundreds and thousands of years harmlessly around them. The dead individuals of the coral-reef serve as a firm foundation for succeeding generations of workmen or polypi, who continue their labors at the same structure. So is it with the tree. What is the dead, fissured bark on the outside of yonder old tree-stem, and the dead wood in its inside, but 
matter which was formed by the labors of generations of shoots and leaves which have preceded the present generation, which still continues to cover its venerable stem and branches with the renewed verdure and beauty of the spring-time of its life?

Reader, if you wish for peace and contentment of mind, study Nature. You will be brought into communion with the infinite and eternal. You will become temperate in your desires. You will love truth and righteousness. The contemplation of this majestic system of continuous and eternal change will give loftiness to your thoughts; free your mind from a groveling and ignorant superstition; give you just, confiding, worthy views of your Creator, and enable you to march through life with a firm, with a manly step. This world is full of beauty little understood or appreciated. An overflowing goodness has covered the earth with flowers and glorious forest trees, yet how few, comparatively speaking, care to know anything about them. We invite you to this grand and ancient library; to the study of these volumes overflowing with wisdom and instruction. It is not the mere study of Nature, but the impressive lessons which she teaches. Thoughts of infinitude and eternity come to me from the distant stars, and from the forms of vanished life laid up in the rocks, reminding me that my own life is fleeting and evanescent, as the vapor of morning. The lofty tree, with its wealth of branches and foliage, perishes alike with one of the lowly undistinguished blades of grass which it overshadows; so none are so high or wellknown but they shall, ere long, lie low and be forgotten. And herein is seen the wisdom and equity of the arrangements of Nature, that all must submit to the same great laws of decay and dissolution. She shows, in this respect, no partiality. Superior talent, energy, or social position, may for awhile elevate some fragments of humanity above their fellows, but all are in the end reduced to the same level. 


\title{
NOTICES OF THE PRESS.
}

\author{
From the "Evening Bulletin," April 11th, 1859.
}

"This work, of which two parts, or 104 pages, are before us, is a vast simile; not unlike that of the tree Ygdrasil, by which the Norsemen typified all creation. Mr. Coultas is an accomplished botanist; the author of 'Organic Life in Animals and Plants,' and other works, and a very earnest thinker. In the present instance he makes a curious, and indeed valuable application of the phenomena of organic conditions and development in a tree to those of society. In the first number we have the nature and manner of growth of a tree set forth very distinctly; so much so that, as a mere chapter in natural philosophy, it could not fail to deeply interest any intelligent reader. This accomplished, an application is made of the organic peculiarities to the growth and forms of that higher organism, society. This is done with great ingenuity, and in a manner displaying a highly philosophic and philanthropic mind. Mr. Coultas is a man of liberal principles, warm heart, and a friend to social progress, as based on the laws of Nature and Health. It is hardly possible to say more in favor of a writer in the present century, when science, reality, earnestness, and genial strength are beginning to take the, place of idle metaphysics, romantic aspiration, morbid melancholy, and weakness.

"The work abounds in reflections, in passages so true, so large-minded and so comprehensive, that we should be sorry indeed not to have read them. His views on labor are truly noble. He recognizes that advancing society casts off the idler, requires more and more the producer, and renders the latter more productive. In short, the whole book will evidently be a marked contribution to American literature. We commend it as one deserving the attention of those who read good and useful books."

\section{From the "American Journal of Pharmacy," July, 1859.}

"We are indebted to the author for sending us, some time ago, parts first and second of this work, and we have just now received part third. The former were read with considerable interest, and as soon as opportunity offers, we hope to derive pleasure and instruction from following the author through Chapter vii, in which he brings forward some new views in regard to the development of leaves, and Chapter viii, a sketch of the geological records of primæral botany. $\mathrm{Mr}$. Coultas certainly has the true enthusiasm of a student of nature, and after setting forth the numerous beauties, harmonies and adaptabilities of vegetable life as exhibited in the tree, he uses them in illustration of his views of political and social economy-aiming to benefit as well as interest his readers. We hope the author will receive substantial encouragement to continue his work to completion."

From the "Sunday Dispatch," October 17th, 1858.

"Mr. Coultas is a Botanist who sees in Nature's works" something more than twigs, leaves, and flowers. He deduces therefrom the most useful lessons, and has the happy enthusiasm which enables him to illustrate his ideas with clearness and interest. This treatise upon the Tree contains very useful information, which is set forth with so much ability, and treated in such an agreeable style, that no one can fail to appreciate and be instructed. It only requires genius to invest the driest subject with interest, and in botanical affairs Mr. Coultas is an undoubted genius."

\section{From the "Pennsylvanian Inquirer," October 9th, 1858.}

"In the multitude of publications which are issued from the press, so valuable a work as this is liable to be overlooked. We have read this first part with a satisfaction bordering upon admiration for its author, who has learned to take Nature by the hand as a parent, a tutor, and guide. No person can read the work without becoming a wiser and better man; and the author may be assured that he has not mastered the secret of labor in vain. His work is destined to survive him, though we trust he may live long to supply the world with his original 
thoughts and the results of his earnest and well-directed labors. In very deed has he surpassed Orpheus. The ancient minstrel made trees dance, but Harland Coultas has made them speak, and with wonderfully attractive eloquence. The true patrons of the highest form of human learning should step out of their way to encourage this philosopher, who gives us the 'sermons in trees' that Shakspeare felt, but has not reported, as is now beautifully done." .

From the "United States Journal of Homoopathy," February, 1860.

"Hugh Miller has given us 'The Testimony of the Rocks,' and Mr. Coultas here offers The Testimony of the Trees. After a careful perusal of the work, we feel deeply interested in its wide-spread circulation, believing that it must prove highly instructive, both as to Botany and the true aims of life, morally, socially, and spiritually. Seldom do we find an author so exact in detail and philosophical, who writes with so much ease and life as Mr. Coultas. We venture the opinion, that no one who reads two pages of his work, could willingly turn away till the last page is read. And we further venture the opinion that, no one who reads it thoughtfully, can cherish any but feelings of kindness for the author, and the best of wishes for the circulation of his book. Buy a copy, my friends, and read it well ; and our word for it, when you go forth again into the 'grim old wood,' or shady grove, you will be astonished to find how talkative and companiable are the trees, through whose habitations you have hitherto found only silence and solitude."

\section{From the "Pittsburg Gazette," Jan. 12th, 1860.}

"This is a well-printed and well-arranged book, and is one of the most valuable, in many of its aspects, of any that has fallen under our notice. All persons who make trees and the growth of vegetables a subject of delightful study, will find this work just to their mind. It is, in fact, the biography of a tree, the laws of its growth and the development and death of the tree. We heartily commend this book to the lovers of the beautiful in nature, and to those who love a somewhat original view of an old subject. Mr. Coultas is agent for his own work, and will eall upon the people to present before them its claims."

\section{From the "Baltimore Patriot," October 7th, 1859.}

“A great deal may be learned from a Tree, as Mr. Coultas, who is an accomplished Botanist, has shown us in this modestly-written book. All men who understand what they are writing about, will write modestly. Taken as a whole, we do not know a book that contains so much interesting matter in so small a compass. It is exceedingly suggestive, and no man can rise from its perusal without acknowledging he has been in the company of a judiciously thinking man."

\section{From the "Baltimore American," October 12th, 1859.}

" What may be learned from a Tree is the title of a very interesting work handed to us by the author. It is a close and minute inquiry into the mode by which vegetable life developes itself into the form of a tree, and the organization of the tree itself in its mature stage. The investigation and close attention paid to the subject are carefully and lucidly described, and the reader will find in the volume much to interest him, and many items of information both novel and striking. In the present volume Mr. C. shows himself to be not only a lover of nature, but a moralist, and omits no opportunity to draw a parallel between the various stages of vegetable and human life. His conclusions are generally such as all will admit. to be correct, proper and judicious, both in a moral and a religious point of view."

From the " Pittsburg Dispatch," Jan. 10th, 1860.

"Mr. Coultas is evidently an enthusiastic student of Nature-a botanist in the higher sense, which seeks to find, beyond mere organic forms, general and culminating laws. It is a little work full of information on what at first thought seems an ordinary subject; but how few, even arnong the more intelligent, understand the economy of nature as displayed in the vegetable world."

The Principles of Botany, as Exemplified in the Cryptogamia (with Illustrations). By Harland Coultas. In one volume. Price 50 cents. For sale by Lindsay \& Blakiston, 25 South Sixth Street, Philadelphia.

Letters and other communications for the author to be addressed as follows: Harland Coultas, Post-Office, Philadelphia, Pa. 





\section{DAY USE}

RETURN TO DESK FROM WHICH BORROWED

This book is due on the last date stamped below, or on the date to which renewed.

Renewed books are subject to immediate recall.

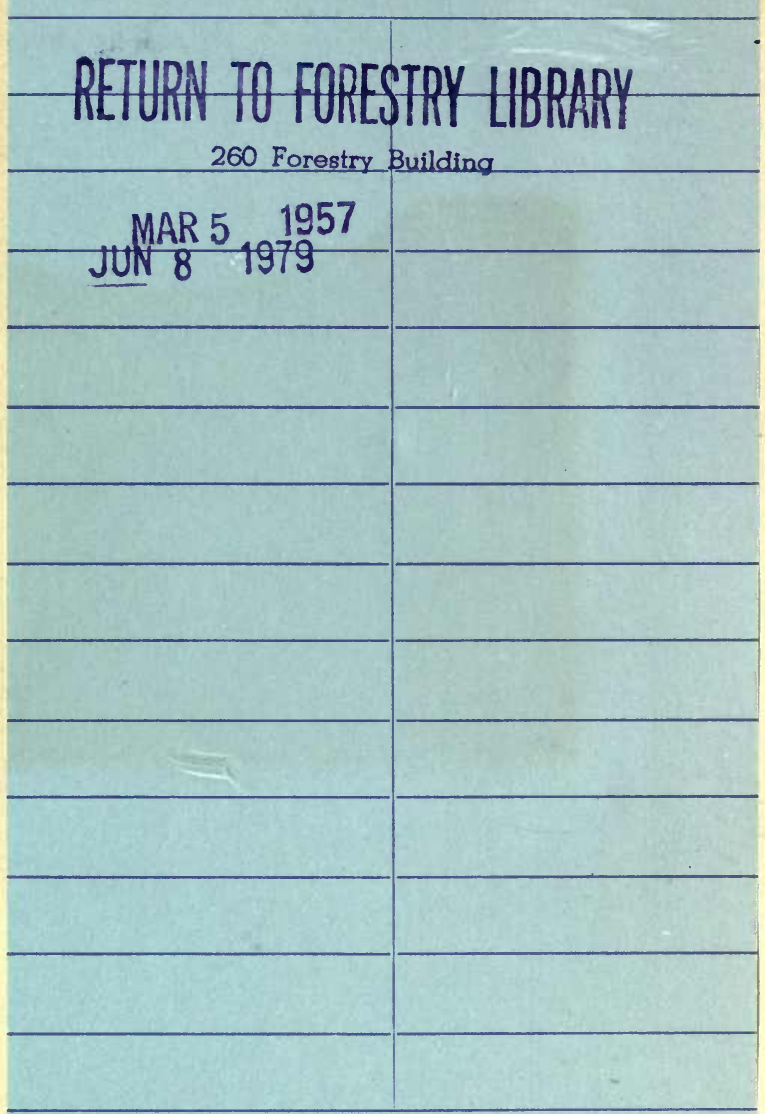

LD 21-100m-6,'56

(B9311s10) 476

General Library

University of California Berkeley 
U.C. BERKELEY LIBRARIES

\section{с믄48 42}

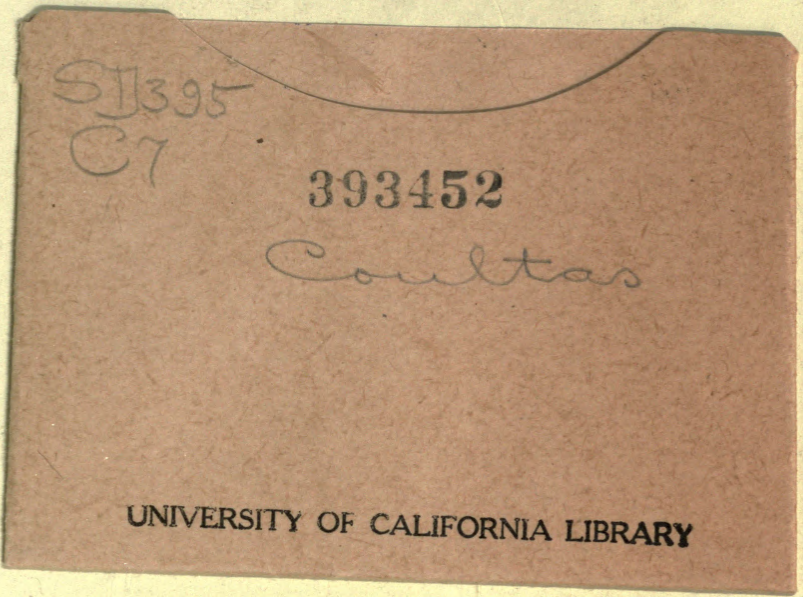


